\title{
THE RELATIONSHIP BETWEEN PROFESSIONAL LEARNING COMMUNITY IMPLEMENTATION AND TEACHER DECISION-MAKING
}

A Dissertation
presented to
the Faculty of the Graduate School
at the University of Missouri-Columbia
In Partial Fulfillment
of the Requirements for the Degree
Doctor of Education
July 11, 2019
MARK A. BOWLES


The undersigned, appointed by the Dean of the Graduate School, have examined the dissertation entitled

\title{
THE RELATIONSHIP BETWEEN PROFESSIONAL LEARNING COMMUNITY IMPLEMENTATION AND TEACHER DECISION-MAKING
}

\author{
presented by Mark A. Bowles, a candidate for the degree of Doctor of Educational \\ Leadership and Policy Analysis, and hereby certify that, in their opinion, it is worthy of \\ acceptance.
}

Dr. Bradley Curs

Dr. Sarah Diem

Dr. Lisa Dorner

Dr. James Sebastian 


\section{DEDICATION}

This dissertation is dedicated to Melanie Bowles, the most remarkably supportive, gracious, and loving individual I have ever met. 


\section{ACKNOWLEDGEMENTS}

In the first summer of the ELPA Ed.D. program, I was placed in a group of fellow students for the purposes of completing a Wicked Problem. I have repeatedly looked to those four individuals, Bradd Anderson, Tina Balser, Angie Boyer, Katie Breckenkamp, for inspiration and encouragement, and they have never let me down.

I also owe a debt of gratitude to my advisor, Dr. James Sebastian, who had his hands full providing good coaching and sound advice to a student who moved through the Ed.D. program during a time of intense personal turmoil. He also went above and beyond during the final few weeks to review and return dissertation drafts on very short time frames.

To Ray Bacon and Ben Graves: Thank you for the invaluable help with SPSS and multiple regression analysis. You both appeared like beacons in the dark at exactly the time I needed your help. The quality of my results and discussion sections was highly and significantly correlated with your instruction and support, $\mathrm{p}<.001$.

Without the involvement of the MO Professional Learning Communities organization, this study would not have been possible. The cooperation, encouragement, and suggestions of the leaders of that organization, Dr. Rob Gordon (State Field Director) and Michelle Smith (Web and Data Coordinator) had a substantive impact on the evolution of the methodology for this study.

Finally, and most importantly, I could not have completed this process without the support, encouragement, and love of my wife, Melanie, and three adult children (and now trusted friends), Zach, Kate, and Anna. 


\section{TABLE OF CONTENTS}

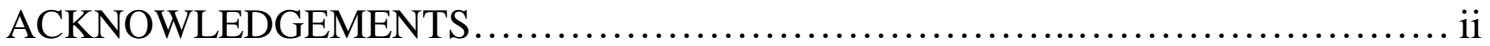

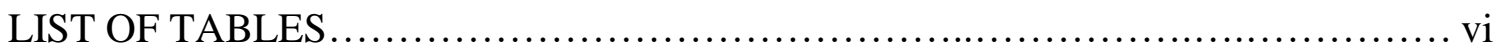

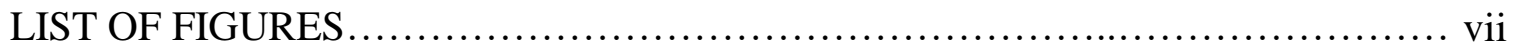

SECTION ONE: INTRODUCTION TO THE DISSERTATION-IN-PRACTICE......... 1

Background.............................................., , ............ 1

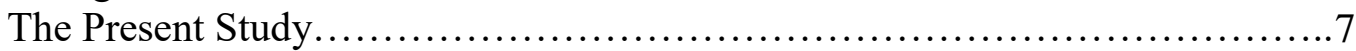

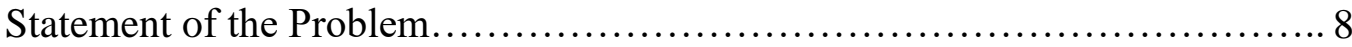

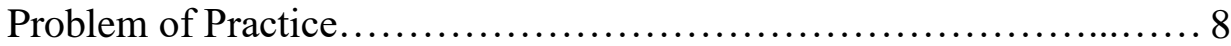

Existing Gap in the Literature .................................... 10

Purpose of the Study ................................................... 10

Research Questions................................................... 11

Conceptual/Theoretical Framework........................................... 12

Professional Community............................................ 12

Participatory Management......................................... 13

Design of the Study ...................................................... 16

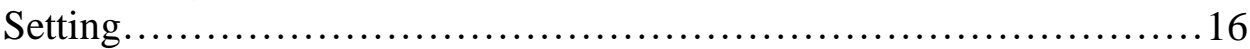

Participants..................................................... 21

Data Collection Tools............................................... 22

Limitations, Assumptions, and Design Controls.............................. 30

Definition of Key Terms................................................ 35

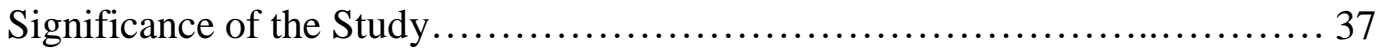

Scholarship....................................................... 37

Practice......................................................................... 39

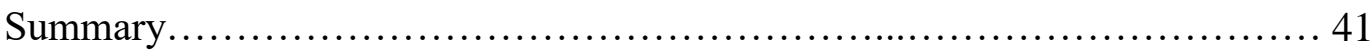

SECTION TWO: PRACTITIONER SETTING FOR THE STUDY $\ldots \ldots \ldots \ldots \ldots \ldots \ldots . . \ldots 2$

Introduction.......................................................... 42

History of the Organization............................................ 42

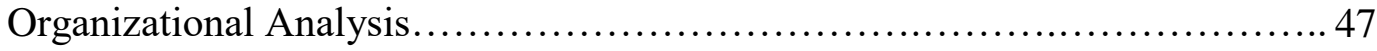

Professional Learning Community................................... 47

Historical Implications.................................... 47

Definition................................................. 48

Structural Framework................................................ 49

Definitions and Tenets....................................... 49

Analysis.................................................... 50

Leadership Analysis................................................... 54

Definition and Tenets.................................................. 54

Analysis.......................................................... 55

Implications for Research in the Practitioner Setting ......................... 58

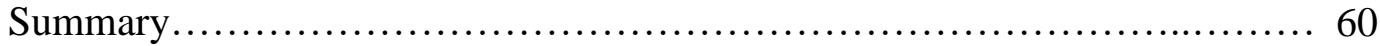




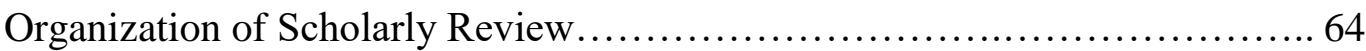

History of Educational Reform............................................ 65

The Excellence Movement......................................66

The Restructuring Movement...................................66

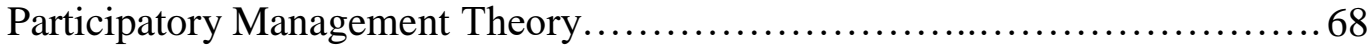

Teacher Empowerment............................................... 70

Results of Teacher Empowerment...................................... 71

Growth of Professional Learning Communities................................. 72

Attributes of Professional Learning Communities...................... 76

Leadership and Professional Learning Communities...................84

Professional Learning Communities and Professional Development.... 85

Professional Learning Communities and Student Achievement......... 87

Quantifying Teacher Influence........................................ 90

Teacher Leadership, Teacher Influence, and Directionality.............91

Research on Qualitative Research................................93

Categories of Qualitative Research about Teacher Influence..... 95

Expectations of Teachers...........................95

Changing Rationales for Teacher Participation............95

Forms of Participation............................. 96

Issues of Teacher Power............................... 97

Bias in Self-Reported Data............................................ 97

Summary......................................................... 99

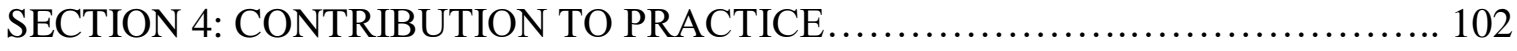

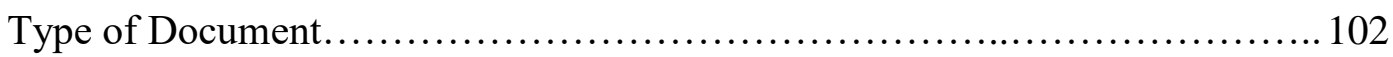

Rational for this Contribution Type..................................... 102

Outline for Proposed Contents.........................................103

"Professional Learning Communities and Teachers' Involvement in

Decision-Making: A Study of Missouri Public Schools"...................... 105

SECTION 5: CONTRIBUTION TO SCHOLARSHIP............................114

Target Journal......................................................... 114

Rationale for this Target.............................................. 114

Outline of Proposed Contents.......................................... 114

"Is There a Relationship between Professional Learning Community

Implementation and Teacher Influence? A Quantitative Study of the

Relationship between PLC Implementation and Teacher Influence in

Missouri PLC Schools" ................................................115

SECTION 6: SCHOLARLY PRACTITIONER REFLECTION...................... 189 
A. Survey Items from the UChicago Consortium on School Research

5Essntials School Reports Survey....................................... 197

B. MO PLC Teacher Influence Survey.................................. 198

C. 5Essentials School Reports Survey Validity and Reliability Reports...........200

D. Rob Gordon Email to MO PLC Administrators............................201

E. MO PLC Teacher Influence Survey Informed Consent...................... 201

F. Survey Items from the MO PLC BAT Survey $2017-18 \ldots \ldots \ldots \ldots \ldots \ldots \ldots \ldots . \ldots 203$

G. Regression Tables for MO PLC Teacher Influence Survey Item............. 207

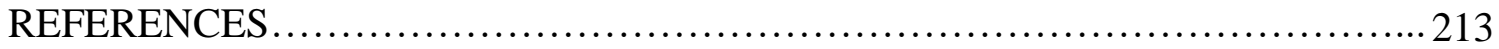

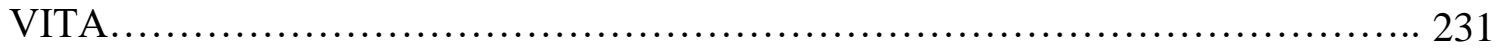




\section{LIST OF TABLES}

Table 1: Comparing Characteristics of Participatory Management and Professional Learning Communities................................... 15

Table 2: Descriptions of Study Variables................................... 22

Table 3: Comparison of MO PLC BAT with PLC Implementation Frameworks....... 26

Table 4: Teacher Responses at ABC Elementary School for BAT Item 1............ 29

Table 5: Determination of Consensus for BAT Item 1 at ABC Elementary School... 30

Table 6: Sample Benchmark Index Score (BIS) Calculation........................ 31

Table 7: Comparing Characteristics of Participatory Management and Professional Learning Communities................................... 75

Table 8: Comparison of Attributes of Professional Learning Communities............ 78

Table 9: $\quad$ Roy and Hord PLC Framework.................................... 80

Table 10: Louis, Marks, and Kruse PLC Framework............................. 81

Table 11: Bryk, Camburn, and Louis PLC Framework......................... 82 


\section{LIST OF FIGURES}

Figure 1: Participatory Management Theoretical Framework....................... 16 


\section{Section 1-Introduction to the Dissertation-in-Practice}

\section{Background}

Educational reform has been a topic of intense interest since the 1950's (Brost, 2000; Lambert, 2003; Servage 2009; Watson, 2014). Researchers have routinely proposed that schools must evolve to be much more adaptable and much more responsive to students' needs (Brost, 2000; Servage, 2009). A great deal of educational research exists that indicates that, in order to accomplish educational reform, teachers must be more involved in decision-making processes (Brost, 2000; Conley, 1991; DuFour \& Eaker, 1998; Odden \& Wohlstetter, 1995; Liontos, 1993; Smylie, Lazarus \& BrownleeConyers, 1996; York-Barr \& Duke, 2004); and empowering teachers to reflect, collaborate, and act collectively as a means to enhance student achievement figures prominently in many current public school reform initiatives (Duffy, Mattingly, \& Randolph, 2006; DuFour \& Eaker, 1998; Gates \& Watkins, 2010). According to Howey (1988), teacher leadership is both natural and necessary in today's climate of increasing demands for excellence being placed on schools. His assertion that reform can only be effective if addressed by those who reside where the problems are is a common theme in educational research (Brost, 2000; Clark \& Clark, 2002; Liontos, 1993; Odden \& Wohlstetter, 1995; Smylie et al., 1996; York-Barr \& Duke, 2004).

One popular reform framework that schools have embraced that incorporates the idea of involving teachers in problem analysis and decision-making is "Professional Learning Communities" (PLCs), (Clark \& Clark, 2002, Gates \& Watkins, 2010; Linder, Post \& Calabrese, 2012). It is defined by DuFour \& Eaker (1998) as an organizational model or framework "characterized by a shared mission, vision, and values; collective 
inquiry; collaborative teams; an orientation toward action and a willingness to experiment; commitment to continuous improvement; and a focus on results" (p. 45). Even though definitions vary somewhat, there are certain characteristics that are commonly cited by educational researchers: A collaborative culture based on the assumptions that groups of teachers are able to achieve more by working together than they can achieve individually (Bolam et al., 2005; Kruse, Louis, \& Bryk, 1994), a commitment to improved student learning driven by data and mutual accountability (DuFour \& Eaker, 1998; Kruse, Louis, \& Bryk, 1994), supportive and shared leadership in which administrators are committed to sharing decision-making with teachers (Roy \& Hord, 2006), and shared personal practice and collective inquiry between teachers that leads to continuous inquiry and reflective dialogue (Roy \& Hord, 2006; Stoll et al. 2006). Hord (1997) observes that the term learning community was "well integrated into the lexicon of American education" (p. 1). It is a movement that has an international impact: After reviewing 25 years of international research on school improvement, Stoll et al (2006) refer to PLCs as a "hot topic in many countries" that holds "considerable promise for capacity building for sustainable improvement" (p. 221). Toole and Louis (2002) reference the presence of PLCs in countries as diverse as Canada, South Africa, the Netherlands, Japan, and Mexico. A search of the literature for the term "professional learning communities in schools" returns over three million references from a wide assortment of countries. Educational research has followed this trend: Huffman (2011) describes research on PLCs as "an international phenomenon with scholars and practitioners in Australia, Canada, China, Taiwan, United States, and United Kingdom engaging in longitudinal and cross-cultural studies" (p. 321, abstract). Additionally, Roy 
and Hord (2006), in an article suitably titled, "It's Everywhere, but What Is It?

Professional Learning Communities," note that PLCs can be found across the spectrum of school settings as they observe PLCs as being in "village schools, city schools, rural settings, and suburban and urban locales" (p. 490). The current study focuses on PLCs in Missouri (United States), and with 254 schools currently participating in a statewide PLC organization in Missouri (MO PLC Organization, see www.moplc.org), it is clear that PLCs have been widely adopted across the state.

A central tenet of the PLC framework is that PLCs can lead to greater teacher influence which indirectly influences student achievement (DuFour \& Eaker, 1998; Linder et al., 2012; Louis \& Marks, 1998; Thompson, Gregg, and Niska, 2004; Sigurðardóttir, 2010). An important result of embedding collaboration into the structures of schools when PLCs are implemented is the incorporation of shared leadership and shared decision-making: "Collaboration can involve various stakeholders in making significant decisions about their school and its programs" (Clark \& Clark, 2002, p. 52). These authors go on to note that "collaborative decision-making can improve the school working environment and lead to instructional improvement and higher student achievement scores" (p. 56), a finding that is supported by other researchers (Hofman \& Dijkstra, 2010; Linder et al., 2012; Schechter, 2008; Thompson et al., 2004;

Sigurðardóttir, 2010; Louis \& Marks, 1998). The observation that PLCs are designed to emphasize teacher-led data-informed decision-making is also well-documented in the literature (Linder et al, 2012; Louis \& Marks, 1998; Thompson et al., 2004; Sigurðardóttir, 2010). 
Given the abundance of research on proposed theoretical connections between PLC and teacher influence, one would expect there to be a body of research documenting the relationship between PLC implementation and teacher involvement in decisionmaking using empirical evidence. However, in their 2004 comprehensive review of over two decades of empirical research related to teacher leadership, York-Barr \& Duke (2004) refer only to "numerous small-scale, qualitative studies that describe dimensions of teacher leadership practice, teacher leader characteristics, and conditions that promote and challenge teacher leadership" (p. 255). They reviewed 140 teacher leadership studies and reviews of studies, and none of these were quantitative research studies examining the relationship between teacher leadership and PLCs. Similarly, although a review of research for this current paper reveals studies examining a wide variety of positive effects from increased collaboration in PLCs [such as better informed teachers (White, 1992), improved teacher communication within and across schools (White, 1992; Wohlstetter, 1995), and reduced isolation of teachers (White, 1992)], there are no quantitative studies directly examining whether or not there is a relationship between PLC implementation and increased teacher influence in schools.

In several studies, teacher influence (a term used interchangeably with the concept of teacher involvement in decision-making processes) is used as a proxy variable for teacher leadership (e.g., Brost, 2000; Bryk et al., 1997; Liontos, 1993; Marks \& Printy, 2003), which makes research into teacher leadership a possible source of data on the relationship being examined in the current study. Teacher leadership studies typically examine correlational relationships between the presence of PLC and various aspects of teacher leadership. Because correlational relationships do not imply directionality, a 
number of researchers have investigated the correlation between PLC and teacher leadership in the opposite direction of the current study, examining the possibility that creating leadership opportunities for teachers drives the implementation of PLCs. For example, Kruse et al. (1994) state that enhancing teacher leadership and teacher autonomy is a critical part of establishing a PLC in a school. This directional finding is also prevalent in studies by Bolam, et al. (2005), Carpenter (2015), Louis \& Marks (1998), Maag (2009), Moller (2006), Sackney \& Walker (2006), and Servage (2008). The importance of having the principal's support in creating leadership opportunities for teachers is underscored by Carpenter (2015), who finds that "the manner in which teachers engaged in the collaborative culture was greatly shaped by shared and supportive leadership trust and respect for teachers as professionals" (p. 689). This finding is supported by Stoll, et al. (2006) who found that distributed leadership ensures that leaders are working collaboratively with teachers to create opportunities for teacher leadership roles. Additionally, Hord (1997) lists the incorporation of shared leadership as one of the distinguishing factors of a PLC. In essence, the strong positive correlational findings of teacher leadership studies suggest that teachers' involvement in leadership and decisionmaking roles enhances the effective implementation of PLCs, but does little to document whether PLC implementation is related to increased teacher influence.

It is important to note that studies examining PLCs in schools generally rely on teacher perceptions of different aspects of PLCs. Perceptual studies have focused on topics such as shared decision-making (Leech, 1999); leadership behaviors (Berry et al, 2008; Leech, 1999), empowerment (Berry et al, 2008), the authenticity of implementation of PLC structures (Kim, 2016), driving forces of instructional decision-making (Griffith 
et al, 2013), the interplay between PLC and teacher self-efficacy (DeNeve et al, 2015; Turner, 2012; Priest, 2015), the impact of professional development on teacher practice (Griffith et al, 2013; Nelson, et al., 2012; Poekert, 2012), the use of performance assessments (Abbott \& Wren, 2016; Nelson, et al., 2012; Skalski \& Romero, 2011), and overcoming barriers for dealing with disruptive student behavior (Maag, 2009), to name a few. However, self-reports of organizational constructs can be biased. Rosenman, Tennekoon, \& Hill (2011) describe the reasons individuals offer biased estimates of selfassessed behavior as "ranging from a misunderstanding of what a proper measurement is to social-desirability bias, where the respondent wants to 'look good' in the survey, even if the survey is anonymous" (p. 321). For these reasons, results of self-assessed behavior must be interpreted with caution.

Finally, studying the relationship between PLCs and teacher involvement in decision-making can help resolve a contradiction in PLC research as it pertains to student achievement outcomes. While there are methodological difficulties in connecting PLCs to student achievement (see Burns et al., 2014), a great deal of research has been conducted to determine what impact, if any, PLC implementation is having on student achievement. Research studies by Andrews \& Louis (2007), Berry et al. (2005), Bolam et al. (2005), Hollins et al. (2004), Louis \& Marks (1998), Phillips (2003), Sigurðardóttir (2010), Strahan (2003), Supovitz (2002), and Supovitz \& Christman (2003) all show slight to moderate impacts of PLC on student achievement. Studies by Bolam et al. (2005), Louis and Marks (1998), Supovitz (2002), and Supovitz and Christman (2003) provide important information about the impact of specific aspects of PLC on achievement. Both the Bolam et al. (2005) and the Louis and Marks (1998) studies 
report positive gains in student achievement related to the strength of the PLC in the schools studied. The studies by Supovitz (2002) and Supovitz and Christman (2003) find significant gains in student achievement in schools where teachers engaged in focused instructional discussions concerning the relationships between teaching practices student work. However, findings to the contrary can also be found in the literature. Studies by Louis \& Marks (1998) and Smylie et al. (1996) find the reported effects of PLCs on student achievement to be small. Further, some research shows no effect, especially when accounting for other school factors such as school climate (Andrews \& Louis 2007; Louis \& Marks, 1998; Sigurðardóttir, 2010; Burns, et al, 2014; Stewart, 2014). Given the importance of teacher influence to the overall framework of PLCs, empirically examining this pathway could help explain why the effects of PLCs on student achievement that are reported in the research are contradictory.

\section{The Present Study.}

This study examined the relationship between PLC implementation and teacher decision-making (also referred to as teacher influence) in schools in Missouri participating in the Missouri Professional Learning Community (MO PLC) organization, which is sponsored by the Missouri Department of Elementary and Secondary Education and provides ongoing training and support to participating schools. The study used an index of PLC implementation calculated from data provided by MO PLC, and a measurement of teachers' involvement in decision-making calculated from surveys (the MO PLC Teacher Influence Survey, Appendix B) returned by 1,107 teachers in 76 MO PLC schools. Multiple regression analysis was used to determine if a significant relationship existed between these two measures. 
As described below (see Methods section), PLC implementation survey results were obtained from the MO PLC for all participating schools and used to calculate index scores to reflect the degree to which each individual school had implemented the essential elements of PLC identified by MO PLC. These survey results record teachers' perceptions about PLC implementation in their buildings. Because MO PLC designates schools according to how many years they have participated in the program (Year 1, Year 2, Year 3, and Year 4/Continuing), we were able to create another variable, "year of implementation," as an additional measure of PLC implementation that was not subjective/perceptual in nature. Since the training and support provided by MO PLC could be considered an intervention for enhancing the implementation of PLC, one might expect more years of participation to result in increased PLC implementation at participating schools. Adding the year of implementation variable allowed us to examine this relationship as well. The MO PLC Teacher Influence Survey was created using an item from the UChicago Consortium on School Research 5Essentials School Reports Survey which was designed to assess teachers' involvement in decision-making. Surveys were received from 76 schools, and an overall teacher involvement score was calculated for each of these schools. Multiple regression statistical analysis was used to determine if there was a statistically significant relationship between the BIS and teacher involvement.

\section{Statement of the Problem}

\section{Problem of practice.}

As mentioned above, Howey (1988) described teacher leadership as both natural and necessary in today's climate of increasing demands for excellence being placed on schools. His assertion that reform could only be effective if addressed by those who 
reside where the problems are is a common theme in educational research (Brost, 2000;

Odden \& Wohlstetter, 1995; Smylie et al., 1996; Wohlstetter, Smyer \& Mohrman, 1994; Clark \& Clark, 2002; Liontos, 1993; York-Barr \& Duke, 2004). Further, researchers have identified a number of positive results of incorporating teachers in the decisionmaking processes of a school, including improved teacher morale (Liontos, 1993; White, 1992); reduced isolation of teachers (White, 1992); enhanced self-esteem and staff morale, commitment, and teamwork (Liontos, 1993; White, 1992); better informed teachers (White, 1992); improved teacher communication within and across schools (White, 1992; Wohlstetter, 1995); improved student motivation (White, 1992); instructional improvement (Clark \& Clark, 2002; Smylie et al., 1996; Newmann \& Wehlage, 1995; Peterson et al., 1996); better student academic outcomes (Newmann \& Wehlage, 1995; Peterson, Marks \& Warren, 1996; Servage, 2008; Smylie et al., 1996; Wohlstetter, 1995); higher quality decisions (Clark \& Clark, 2002; Liontos, 1993); and increased incentives that serve to attract and retain quality teachers (White, 1992; Liontos, 1993; Smylie et al., 1996). Studies have also made it clear that involving teachers in decision-making processes requires more than simply giving them a voice. It requires a real transfer of power from principals and administration to teachers themselves (Brost, 2000; Odden \& Wohlstetter, 1995; Wohlstetter, 1995; Wohlstetter et al., 1994; Wilson, 2016). Further, to provide lasting and successful reform, decisionmaking authority must include the following areas: Budget, personnel, and instructional methods (Wohlstetter, 1995), as well as curriculum (Odden \& Wohlstetter, 1995).

However, in spite of the research cited in the previous paragraph and the efforts of educational reform movements, early 20th Century schools continued to be modeled on 
Taylor's design for industrial bureaucracy, where decisions were made by a few people at state governmental agencies, handed down to local Boards of Education, passed on to the superintendent and the building administrator, and finally delivered to teachers who were expected to carry out the decisions of their supervisors (Dufour \& Eaker, 1998). In light of the evidence related to the numerous positive outcomes of involving teachers in decision-making processes (see, for example, DuFour \& Eaker, 1998; Linder et al., 2012; Thompson et all, 2004; Sigurðardóttir, 2010; Louis \& Marks, 1998), including increased student achievement (see, for example, Clark \& Clark, 2002; Hofman \& Dijkstra, 2010; Linder et al., 2012; Schechter, 2008; Thompson et al. 2004; Sigurðardóttir, 2010; Louis \& Marks, 1998), it is reasonable to consider the possibility that the failure of PLCs to produce a significant positive impact on students can be explained by the failure of PLCs to enhance teachers' decision-making involvement. This current study makes its contribution to the body of research surrounding public schools and PLCs by providing quantitative evidence of the extent to which implementing PLCs in schools is correlated with the involvement of teachers in decision-making.

\section{Existing gap in the literature.}

As indicated in the Introduction, there is an abundance of research on proposed theoretical connections between PLC and teacher influence. As such, one would expect there to be a body of research documenting the relationship between PLC and teacher involvement in decision-making using empirical evidence. In their 2004 comprehensive review of over two decades of empirical research related to teacher leadership, York-Barr \& Duke (2004) refer only to "numerous small-scale, qualitative studies that describe dimensions of teacher leadership practice, teacher leader characteristics, and conditions 
that promote and challenge teacher leadership" (p. 255). They reviewed 140 teacher leadership studies and reviews of studies. None of these were quantitative research studies examining the relationship between teacher leadership and PLCs. Similarly, although a review of research for this current paper revealed studies examining positive effects from increased collaboration in PLCs, such as better informed teachers (White, 1992), improved teacher communication within and across schools (White, 1992;

Wohlstetter, 1995), and reduced isolation of teachers (White, 1992) there were no quantitative studies directly examining whether or not there is a relationship between PLC implementation and increased teacher influence in schools.

\section{Purpose of the Study}

The purpose of this study was to determine if there was a relationship between implementation of PLC' and teachers' perceptions of their involvement in decisionmaking. Additionally, because participating schools were categorized based on their year of involvement in the MO PLC implementation process (Year 1, Year 2, Year 3, and Year 4/Continuing), we also examined whether a relationship existed between year of involvement in the MO PLC implementation process and actual implementation of PLC (as measured by the BIS). Finally, the data allowed us to determine if there was a relationship between the year of involvement in the implementation process and teacher decision-making.

\section{Research Questions}

This study was designed to answer the following research questions:

1. What is the relationship between the year of implementation of PLC reform and actual PLC implementation? 
2. What is the relationship between PLC implementation and teacher involvement in decision-making?

3. What is the relationship between the year of implementation of PLC reform and teacher involvement in decision-making?

\section{Conceptual/Theoretical Framework}

There are two theories underlying the present study: PLC (which as indicated in the introduction, is described by multiple frameworks in the literature), and participatory management theory.

\section{Professional Community.}

It is important to consider various PLC frameworks to compare them to the instruments used by the MO PLC organization to measure PLC implementation. For the 2017-18 school year, the BAT was redesigned to align with six "strands" corresponding to an implementation rubric developed by MO PLC: The process of identifying the school's mission and vision, the nature of their building's culture (collaborative culture and shared decision-making), the use of SMART goals and priority goals, the nature of collaborative teams, and the implementation of school-wide tiered interventions. PLC frameworks created by Roy and Hord (2006) and Louis, Marks, and Kruse (1996) are representative of others found in the PLC literature. Roy and Hord, hereafter referred to as $\mathrm{RH}$, reviewed 15 years of PLC research and proposed a PLC framework of five elements: Supportive \& shared leadership, collective learning and application, shared values and vision, supportive conditions, and shared practice. Louis, Marks, and Kruse, hereafter referred to as LMK, identified five distinguishing elements of PLCs: Shared 
values, focus on student learning, collaboration, deprivatized practice, and reflective dialogue.

These PLC frameworks have similarities: References to reflective dialogue (although RH include it as part of "collective learning and application"); shared values; collaboration (referred to as "shared practice," by RH); and focus on student learning (included as part of "shared values and vision in RH"). There are, however, important differences to note between the frameworks. "Deprivatized practice" is included as an element by LMK, but is not included by RH (although it is suggested as part of "supportive conditions" in RH); "supportive and shared leadership" and "supportive conditions" from the RH framework have no counterparts in LMK (other than a common reference to affiliation and mutual support between teachers that appears in both LMK's “deprivatized practice” and RH’s “supportive conditions”).

\section{Participatory Management.}

The theoretical framework that examines the directional relationship between PLCs and teacher involvement is based on participatory management theory. The participatory management movement (also known as shared leadership, participative decision-making, and distributed leadership) has gained much popularity over the last three decades (Spillane, Halverson, and Diamond, 2005). It stands in contrast to the seminal work of Frederick Taylor on scientific management (Taylor, 1911), which was based on controlling variables in the workplace and creating predictable outcomes for the organization. As such, Taylor's ideas clearly did not support the concepts of participation and empowerment, focusing instead on "centralization, standardization, hierarchical top-down management, a rigid sense of time, and accountability based on 
adherence to the system" (DuFour \& Eaker, 1988, p. 20). Application of the principles of Taylor's time and motion studies and assembly line cultures led to negative employee reactions which resulted, over time, in Taylor's ideas being largely discredited.

Spillane et al. (2005) describes participatory management as a process that engages all members of an organization or organizational division in jointly identifying its vision, goals, and strategies, and involves them in key areas of decision-making. Sarafidou and Chatziioannidis (2013) state that "this empowerment of individuals is considered fundamental for enhancing their morale and motivation, increasing levels of job satisfaction and promoting a sense of responsibility and commitment to organizational effectiveness and improvement" (p. 170). Other researchers in the field of participatory leadership (MacBeath, 2005; Harris, 2010) emphasize the importance of collaborative decision-making as the focus of new organizational management practices that serve to cultivate synergistic creativity and facilitate the incorporation of highperformance practices into the workplace. Lange (1993) ascribes multiple benefits of decentralizing school governance with through participatory management, including a commitment to decisions, a perception that higher quality decisions were made, increased staff cohesion, and increased trust among staff members and principals.

Comparing the characteristics of participatory management (from the Reference for Business website, www.referenceforbusiness.com) with those of PLCs shows remarkable similarities (Table 1). Table 1 shows that the fundamental features of both PLC and participatory management research are collective inquiry/information sharing, collaboration, a focus on outcomes, and shared decision-making. The similarity between the characteristics and outcomes of participative management and PLCs is evidence of 
the utility of participative management as the theoretical framework of this study, especially in terms of increasing involvement in employees in decision-making processes as an outcome: As noted earlier in the problem statement section, one of the defining Table 1

Comparing Characteristics of Participatory Management and Professional Learning Communities

\begin{tabular}{ll}
\hline $\begin{array}{l}\text { Characteristics of } \\
\text { Participative Management }\end{array}$ & $\begin{array}{l}\text { Characteristics of } \\
\text { Professional Learning Communities }\end{array}$ \\
\hline Commitment & Commitment to student learning \\
Information sharing & Collaboration \\
Training/skill development & Collective inquiry \\
Employee decision-making & $\begin{array}{l}\text { Supportive and shared decision- } \\
\text { making }\end{array}$ \\
Rewards for performance & Focus on outcomes \\
\hline
\end{tabular}

characteristics of a PLC is supportive and shared leadership in which administrators are committed to sharing decision-making with teachers (Roy \& Hord, 2006; Kruse, Louis, \& Bryk, 1994; DuFour, Eaker \& DuFour, 2005; Rosenholtz, 1989). These authors cite distributed leadership as a necessity in order to build an effective PLC. Similarly, in their study on creating and sustaining PLCs, Bolam, et al. (2005) stated that "school autonomy, as evidenced in site-based management, is seen as essential for the development of a learning community" (p. 25). The literature cited in the Introduction section is unequivocal in its call for increased participation of teachers in the implementation of PLCs, and participatory management theory provides the foundation for understanding the connection between PLC implementation and increased teacher influence (see Figure 1). 
Based on the above information about PLCs and participatory management and its theoretical connections to greater stakeholder involvement, applied to the educational setting, the current study was designed to investigate the following.

Hypothesis. PLC implementation and increased teacher participation in decision-making have a positive relationship.

Figure 1

Participatory Management Theoretical Framework
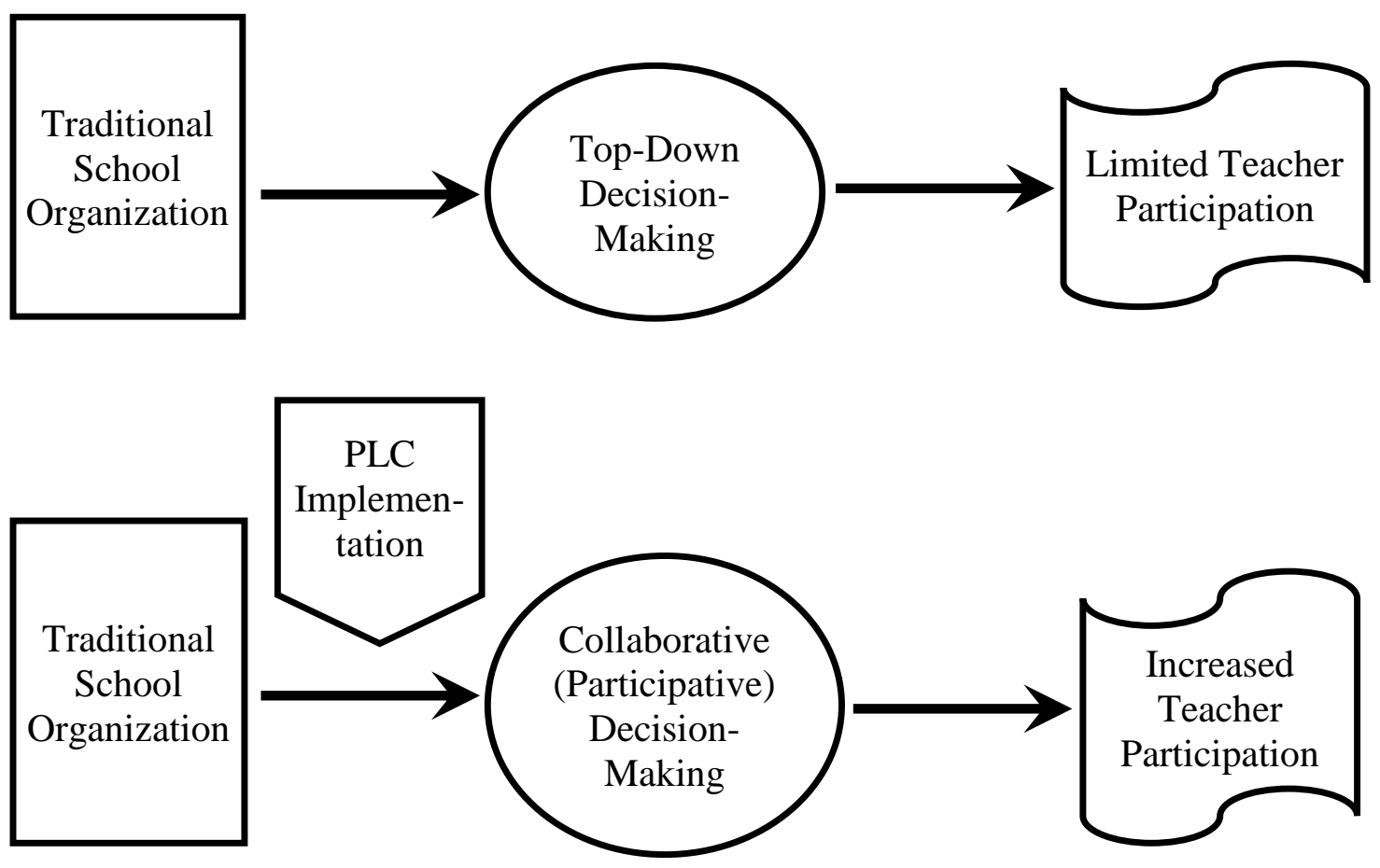

\section{Design of the Study}

\section{Setting.}

As indicated above, teachers' perceptions of their involvement in decision-making was measured using a part of a larger instrument, the UChicago Consortium on School Research 5Essentials School Reports "My School, My Voice” survey. To encourage a high response rate, the support of the director of the MO PLC organization, Dr. Rob 
Gordon, was solicited. He agreed to allow the format and distribution of the decisionmaking survey to imitate that of the BAT, as follows. The building principal in each school participating in the MO PLC organization was sent an email from Dr. Gordon in September 2019 in which he invited them to encourage their teachers to complete the survey (Appendix D). The email contained a link to the survey. Attached to the email was an informed consent document (see Appendix E). Participation in the survey was optional. As a further means to achieve a high response rate, the survey was kept to nine items and an anticipated completion time of less than two minutes. Reminder emails were sent weekly for the following two weeks, and a thank you email was sent the third week after survey distribution. Surveys were received from 16 of the 51 Year 1 schools (31\%), 16 of the 53 Year 2 schools (30\%), 23 of the 40 Year 3 schools (58\%), and 18 of the 58 Year 4 and Continuous schools (31\%). Overall, $36 \%$ of the schools participating in MO PLC at the time of the survey distribution responded to the survey.

Responses to the survey about teacher decision-making were collected as ordinal data $($ None $=1$, A little $=2$, Some $=3$, A great deal $=4)$, and means were calculated for each teacher and, subsequently, for each building. Schools were assigned to one of four groups based upon the number of years they had completed in their involvement with MO PLC training (Year 1, Year 2, Year 3, and Year 4/Continuing). For regression analysis, this data was converted into binary "dummy" variables, with binary variables created for all four categories. A similar process was used for each of the other categorical variables involved in the study: Grade configuration (elementary, middle, and high school) and setting (rural and urban). In the regression equations for each of the research questions (see below), one of the categories of each of the categorical variables 
was omitted from the equation: Year 1 schools, elementary school configuration, and rural setting. This allowed $\beta_{0}$ (the y-intercept) to have meaning when all other coefficients were 0 - a rural elementary school in its first year of participation with MO PLC. (A complete description of this instance is given in the explanation of the regression equations below in Analytical Procedures.) Procedures for calculating the BIS from the April 2018 administration of the BAT were provided by the MO PLC, and a BIS was calculated as described in the Sample and Data Sources section (above) for each school that participated in the MO PLC Teacher Influence Survey.

As indicated in the Introduction, this study investigated three research questions. First, this study asked whether or not there was a relationship between year of implementation of PLC reforms (as determined by year of involvement in the MO PLC organization) and actual PLC implementation (as determined by the BIS score). The regression model used to examine this relationship was as follows.

PLC implementation $=\beta_{0}+\beta_{1}$ Year 2 of PLC implementation +

$\beta_{2}$ Year 3 of PLC implementation $+\beta_{3}$ Year 4 of PLC implementation $+\beta_{4}$ School size + $\beta_{5} \%$ Minority students $+\beta_{6}$ Average $\%$ attendance $+\beta_{7} \%$ students on $F / R$ lunches + $\beta_{8}$ English MPI $+\beta_{9}$ Math MPI $+\beta_{10}$ Expenditures per ADA + $\beta_{11}$ Middle school grade configuration $+\beta_{12}$ High School grade configuration + $\beta_{13}$ Urban setting $+\varepsilon_{i}$

There are three categorical variables in this equation: Year of PLC implementation (Y1, Y2, Y3, and Y4), school configuration (elementary, middle, and high school), and setting 
(rural and urban). The intercept, $\beta_{0}$, represents the expected value of the BIS when all predictors are zero. Because it is not possible to have a school in this study that has no year of implementation, school configuration, or setting (i.e., if all categorical variables are equal to 0), one variable from each category was removed from the equation: Year 1 (for year of PLC implementation), elementary school (for configuration), and rural (for setting). With these values of the categorical variables removed from the equation, $\beta_{0}$ represented the BIS in a rural elementary school in its first year of participation in MO PLC with no students, $0 \%$ minority, $0 \%$ attendance rate, $0 \%$ of students on free or reduced lunches, MPI's of 0 in math and English, and $\$ 0$ expenditures per ADA. The coefficient, $\beta_{1}$, was the expected change in the BIS when the predictor, year of implementation of PLC reforms, increases by one unit (i.e., year 2 of PLC implementation), holding all other predictors constant. Similarly, $\beta_{2}$ was the expected change in the BIS for schools in their third year of PLC implementation, and $\beta_{3}$ was the expected change in the BIS for schools in their in their fourth (or greater) year of PLC implementation.

The second research question of this study constituted the primary focus of the research: What is the relationship between PLC implementation (BIS) and teacher involvement in decision-making? The following regression model was used to examine the relationship between PLC implementation and teachers' perceptions of their involvement in decision-making.

Teacher influence $=\beta_{0}+\beta_{1} P L C$ Implementation $+\beta_{2}$ School size +

$\beta_{3} \%$ Minority students $+\beta_{4}$ Average $\%$ attendance $+\beta_{5} \%$ students on $F / R$ lunches + 
$\beta_{6}$ English MPI $+\beta_{7}$ Math MPI $+\beta_{8}$ Expenditures per $A D A+\beta_{9}$ Year 2 of Implementation

$+\beta_{10}$ Year 3 of Implementation $+\beta_{11}$ Year 4 of Implementation +

$\beta_{12}$ Middle school grade configuration $+\beta_{13}$ High school grade configuration $+\beta_{14}$ Urban setting $+\varepsilon_{i}$

Here, the outcome was the average building-level numerical score associated with teachers' perceptions of their involvement in decision-making. The intercept, $\beta_{0}$, represented the expected value of teacher influence when all predictors were zero. Specifically, it represented teacher influence in a rural elementary school in its first year of participation in MO PLC with no students, $0 \%$ minority, $0 \%$ attendance rate, $0 \%$ of students on free or reduced lunches, MPI's of 0 in math and English, and $\$ 0$ expenditures per ADA. The coefficient, $\beta_{1}$, was the expected change in the outcome, teacher influence, when the predictor, PLC implementation (as measured by the BIS) increased by one unit, holding all other predictors constant.

Finally, this study explored a third research question: What is the relationship between year of implementation of PLC reforms and teacher influence? The equation for this research question was substantially the same as equation (2). However, in both instances, simple regression analysis was conducted first (without including additional covariates) to allow us to compare the unique correlations of BIS with teacher influence [equation (2)] and year of implementation with teacher influence [equation (3)]. The regression model used to examine the relationship between PLC implementation and teachers' perceptions of their involvement in decision-making was as follows. 
Teacher influence $=\beta_{0}+\beta_{1}$ Year 2 of PLC implementation +

$\beta_{2}$ Year 3 of PLC implementation $+\beta_{3}$ Year 4 of PLC implementation $+\beta_{4} P L C$

Implementation $+\beta_{5}$ School size $+\beta_{6} \%$ Minority students $+\beta_{7}$ Average $\%$ attendance + $\beta_{8} \%$ students on $F / R$ lunches $+\beta_{9}$ English MPI $+\beta_{10}$ Math MPI $+\beta_{12}$ Expenditures per $A D A+\beta_{12}$ Middle school grade configuration $+\beta_{13}$ High School grade configuration + $\beta_{14}$ Urban setting $+\varepsilon_{i}$

Here, the outcome, as in the second research question, was the average buildinglevel numerical score associated with teachers' perceptions of their involvement in decision-making, this time using year of implementation as the predictor variable. The intercept, $\beta_{0}$, represented the expected value of teacher influence when all predictors were zero. Specifically, it represented the teacher influence in a rural elementary school in its first year of participation in MO PLC with no students, $0 \%$ minority, $0 \%$ attendance rate, $0 \%$ of students on free or reduced lunches, MPI's of 0 in math and English, and $\$ 0$ expenditures per ADA. The coefficient, $\beta_{l}$, was the expected change in teacher influence when the predictor, year of implementation of PLC reforms, increased by one unit (i.e., year 2 of PLC implementation), holding all other predictors constant. Similarly, $\beta_{2}$ was the expected change in teacher influence for schools in their third year of PLC implementation, and $\beta_{3}$ was the expected change in teacher influence for schools in their fourth (or greater) year of PLC implementation.

\section{Participants.}

The sample for this study included the instructional staff of the 202 schools participating in the Missouri Professional Learning Community organization (MO PLC, 
see www.moplc.org) during the spring semester of the 2017-18 school year. Descriptive information about all of the variables included in the study is shown in Table 2.

\section{Data Collection Tools.}

Data on involvement in decision-making (the independent variable) was collected using items from the UChicago Consortium on School Research (CCSR) 5Essentials School Reports "My School, My Voice" survey (Appendix A) that asked teachers to indicate how much influence they have over policy in each of six areas: Hiring new professional personnel, planning how discretionary school funds should be used, determining books and other instructional materials used in classrooms, establishing the curriculum and instructional program, determining the content of in-service programs,

Table 2

Descriptions of Study Variables

\begin{tabular}{lll} 
Variable & Type & Classification \\
\hline PLC implementation (BIS) & Independent Variable & Continuous \\
Teacher influence & Dependent Variable & Continuous \\
Attendance rate & Covariate & Continuous \\
$\%$ Free/reduced lunch & Covariate & Continuous \\
School size & Covariate & Continuous \\
Student achievement (MAP & & \\
$\begin{array}{l}\text { Performance Index (MPI) } \\
\text { for Math and }\end{array}$ & & Continuous \\
$\begin{array}{l}\text { English/Language Arts } \\
\text { (2017-18 school year) } \\
\% \text { Minority students }\end{array}$ & Covariate & \\
$\begin{array}{l}\text { Expenditures per ADA } \\
\text { School grade configuration } \\
\text { (Elementary, Middle, High) }\end{array}$ & Covariate & Continuous \\
Rural/Urban & Covariate & Continuous \\
Year of MO PLC & Covariate & Categorical \\
implementation & Categorical \\
\hline
\end{tabular}


and setting standards for student behavior. The 5Essentials School Reports Survey has been widely used in educational research (e.g., Bryk, et al., 2010; Lee, Robinson, \& Sebastian, 2012) and has undergone testing for validity and reliability (Bryk, et al., 2010; Levenstein, R., 2014; Appendix C). The final nine-item survey used in the current study (which added three demographic questions for subsequent disaggregation) was constructed in Qualtrics and named "MO PLC Teacher Influence Survey" (Appendix B). Items were rated on a four-point Likert scale: "None," "A little," "Some," and "A Great Deal."

The independent variable in this study was a building-level calculated index (number between 0 and 105), the Benchmark Assessment Tool Index Score (BIS) that reflects the extent to which each school building has implemented PLC. The BIS was calculated based on responses to an annual online survey, the Benchmark Assessment Tool (BAT) that is administered online each spring. There are three components of the BAT: The Leadership Team Survey, completed by the Building Leadership Team, the Administrative Survey, completed only by building administrators, and the PLC Staff Survey. For the purposes of this study, only the final component was utilized. The BAT survey included 15 questions and assessed the perspectives of these staff members on the degree to which the following aspects of PLC had been implemented in their respective buildings: The process of identifying the school's mission and vision, the nature of their building's culture, the use of SMART goals and priority goals, the nature of collaborative teams, and the implementation of school-wide tiered interventions (see Appendix F). The BIS was developed when the MO PLC organization was created in 2003 as part of their annual assessment of participating schools. It was calculated (described below) and 
reported to each participating school from 2003 until the BAT was redesigned in 2017. The BIS was used as a feedback tool for the buildings to determine the extent to which they had implemented the essential features of PLC. Higher values of the BIS indicated greater PLC implementation. Since the BIS was calculated each year, Dr. Rob Gordon (former State Field Director of MO PLC) indicated that it was a very useful index for schools to use as an indication of their progress towards PLC implementation.

Because the extent to which the BAT items correspond to the six strands of PLC implementation identified by MO PLC as well as existing PLC frameworks reflects on its ability to accurately assess PLC implementation, a comparison of the items on the redesigned BAT to the strands and the frameworks was necessary (see Table 3). All survey items reflect some element of at least one of the PLC frameworks. Still, there are omissions that stand out. A match for the item, "How is shared decision-making encouraged in your building," can only be found in one PLC framework-RH's "supportive \& shared leadership." Further, there are some elements from the frameworks that are not represented by any of the 15 questions in the survey. RH's "supportive conditions" doesn't neatly fit any of the survey items, although it includes the attributes of trust, respect, feedback, collegiality, and risk-taking that are commonly referred to as outcomes of collaboration. "Deprivatized practice," included as an element of PLC by LMK, isn't specifically referenced by any of the survey items.

With the redesign of the BAT in 2017, the MO PLC discontinued calculating the BIS, replacing it with an evaluation process that included the collection of artifact data demonstrating implementation of PLC practices related to each of the six strands, and the evaluation of this artifact data by a site visit of educators trained in PLC implementation. 
When the organization reorganized their PLC implementation elements around six strands in 2018 (described below), it also shifted its focus away from the BIS in favor of evaluating artifact data on a site visit. When this was implemented in 2017, the BIS was discontinued. The calculation of the BIS from the redesigned 2018-19 BAT for the current study duplicated the mathematical calculations utilized with the original BAT. As indicated above, this replaced the original three response choices with four response choices (written as rubric-style statements) which reflected the following: Deep implementation, proficient implementation, partial implementation, and minimal implementation, respectively. To convert teacher responses to a building-level BIS score, all responses for each question were converted to numeric equivalents (minimal implementation $=1$, partial implementation $=2$, proficient implementation $=3$, deep implementation $=4$ ), which allowed a building-wide average to be calculated for each question. Subsequently, these average scores were examined in order to distinguish between scores that showed a great deal of agreement and those that were widely dispersed. For each survey item, the total number of responses for each of the choices (i.e., no implementation, minimal implementation, moderate implementation, exemplary implementation) were tallied and percentages calculated. On each item, the response that received the highest percentage was designated as the categorical response for that particular survey item. If that percentage was $80 \%$ or greater, that response category was considered to show "consensus." Any percentage less than $80 \%$ was designated "without consensus." For example, Table 4 shows the responses given by the 10 teachers who returned BAT surveys from a hypothetical school (ABC Elementary) on item 1: Choose the best descriptor of your building's collaboratively developed mission. 
Table 3

Comparison of MO PLC BAT with PLC Implementation Frameworks

\begin{tabular}{|c|c|c|c|c|}
\hline Survey items & Full implementation & MO PLC Strands & RH & LMK \\
\hline $\begin{array}{l}\text { Choose the best } \\
\text { descriptor of your } \\
\text { building's collaboratively } \\
\text { developed mission. }\end{array}$ & $\begin{array}{l}\text { The mission focuses on student } \\
\text { learning and is referred to } \\
\text { regularly. }\end{array}$ & $\begin{array}{l}\text { Learning community } \\
\text { culture \& continuous } \\
\text { improvement }\end{array}$ & $\begin{array}{l}\text { Shared values } \\
\text { and vision }\end{array}$ & $\begin{array}{l}\text { Shared values } \\
\& \\
\text { expectations }\end{array}$ \\
\hline $\begin{array}{l}\text { Choose the best } \\
\text { descriptor of your } \\
\text { building's vision. }\end{array}$ & $\begin{array}{l}\text { Our vision was collaboratively } \\
\text { developed, is reviewed regularly, } \\
\text { and we have commitments } \\
\text { aligned to our vision. }\end{array}$ & $\begin{array}{l}\text { Learning community } \\
\text { culture \& continuous } \\
\text { improvement }\end{array}$ & $\begin{array}{l}\text { Shared values } \\
\text { and vision }\end{array}$ & $\begin{array}{l}\text { Shared values } \\
\qquad \& \\
\text { expectations }\end{array}$ \\
\hline $\begin{array}{l}\text { Choose the best } \\
\text { descriptor of your } \\
\text { building's collaborative } \\
\text { culture. }\end{array}$ & $\begin{array}{l}\text { Collaborative teams share ideas } \\
\text { and resources for problem- } \\
\text { solving and decision-making } \\
\text { within and across teams. }\end{array}$ & $\begin{array}{l}\text { Learning community } \\
\text { culture \& continuous } \\
\text { improvement }\end{array}$ & Shared practice & Collaboration \\
\hline $\begin{array}{l}\text { Which best describes } \\
\text { building level SMART } \\
\text { goals in your school? }\end{array}$ & $\begin{array}{l}\text { Our building has measurable, } \\
\text { SMART goals around student } \\
\text { learning that influence my } \\
\text { instruction. }\end{array}$ & $\begin{array}{l}\text { What do students } \\
\text { need to know and } \\
\text { do? }\end{array}$ & $\begin{array}{l}\text { Shared values } \\
\text { and vision }\end{array}$ & $\begin{array}{l}\text { Focus on } \\
\text { student } \\
\text { learning }\end{array}$ \\
\hline $\begin{array}{l}\text { Describe the level of trust } \\
\text { in your team. }\end{array}$ & $\begin{array}{l}\text { I am comfortable sharing my } \\
\text { strengths and weaknesses about } \\
\text { teaching and learning with all } \\
\text { members of my team. }\end{array}$ & $\begin{array}{l}\text { How effective teams } \\
\text { work }\end{array}$ & $\begin{array}{l}\text { Supportive } \\
\text { conditions }\end{array}$ & Collaboration \\
\hline $\begin{array}{l}\text { I believe that } \\
\text { collaboration through } \\
\text { teacher teams is } \\
\text { improving the education } \\
\text { we provide to all our }\end{array}$ & $\begin{array}{l}\text { Yes, and this happens in my } \\
\text { team. }\end{array}$ & $\begin{array}{l}\text { How effective teams } \\
\text { work }\end{array}$ & $\begin{array}{l}\text { Shared practice/ } \\
\text { Shared values } \\
\text { and vision }\end{array}$ & $\begin{array}{l}\text { Collaboration/ } \\
\text { Focus on } \\
\text { student } \\
\text { learning }\end{array}$ \\
\hline
\end{tabular}

students. 
How is shared decisionmaking encouraged in your building?

Which best describes your collaborative team meetings.

Which best describes how your team uses meeting protocols such as roles, norms, timed agendas, minutes, schedules?

How do teachers participate in the identification of priority standards?

How does your team utilize identified priority standards?

Choose the best descriptor of your team.
Collaborative teams directly contribute to decision-making about critical issues impacting instruction and directly contribute to plans for addressing those issues.

\section{Collaborative teams meet} weekly during the contract day and are teacher-led, focusing on student learning and data-driven decision-making.

Our team makes effective use of all meeting protocols.

All teachers are directly involved in identifying priority standards for the subject areas they teach.

Our team uses priority standards as the basis for determining our formative assessments on a regular basis.

My team collaboratively identifies instructional strategies which are aligned with priority standards and we are committed to implementing them.
Effective leadership teams

Supportive \& shared leadership

How effective teams work

How effective teams work

What do students need to know and do?

What do students need to know and do?

How will we know when students have learned?
Shared practice

Collaboration

Shared practice/ Collective learning and applications

Shared values and vision/

Supportive and shared leadership

\section{Shared values and vision/}

Shared practice

Shared values and vision/

Collective

learning and applications
Collaboration
Focus on student learning

Collaboration/ Focus on student learning

Focus on student learning 
I am a member of a

collaborative team that uses student data to drive problem-solving and decisions.

As a team we collaboratively establish SMART goals and implement strategies and action plans based on student data. Choose the best descriptor of your team's use of SMART goals.

What is the level of implementation of school-wide tiered interventions?
My team routinely reviews student data to inform problemsolving and decisions.

Our team has established SMART goals and action plans based on student data.

School-wide implementation with review of targeted data points for all students. student success
Systematic process for

intervention/student success

Shared values and vision/ Collective

Focus on student learning and applications

How will we know when students have learned?

Shared values

Focus on student learning

Systematic process for intervention and
Shared values

Focus on and vision 
Table 4

Teacher Responses at ABC Elementary School for BAT Item 1

\begin{tabular}{cc} 
Teacher & Response \\
\hline 1 & 3 \\
2 & 4 \\
3 & 4 \\
4 & 3 \\
5 & 4 \\
6 & 4 \\
7 & 4 \\
8 & 4 \\
9 & 3 \\
10 & 3 \\
\hline
\end{tabular}

Table 5 shows the conversion of these responses percentages in order to determine the categorical response (the response with the highest percentage) and to determine if that response reflected consensus for this item. In this example, the majority of teachers at $\mathrm{ABC}$ Elementary rated the best descriptor of their building's collaboratively developed mission as "exemplary," so this item was rated a 4 (fully implemented) in the BIS calculation. However, since that rating was chosen by less than $80 \%$ of the teachers, it was designated "without consensus."

The final BIS is a weighted score calculated by totaling the number of practices in each category, multiplying each by a factor reflecting the degree of implementation (ranging from 7 for the greatest implementation with the highest degree of consensus to 0 for the least implementation with the lowest degree of consensus), and then summing all of the results. (See Table 6 for a sample calculation.) In that example, BAT items 1, 3, and 9 received over $80 \%$ " 4 " ratings by teachers at ABC Elementary. Items 7 and 10 received a majority of " 4 " ratings, but the percentage was less than $80 \%$. Items $2,4,5,6$, and 11 through 14 received over $80 \%$ "3" ratings. Item 9 received a majority of "3" 
Table 5

Determination of Consensus for BAT Item 1 at ABC Elementary School

\begin{tabular}{lcc} 
Response & $\begin{array}{c}\text { Number of } \\
\text { responses }\end{array}$ & $\%$ of response \\
\hline 4 (fully implemented) & 6 & $60 \%$ \\
3 (partially implemented) & 4 & $40 \%$ \\
2 (minimally implemented) & 0 & $0 \%$ \\
1 (not implemented) & 0 & $0 \%$ \\
\hline
\end{tabular}

ratings, but the percentage was less than $80 \%$. Item 15 received over $80 \%$ " 2 " ratings. No survey items received a majority of "1" ratings.) Building-level BIS scores range from 0 to a "perfect" score of 105 . This score provides a comparative measure of PLC implementation that was used to answer this study's research questions.

Because schools vary in size, rural versus urban setting, student socioeconomic status, percentage of minority students, attendance rate, expenditures per student, and prior academic performance, these variables were all included as covariates. Individual school data for these covariates was obtained from the Missouri Department of Elementary and Secondary Education (see https://dese.mo.gov/school-data). Information concerning the length of time schools have been involved in the MO PLC organization (i.e., divided into four categories: Year 1, Year 2, Year 3, and Year 4 \& Continuing schools) was provided by the MO PLC organization.

\section{Limitations, Assumptions, and Design Controls}

The timing of the survey gives rise to one limitation in this study. Both the BAT and the MO PLC Teacher Influence Survey are collecting perceptual data. This study compared teachers' perceptions as reported on the BAT in March and April to their perceptions as reported on the MO PLC Teacher Influence Survey in September and August. Although this is a matter of a few weeks on the 9-month academic calendar, it 
Table 6

Sample Benchmark Index Score (BIS) Calculation

\begin{tabular}{|c|c|c|c|c|c|c|c|c|}
\hline \multirow{2}{*}{ Question } & \multicolumn{2}{|c|}{$\begin{array}{c}\text { Fully } \\
\text { implemented }\end{array}$} & \multicolumn{2}{|c|}{$\begin{array}{c}\text { Partially } \\
\text { implemented }\end{array}$} & \multicolumn{2}{|c|}{$\begin{array}{c}\text { Minimally } \\
\text { implemented }\end{array}$} & \multicolumn{2}{|c|}{$\begin{array}{c}\text { Not } \\
\text { implemented }\end{array}$} \\
\hline & $\begin{array}{l}\text { with } \\
\text { cons. }\end{array}$ & $\begin{array}{l}\text { without } \\
\text { cons. }\end{array}$ & $\begin{array}{l}\text { with } \\
\text { cons. }\end{array}$ & $\begin{array}{l}\text { without } \\
\text { cons. }\end{array}$ & $\begin{array}{l}\text { with } \\
\text { cons. }\end{array}$ & $\begin{array}{l}\text { without } \\
\text { cons. }\end{array}$ & $\begin{array}{l}\text { with } \\
\text { cons. }\end{array}$ & $\begin{array}{l}\text { without } \\
\text { cons. }\end{array}$ \\
\hline 1 & 1 & 0 & 0 & 0 & 0 & 0 & 0 & 0 \\
\hline 2 & 0 & 0 & 1 & 0 & 0 & 0 & 0 & 0 \\
\hline 3 & 1 & 0 & 0 & 0 & 0 & 0 & 0 & 0 \\
\hline 4 & 0 & 0 & 1 & 0 & 0 & 0 & 0 & 0 \\
\hline 5 & 0 & 0 & 1 & 0 & 0 & 0 & 0 & 0 \\
\hline 6 & 0 & 0 & 1 & 0 & 0 & 0 & 0 & 0 \\
\hline 7 & 0 & 1 & 0 & 0 & 0 & 0 & 0 & 0 \\
\hline 8 & 0 & 0 & 0 & 1 & 0 & 0 & 0 & 0 \\
\hline 9 & 1 & 0 & 0 & 0 & 0 & 0 & 0 & 0 \\
\hline 10 & 0 & 1 & 0 & 0 & 0 & 0 & 0 & 0 \\
\hline 11 & 0 & 0 & 1 & 0 & 0 & 0 & 0 & 0 \\
\hline 12 & 0 & 0 & 1 & 0 & 0 & 0 & 0 & 0 \\
\hline 13 & 0 & 0 & 1 & 0 & 0 & 0 & 0 & 0 \\
\hline 14 & 0 & 0 & 1 & 0 & 0 & 0 & 0 & 0 \\
\hline 15 & 0 & 0 & 0 & 0 & 1 & 0 & 0 & 0 \\
\hline Subtotals & 3 & 2 & 8 & 1 & 1 & 0 & 0 & 0 \\
\hline $\begin{array}{l}\text { Factor } \\
\text { weighting }\end{array}$ & 7 & 6 & 5 & 4 & 3 & 2 & 1 & 0 \\
\hline Totals & 21 & 12 & 40 & 4 & 3 & 0 & 0 & 0 \\
\hline BIS & & & & & & & & \\
\hline
\end{tabular}

reflects several months on the 12-month yearly calendar. It also represents the difference between the end of one school year and the beginning of another. To the extent that teachers' attitudes in March and April of one year are different than their attitudes in September and October of the subsequent year, this could lead to variations in the data. Camburn et al. (2017) identifies this factor as limitation on self-reported data, referring to it as "recall bias" (p. 80). Other issues related to the use of self-report surveys were addressed previously in the Introduction section. 
Several limitations fall under the general category of personnel. As was mentioned above in the Conclusions section, central office administration and Boards of Education exert a great deal of influence over activities in school buildings within a district. Although one might assume that in order to gain approval for their buildings to participate in the MO PLC organization, a building principal would first secure the blessings of the central office and the Board of Education, that might not be universally true. Further, since participation spans several years, it is possible that changing attitudes or changing personnel in the central office or on a Board of Education could result in a change in the support for this initiative. Similarly, anything that might cause a change in building-level instructional staff - either a large turnover of teachers or a small turnover of influential teachers - could impact the overall attitude of a building to change in general and to PLC implementation in particular. This is especially true concerning the role of the building principal: Horton (2009) observed that a PLC is most successful "when it... becomes institutionalized so that when a leader leaves, the process continues" (p. 103). Data were not available to indicate which buildings in the MO PLC organization had experienced changes in principals at some point during their participation. One might expect that the search process for a new principal for a building involved in PLC implementation would place a priority on finding a candidate capable of picking up the PLC implementation process where the previous principal left off. There was no available evidence to evaluate that assumption.

Care must be taken when making comparison of BIS scores between schools in different implementation year cohorts. BIS scores were designed to provide longitudinal feedback to schools on their PLC implementation progress: Schools are able to compare 
BIS scores year-to-year as they progress through the MO PLC implementation process as one measure of their progress. In the current study, we collected only current year BIS scores. This cross-sectional data limits our interpretation of the BIS data. It is true that one could compare BIS scores between two schools and draw comparisons about the degree to which each school had implemented PLC. It is not, however, possible from the cross-sectional data provided in the current study to draw any conclusions about the progress being made by each school. To make this inference would require knowledge of the BIS from at least the previous year. For this same reason, one cannot draw any conclusions about PLC implementation between implementation year cohorts: Doing so would require all schools in each implementation cohort to start with a common baseline BIS, which is not reflected in the data. This limitation prevents any measurement of longitudinal progress in PLC implementation, which could explain the lack of findings between year of implementation and BIS.

The use of the BAT as the source of data from which the BIS was calculated is limited to the degree that it reflects accepted PLC frameworks. Table 6 in the Methods section listed each of the 15 questions from the BAT and cross referenced them to existing PLC frameworks. Although there were areas of overlap, there was not a complete correspondence between the questions and the frameworks. While all survey items reflected some element of at least one of the three PLC frameworks, there were salient omissions. "How is shared decision-making encouraged in your building," can only be found in Roy \& Hord (2006) as "supportive \& shared leadership." Neither Roy and Hord's (2006) “supportive conditions” nor Louis, Marks, and Kruse's (1996) "deprivatized practice" were referenced by any of the survey items. This raises a 
question about the validity of the BIS as an accurate representation of the implementation of PLC: It is possible that a study using a PLC implementation measure based entirely on any one of the frameworks may have yielded different results.

Finally, because the statistical analysis utilized in this study examined correlational relationships, it is important to acknowledge that no causal relationships can be conferred. Field (2013) describes correlational research (also referred to as crosssectional research) as an observation of what is naturally occurring in the world without directly interfering with it. That is contrasted with experimental research, in which natural events are manipulated. Price, Jhangiani, and Chiang (adapted by the Saylor Foundation without attribution) define correlational research as "a type of nonexperimental research in which the researcher measures two variables and assesses the statistical relationship (i.e., the correlation) between them with little or no effort to control extraneous variables" (p. 130). Bleske-Rechek, Morrison, and Heidtke (2015) observe that humans have a tendency to "conflate correlation with causation" (p. 49), although they go on to acknowledge that, in social science research, the distinction between the two is not obvious. An interesting example of this is provided by Baumeister, Campbell, Krueger, and Vohs (2003), who found that it is easier for individuals to assume that self-esteem enhances high academic performance than to assume the opposite (that high academic performance results in increased self-esteem).. Their data indicated that much of the incorrect inference of causation resulted from associations that coincided with their preconceived notions. Price, Jhangiani, and Chiang Price et al. (adapted by the Saylor Foundation without attribution) list two reasons for conducting a correlational study instead of an experiment: The researcher doesn't believe 
the relationship is causal, and the researcher cannot manipulate the independent variable. In the current study, both of these reasons apply and it is not, therefore, possible to infer causality (or the lack of it) from the data.

\section{Definitions of Key Terms}

Professional learning communities (PLC) is an organizational model or framework "characterized by a shared mission, vision, and values; collective inquiry; collaborative teams; an orientation toward action and a willingness to experiment; commitment to continuous improvement; and a focus on results" (DuFour \& Eaker, 1998, p. 45)

Collaboration is a term that describes processes in a PLC that are deeply embedded in the daily function of the school and act to replace teachers working in isolation with teachers working together in collaborative teams "in a collective effort to help all students learn at high levels" (DuFour, Eaker, \& Burnette, 2002, p. 5).

Collaboration includes activities such as clarifying learning outcomes, developing common assessments, joint analysis of achievement data and establishing team improvement goals, and sharing instructional strategies.

The Benchmark Assessment Tool (BAT) is an online survey designed by the Missouri PLC organization to assess implementation of essential features of PLC at its participating schools. Questions are organized into six strands: Learning Community Culture \& Continuous Improvement; Effective Building Leadership Teams; How Effective Teams Work; What Students Need to Know and Do; How will We Know They Have Learned?; and Systemic Process for Student Success. There are three components of the BAT: The Leadership Team Survey, completed by the Building Leadership Team, 
the Administrative Survey, completed only by building administrators, and the PLC Staff Survey, completed by all instructional personnel involved in PLC implementation at the building.The Benchmark Assessment Tool Index Score (BIS) is a numerical calculation ranging from 0 to 105 that is used as a measure of PLC implementation by the Missouri PLC organization. It is calculated from responses to the BAT. (For a complete description of the mathematical process, see "Data Collection Tools" section above.)

MAP Performance Index (MPI) is a metric used to set academic achievement targets for Missouri schools as part of the Missouri School Improvement Process (MSIP). In its "Glossary of 2012 Accountability Reporting Terms," the Missouri Department of Elementary and Secondary Education defines it as "a single composite number that represents the MAP assessment performance of every student by awarding points to each student based on the four achievement levels. The points for all students in the LEA, school or student group in a subject area are summed together, divided by the number of students in the group being measured and then multiplied by 100 . The result is the MPI for that group and subject" (p. 2).

Rural schools are defined by the Department of Education in the Common Core of Data Public Universe files (see https://www2.ed.gov/pubs/OSEP95AnlRpt/ch7a-

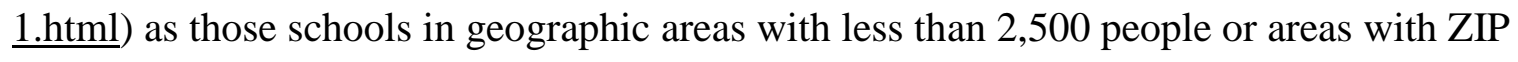
codes designated as rural by the Census Bureau.

Urban schools area defined as all schools not designated as rural schools.

Participatory management is a process that engages all members of an organization or organizational division in jointly identifying its vision, goals, and strategies, and involves them in key areas of decision-making (Spillane et al., 2005). 


\section{Significance of the Study}

\section{Scholarship.}

This study asks a very specific question: Is there a relationship between PLC implementation and teacher involvement in decision-making? The answer fills a very specific gap in the literature. As indicated in the Introduction, there is an abundance of research on proposed theoretical connections between PLC and teacher influence, but a lack of research documenting the relationship between PLC and teacher involvement in decision-making using empirical evidence. That being the case, this study adds to the body of research documenting the effects of PLC implementation [e.g., better informed teachers (White, 1992), improved teacher communication within and across schools (White, 1992; Wohlstetter, 1995), and reduced isolation of teachers (White, 1992)], and in so doing, serves as the basis for additional research designed to explore possible explanations for the findings.

A finding that PLC implementation and teacher influence were related would confirm that PLC, as a conceptual framework for increasing teacher involvement in decision-making, was working. This would be a considerable finding, given that research on the effectiveness of other reform models at increasing teacher influence has shown little or no increase (Ben-Peretz, 2001; Brost, 2000, Clark \& Clark, 2002, Howey, 1988; Lambert, 2003; Servage, 2006; Servage, 2009; Taylor \& Bogotch, 1994; White, 1992; Wilson, 2016; Wohlstetter et al., 1994). Conversely, a finding of no relationship between PLC implementation and teacher influence would generate further studies on the effectiveness of PLC implementation as a conceptual framework for school reform. 
Much of the research on PLC's seeks to describe PLC's (Louis, Marks, \& Kruse, 1996; Roy \& Hord, 2006) or examine various aspects of the impact of PLC's [e.g., on changes in teaching practice (see Vescio, Ross, \& Adams, 2008); on student achievement (see Vescio, Ross, \& Adams, 2008); on teacher efficacy (Priest, 2015; Shetzer, 2011; Turner 2012); on professional development (Grodsky \& Gamoran, 2003)]. There are a few studies that examine the PLC implementation process itself. In a doctoral dissertation, Ameyaw (2007) conducted a qualitative study to determine how teachers in one urban elementary school described the functioning of their school (which had recently attempted PLC implementation) to determine if failure to implement the essential elements of PLC could explain the lack of improvement in student achievement. Similarly, in another doctoral dissertation, Johnson (2016) conducted a qualitative study to examine whether schools identified as PLC's in Minnesota were actually implementing essential elements of PLC's. Bostic (2013) conducted her doctoral research along similar lines, using a mixed methods approach to assess the presence of essential PLC elements in schools in a large suburban school district in North Carolina as a measure of PLC implementation. She compared this measure against longitudinal achievement data for the three years since PLC's were implemented to determine the effectiveness of PLC implementation.

Missouri appears to be unique by virtue of the creation of the Missouri Professional Learning Communities organization (MO PLC) by the State Department of Elementary and Secondary Education (DESE). The mission of MO PLC was to provide training and support to Missouri schools for the process of implementing PLC's. As such, MO PLC constituted an intervention program for PLC implementation. A thorough 
search of the literature could not locate any other states that have created a similar statewide intervention program. Additionally, there does not appear to be any study evaluating the effectiveness of MO PLC. The current study, which examines the relationship between PLC implementation and teacher involvement in decision making (one of the essential elements of PLC) is among the first to serve as an evaluation of a PLC intervention program.

\section{Practice.}

One of the defining characteristics of a PLC is supportive and shared leadership in which administrators are committed to sharing decision-making with teachers (DuFour, Eaker \& DuFour, 2005; Rosenholtz, 1989; Roy \& Hord, 2006). Similarly, research by Odden and Wohlstetter (1995) and Wohlstetter, et al. (1994) demonstrated the critical importance of principals' leadership in determining if teacher involvement in decisionmaking would impact student achievement and in developing visions, setting goals, and establishing high expectations. Murphy (1994) identified facilitating groups, directing group processes, and managing change processes as necessary skills for principals in schools where shared decision-making is occurring. Bird et al. (2009) found that the authenticity of the school principal has a significant positive correlation on the levels of trust and engagement among teachers. Smylie and Denny (1990) found that teachers willingness to participate in shared decision-making processes in schools was influenced primarily by their relationships with their principals; that teachers were more willing to participate if they perceived their relationships with their principals as "more open, collaborative, facilitative and supportive," and less willing if those relationships were characterized as "closed, exclusionary, and controlling" (p. 63). Streck (2009), studying 
the impact of leadership practices and shared decision-making in schools, identified the two most frequently mentioned practices that needed improvement as establishing a trusting environment and maintaining open lines of communication. All of this research points to the importance of the role of the principal on teachers' involvement in decisionmaking. Determining whether or not a relationship exists between PLC implementation and teacher influence provides important feedback for administrators in PLC schools on the effectiveness of their efforts at sharing and distributing leadership, and, based on the findings, suggests a number of areas for professional development to enhance those efforts.

The importance of the findings of this study don't stop at the school building. In addition to individual principal's leadership skills, it is district level leadership also has an important impact on the process of teacher empowerment. Leech (2019) concluded that "individual leadership behaviors of school principals may have less influence on the decision-making culture than the organizational structure and culture of the schools and school district" (pp. xiii-xiv). One can readily speculate that the organizational structure and culture Leech describes refers to the pressure applied by central office administration or Boards of Education directly on building principals. Through budget processes, staffing decisions, and through the process of approving building schedules, central office administration and Boards of Education wield significant power over all aspects of school district operations, including the general process of PLC implementation and specific efforts to incorporate teachers in decision-making processes to a greater degree. The findings of this study provide valuable feedback to central office administrators and Boards of Education on the effectiveness of PLC implementation efforts in their districts. 
Based on those findings, these individuals can make policy decisions that will positively impact both PLC and teacher empowerment in their districts.

\section{Summary}

The conceptual framework of PLC has been adopted by schools worldwide, and research has established many positive outcomes associated with PLCs. Given the inclusion of "supportive and shared leadership" as a critical element of PLCs in numerous PLC studies (Roy \& Hord, 2006), as well as a great deal of research into participatory management and site-based decision-making, this study asked the question, is there in fact a relationship between PLC implementation and increased teacher influence? The findings of this study suggest that there is not: For all the benefits associated with PLC implementation, this study found no relationship between PLC implementation and empowering teachers to be involved in making decisions concerning critical areas of the school function (hiring, discretionary spending, choice of curriculum and instructional programs, establishing student behavior standards, selection of textbooks and other instructional materials, and determining the content of in-service programs). 


\section{Section Two-Practitioner Setting for the Study}

\section{Introduction}

My current position is in higher education (Director, TRiO Student Support Services at Columbia College), but my goal for pursuing the Ed.D. in Educational Leadership and Policy Analysis is to return to public education as a central office administrator. In 2003, I was in that role-Cape Girardeau School District No. 63 Superintendent. I was entering my second year championing a transition of our buildings into professional learning communities (PLCs). Two years later, when I left the district, the Board hired a new superintendent with new priorities and a different skill set, and the process, as I understand from feedback from several building level administrators in the district, stalled.

Although it is unlikely that I would ever be employed again in the Cape Girardeau School District, it is the setting in which I practiced the leadership and policy skills germane to my research in the ELPA Ed.D. program. As such, I use it as my practitioner setting for this dissertation. Further, in any district to which I would return and lead (or continue) the implementation of PLCs, I would encounter the obstacles (or others very much like them) that exist in the Cape Girardeau School District: They are issues incumbent in most organizations seeking to bring about significant organizational change.

\section{History of the Organization}

The Cape Girardeau School District serves a community of just over 38,000 and a student population of approximately 4,000 pre-kindergarten through twelfth grade students. There are five pre-kindergarten through fourth grade "neighborhood" 
elementary buildings, one fifth and sixth grade middle school, one seventh and eighth grade junior high school, and one comprehensive high school serving grades nine through twelve. The student population is $81.4 \%$ white, $12.6 \%$ black or African Americans, $3 \%$ Hispanic, and 2\% Asian. The District also operates an area career and technology center serving nine high schools as well as adult students, and an Alternative Education Center that is housed at the Central Administration Office building, providing services for students in grades six through twelve.

I entered my second year as district superintendent convinced by two extraordinary events from the previous year that our district could benefit from restructuring our governance from a very traditional, centralized, top-down approach to a decentralized professional learning community (PLC) structure. The first of these events was the completion of a district-wide restructuring that had been several years in the making. Struggling to meet yearly progress on our MAP scores, facing overcrowded buildings, and hampered by aging facilities, the District presented the community with a bold restructuring plan, the linchpin of which was an $\$ 18$ million bond issue, most of which was dedicated to building a state-of-the-art comprehensive high school. Prior to 2002, our elementary schools had all been kindergarten through sixth grade with our district-wide pre-kindergarten program housed at one of the elementary school buildings. Seventh graders were housed in a separate building (built in 1915). Eighth and ninth graders were part of Cape Central Junior High School, and Central High School served grades ten through twelve.

After the bond issue passed in 2000, the District opened the new high school in 2002, allowing us to consolidate grades nine through twelve. Grades seven and eight 
were moved to the former high school building, and a brand-new middle level program for grades five and six was located at the former junior high school building. With two fewer grade levels, each elementary school was able to add pre-kindergarten programming.

The second significant event from the 2002-03 school year was what educators and policymakers across the nation described as the "perfect storm" that broke against funding for public education. As schools across the country were bracing for the worst by not renewing contracts for all of their probationary teachers and cutting programs from fine arts to varsity athletics, I met with the District's central office administrators (the Administrative Cabinet), and we collectively devised a process for community-wide involvement in making a budget-cutting proposal to the Board of Education. We made an open invitation to the community to participate in the process, and ultimately divided 104 community volunteers, comprised of roughly equal parts community members and school employees, into seven problem-solving teams, each focusing on a different service area and each given the same charge: Identify all reasonable cuts that could be made. After five team meetings over a two-week period, the committee chairs met to prioritize the one hundred-plus recommendations and formulate a final budget-cutting proposal to the Board of Education. In the end, we implemented seventy-five of the recommendations for a total reduction of $\$ 1.2$ million. The process was praised as open and candid by the participants, nearly all of whom emerged with an appreciation for the complexity of the organization and a feeling that the District was making efficient use of its resources. 
Ironically, although both of these events had positive outcomes for the district, they both fed into an unintended and ominous realization: Our district was losing ground in our efforts to achieve AYP on our achievement test scores and graduation rate. Further, it was apparent that restructuring our buildings, although a step in the right direction toward better meeting the developmental needs of students and more efficiently utilizing our resources, was not likely to reverse those trends. Worse, the budget reduction actions, which eliminated some teacher positions by attrition and reduced program budgets, were going to exacerbate the issues. It was clear that a systemic restructuring of our instructional efforts was going to have to occur. For that, we turned to the PLC model.

In 2001, the year before I became superintendent, I attended a PLC workshop presented sponsored by the Southeast Missouri Regional Professional Development Center (RPDC) and led by Rick DuFour. Inspired by that workshop, in 2002 I took the entire Administrative Council [central office administrators (Administrative Cabinet) plus the lead administrator from each of the District's buildings] to a follow-up workshop on PLC. In subsequent Council meetings, we discussed the pros and cons of the model itself and debated whether or not it addressed the needs that we faced and was a concept that fit into the context of our district. As with any innovation, getting buy-in by front line staff members (in our case, classroom teachers) was critical if the effort was to have any chance at changing behavior, so our primary dilemma was how to create a unified and motivated commitment from our instructional staff to PLC as a conceptual framework that met our needs. 
Our approach was a three-year plan. Year one (2003-04) saw the Administrative Cabinet acting as a PLC itself, reading and discussing PLC literature to prepare each building administrator to lead that same effort at their individual schools during year two (2004-05). During year two, the goal was to establish a "PLC Action Plan" for implementing PLCs at each building beginning in year three (2005-06). The degree of engagement shown by building administrators in our training sessions was matched only by the deepening collegial relationships that grew between them, crossing the invisible boundaries that typically divide elementary, middle, and high school programs.

When the Board decided in the fall of 2004 not to renew my contract at the end of the 2004-05 school year, one of the major concerns of the administrative staff was the potential loss of support for implementing PLC. Fortunately, as a result of presentations we had made at Board meetings about our efforts, the Board was invested in continuing the work and made knowledge about PLC a main focus of their interviews for a new superintendent. Unfortunately, the candidate they hired did not follow through, which caused district-wide PLC implementation to founder. Some progress continued based on the commitment of individual administrators, but the collaborative team effort was lost.

The district currently faces many of the same dilemmas that we faced in 2003 with the added dimension that the uncoordinated efforts of administrators has resulted in, at best, uneven and, at worst, conflicting and inaccurate knowledge about PLC. In addition, some current staff members who were in the district during the initial implementation process from 2003-2005 may have a preconceived cynical attitude based on their perception of the apparent failure of the previous effort to implement the concept. 


\section{Organizational Analysis}

In this section, I will examine Cape Public Schools (CPS) through the lens of Bolman and Deal's (2008) structural frame. That choice reflects the structural description of PLC given by DuFour and Eaker (1998) as a conceptual framework for organizing schools that embeds a capacity for change in the school structure and processes in order to create a culture of sustained, substantive school improvement. The structural frame highlights unique and innovative aspects of PLC structure and organization. To set the context for that analysis, we will first look at schools through the organizational lens of PLC. DuFour and Eaker (1998) describe characteristics of PLC (which they refer to using the structural metaphor of building blocks), most of which are at least in part structural in nature: The overall organizational mission, vision, and values (reflecting the organizational hierarchy); collective inquiry (that requires structural processes in place to allow for joint planning and coordinated action); collaborative teams (dependent on common schedules and conference periods, making it arguably the most structural component of all); action orientation and experimentation (again requiring structural processes in place to allow for the reflection required to make this happen). With so much of this conceptual framework dependent on structural aspects of the organization, the structural frame provides the best lens for achieving a better understanding of the organization involved in PLC implementation.

\section{Professional learning community.}

\section{Historical implications.}

It is my observation that, in the years since Richard DuFour and Robert Eaker published their first book on PLC (DuFour and Eaker, 1998), the term, "PLC," has been 
used to describe so many different improvement efforts that it has almost entirely lost any functional meaning. At its heart, PLC is based on the premise that it is possible to improve schools without waiting for parents to "provide schools with a better class of students" or society to solve its problems (p. 12). The authors made the bold assertion that "If schools are to be significantly more effective, they must break from the industrial model upon which they were created and embrace a new model that enables them to function as learning organizations" (p. 15).

The enduring structure of our schools was born during the Industrial Revolution, during which "The uniformity, standardization, and bureaucracy of the factory model soon became predominant characteristics of the school district" (DuFour \& Eaker, 1998, p. 21). This model worked well at "sorting and selecting students" (p. 23), but was "inadequate for meeting the national education goals of today—goals that call for all students to master rigorous content, learn how to learn, pursue productive employment, and compete in a global economy" (p. 23).

\section{Definition.}

In response, DuFour and Eaker proposed a structure with the following characteristics: (1) Shared mission, vision, and values, (2) collective inquiry, (3) collaborative teams, (4) action orientation and experimentation, (5) continuous improvement, and (6) results orientation (pp. 25-29). The nature of these characteristics suggests that this school improvement model is not a prescriptive framework to be duplicated and incorporated in essentially the same format from one school to the next, an understanding that is evident in the authors' choice of terminology: They alternately refer to PLC as a "conceptual model" (DuFour \& Eaker, 1998, p. 23) and a "conceptual 
framework" (Eaker, DuFour, \& Burnette, 2002, p. 1). Instead, as is indicated in the title of Eaker, DuFour, and Burnette's book (2002), Getting Started: Reculturing Schools to Become Professional Learning Communities, it is more of a roadmap for "developing the capacity of school personnel to function as a professional learning community" (p. 1). PLC is based on utilizing the teacher as a highly-trained and experienced professional to work collaboratively with other teachers to create a community that is "relentless in questioning the status quo, seeking new methods, testing those methods, and then reflecting on the results" (DuFour and Eaker, 1998, p. 25). Unfortunately, our schools in general continue to operate according the factory model made popular by Frederick Taylor's (1911, as cited in Bolman and Deal, 2008) work on industrial organizations. While schools in the Cape Girardeau School District were in many ways very progressive (e.g., reading and writing specialists, interdisciplinary teams, vertical articulation of curriculum review), the isolation of teachers and limited opportunities for collaboration reflected a very traditional, factory-oriented approach to education. We understood that the shift to the PLC model would require substantive change. The following organizational and leadership analyses are specific to PLC in public schools drawing on examples from the Cape Girardeau School District.

\section{Structural Framework.}

\section{Definition and tenets.}

In their discussion of the structural frame, Bolman and Deal (2008) define it as an organizational perspective concerned with putting people in the right roles and relationships. It is based on the assumptions that: 
organizations exist to achieve established goals and objectives, organizations increase efficiency and enhance performance through specialization and appropriate behavior, suitable forms of coordination and control ensure that diverse efforts of individuals and units mesh, organizations work best when rationality prevails over personal agendas and extraneous pressure, structures must be designed to fit an organization's current circumstances, and problems arise and performance suffers from structural deficiencies, which can be remedied through analysis and restructuring (pp. 45-46).

They explain that organizations delineate positions or roles and then group people into working units in several ways: By knowledge or skill, based on time (i.e., work shift), by product, around customers or clients, around place or geography, or around process. These groupings are then controlled vertically (authority, rules and policies, and planning and control systems) as well as laterally (meetings, task forces, coordinating roles, matrix structures). These twin processes of differentiation and integration drive the decision about which structure is the best for an organization.

\section{Analysis.}

Mintzberg (as cited in Bolman \& Deal, 2008) offers six models of structural design (pp. 78-86). As indicated previously, the organizational structure of schools has changed little since the Industrial Revolution, and the design that best fits most districts is the "Divisional Form" (p. 84), where important decisions are made at the headquarters (e.g., the Central Administrative Office) and the "divisions" correspond to individual school buildings, which are typically grouped according to student age and act as "quasi- 
autonomous units" (p. 83). Mintzberg observes that this structure is efficient and effective for organizations involved in routine tasks (p. 80).

In contrast, Bolman and Deal (2008) indicate that an organization's structure should match the nature of the task that it performs (p. 51). It would be hard to find someone who would argue with the notion that challenges facing education today make it anything but a routine task. There are, however, multiple challenges in determining a better design. Bolman and Deal (2008) describe several of these as dichotomous extremes. One of these is the necessity for organizations to balance excessive autonomy against excessive interdependence. The PLC characteristics of collective inquiry and collaborative culture emphasize the need for interdependence and communication between teachers, breaking down the isolation that is typical of most school buildings (DuFour \& Eaker, 1998, pp. 25-27). Breaking down this isolation is a significant change to the culture of schools, and Cape Public Schools was no exception. However, based on their experiences with other innovations over the past few years (especially curriculum changes and instructional modifications associated with inclusion of special education students like class-within-a-class) the majority of the building administrators anticipated that their staff members would embrace opportunities to collaborate with one another. Modifying class schedules and supervision responsibilities in order to create the necessary common planning time was part of the building-level PLC implementation plan of every building administrator.

Another dilemma, referred to as "too loose versus too tight" by Bolman and Deal (2008) addresses the need to "hold an organization together without holding it back" (p. 75). Too much looseness enables people to pursue their own directions independent of 
others, but too much tightness stifles creativity and flexibility (p. 75). Given the nature of the PLC to encourage teachers to work collaboratively in a culture of action orientation and experimentation with a commitment to continuous improvement, a degree of looseness is necessary. Roy and Hord (2006) list supportive and distributed leadership as a defining element of PLC, and we were fortunate in Cape Public Schools to have administrators who collectively endorsed the idea of sharing leadership with teachers. They also understood that moving in this direction would change some fundamental aspects of how they conducted business in ways that would be noticed in the community. For that reason, we realized early on that we would need educate the Board of Education about PLC and get a commitment from them at the outset to support our efforts. During the spring semester of my last year as superintendent, each building administrators presented the PLC implementation plan for his/her building at a Board meeting, and we asked the Board at the next meeting to officially endorse the plans as presented.

Additionally, organizations must determine the blend of vertical and horizontal procedures (Bolman \& Deal, 2008, pp. 59-60) that best suits their goals. Bolman and Deal (2008) explain: "Vertical coordination is generally superior if an environment is stable, tasks are well understood and predictable, and uniformity is essential. Lateral communications work best when a complex task is performed in a turbulent, fastchanging environment" (p. 60). Again, one would be hard-pressed to find anyone who would dispute that today's schools are complex and fast-changing, which would mitigate in favor of using horizontal procedures. Ironically, the industrial era structure of our schools that compartmentalizes learning in isolated classrooms effectively prevents horizontal communication between teachers from occurring. The collaborative teams and 
the emphasis on collective inquiry, which are hallmarks of PLC, make it much better suited for the complicated task of teaching. Creating collaborative teams was a part of every building PLC implementation plan that was presented to the Board of Education during my final year as superintendent.

With these findings in mind, Mintzberg's (as cited in Bolman \& Deal, 2008) "professional bureaucracy" design (pp. 82-83) appears to be the best fit for the concept of PLC. Bolman and Deal (2008) describe the design as "Freeing highly trained experts to do what they do best" (p. 83). Bolman and Deal's (2008) description of the strategic apex (i.e., the superintendent and other central officer administrators in a school district) articulates one of the most daunting challenges of incorporating the PLC in a school district: "The strategic apex — top management— tends to exert centralizing pressures.... Deep down, they long for a simple structure they can control" (p. 88). The PLC is, by design, a decentralized system that moves the decision-making power from the central office to the school building. Teachers meet and confer to identify the needs of their students, collectively research possible solutions, select those that appear to have the best opportunity for meeting the needs of their students, strategically plan to incorporate them, collect evidence of their effectiveness, and use that evidence to decide whether to continue with the solution or discard it. It is a daunting cultural change not only for the administrator who is relinquishing control over curriculum and evaluation processes which have heretofore been centralized, but also for the classroom teacher, many of whom are conditioned to work in isolation delivering curricula that were developed through processes over which they exert little or no control. 
The structural frame predicts that top-level administrators will resist serious efforts to restructure their districts in accordance with the PLC model. That is consistent with my observation that many districts embrace the PLC in name only, incorporating a few PLC elements that augment existing processes into the existing structural design without requiring any significant changes in the structure or culture of the organization itself. I speculate that many change initiatives designed to bring about school improvement focus on the structure of schools because it is relatively easy to do, requiring only a staff-wide memo for reasonably small changes and three readings and a vote at a Board of Education meeting for bigger ones. I would like to say that we accomplished that in Cape Public Schools. It is one of my greatest regrets that I was not able to stay in the district to see our building-level PLC implementation plans take effect.

\section{Leadership Analysis}

With the collaborative team at the heart of PLC, understanding and having skills at distributing leadership and creating opportunities for teachers to participate in decision-making is a necessity for administrators working in PLC buildings as well as central office administrators overseeing building-level performance. The theoretical framework utilized in the current study is based on participation management theory, which makes it appropriate to utilize that theory to conduct a leadership analysis related to PLC.

\section{Definition and tenets.}

Spillane et al. (2005) describes participatory management as a process that engages all members of an organization or organizational division in jointly identifying its vision, goals, and strategies, and involves them in key areas of decision-making. 
Sarafidou and Chatziioannidis (2013) state that "this empowerment of individuals is considered fundamental for enhancing their morale and motivation, increasing levels of job satisfaction and promoting a sense of responsibility and commitment to organizational effectiveness and improvement" (p. 170). Other researchers in the field of participatory leadership (MacBeath, 2005; Harris, 2010) emphasize the importance of collaborative decision-making as the focus of new organizational management practices that serve to cultivate synergistic creativity and facilitate the incorporation of highperformance practices into the workplace. Lange (1993) ascribed multiple benefits of decentralizing school governance through participatory management, including a commitment to decisions, a perception that higher quality decisions were made, increased staff cohesion, and increased trust among staff members and principals.

\section{Analysis.}

When one reads the definition and tenets of participatory management above and compares them to characteristics of PLC, one sees how closely aligned this theory regarding decision-making in organizations (participatory management) and this conceptual framework for organizing schools to embed within them a capacity for change (PLC) truly are. Both participatory management and PLCs clearly champion increasing involvement of employees in decision-making processes as an outcome. Numerous authors cite distributed leadership as a necessity in order to build an effective PLC (DuFour et al., 2005; Rosenholtz, 1989; Roy \& Hord, 2006). Similarly, in their study on creating and sustaining PLCs, Bolam, et al. (2005) stated that "school autonomy, as evidenced in site-based management, is seen as essential for the development of a learning community" (p. 25). All of this literature is unequivocal in its call for increased 
participation of teachers in the implementation of PLCs, and participatory management theory provides the foundation for understanding the connection between PLC implementation and increased teacher influence. The leadership implications are clear: To lead the process of implementing PLC, whether one is engaged in that from a central office position or as a building administrator, one has to demonstrate commitment to providing supportive leadership that shares decision-making. Am I able to provide evidence of this? I believe I can from my administrative experience at both the building level and the central office level.

The years I worked at Perry County School District No. 32 saw a dramatic transition in middle level education. I was hired as assistant principal at Perryville Junior High School, which included a very traditional junior high instructional program for grades seven and eight, and an equally traditional self-contained sixth grade program that was included at the junior high building solely because there was no room at the elementary building. Successful bond and tax levy issues provided building renovations and classroom additions that allowed the entire district to restructure, with the junior high program picking up the fifth-grade program and relocating to the former elementary building. During the year prior to the restructuring, I helped lead the leadership team that coordinated the process of reeducating our staff about middle level education and guided them through a process of evaluating a variety of options for redesigning our instructional program. I helped champion the effort to include the entire staff on multiple site visits to exemplary middle school programs around the state, and, ultimately, a collective effort to achieve consensus on final decisions. As a result, we began a new year in new 
surroundings with a new name (Perry County Middle School), a new mindset, and a staffwide commitment to meeting the unique needs of our middle-school-aged students.

During my time as a central office administrator in Cape Girardeau, we opened the brand new Cape Girardeau Career and Technology Center, expanded the Alternative Learning Center program, opened a new comprehensive high school that required a district-wide restructuring and reorganization (and multiple renovations), coordinated a community-based budget reduction program, and implemented professional learning community concepts throughout the district. Throughout all of these projects, I worked relentlessly to ensure that we never wavered in keeping our focus on the needs of teachers and improving experiences for students and focused on building a work environment characterized by caring, trusting, collegial relationships based on mutual respect. Three efforts highlight my commitment to supportive and distributive leadership. In my final year as Assistant Superintendent, I coordinated preparations for a district-wide staff reorganization necessitated by the opening of a new high school that moved freshmen out of the junior high and created a brand-new middle school attendance center. I worked closely with building administrators to craft a process that solicited input from teachers on everything from organizing physical spaces to final decisions on teaching assignments. Also while I served as assistant superintendent, I was tasked with overseeing and applying district-wide policies related to personnel and established participatory hiring processes at all levels. We hired new principals/head building administrators for six of our eleven buildings during my tenure in charge of district-wide human resources, and every hire included active and authentic participation on the part of the entire staffs of the affected buildings. Finally, as superintendent, I worked 
collectively with district-wide administrative staff as we embarked on a process to transition our culture to that of a PLC. That process began by creating a collaborative team of the lead administrator from every building in the district during an initial year of education at the administrative level. Watching that group of individuals representing elementary, middle, high school, vocational, and alternative programs cross the barriers that defined their respective programs and learn from each other stands as one of most cherished memories. Our second year of implementation was devoted to mutual support as each administrator replicated the educational process we had just completed at their respective buildings with the goal of creating PLC implementation plans to present to the Board of Education. My final year as superintendent saw each building beginning the implementation process. Through multiple contacts with individuals from that district over the ensuing years, I have learned that efforts that were started during those years have continued.

\section{Implications for Research in the Practitioner Setting}

This study generates useful descriptive statistics on teacher influence as well as levels of implementation across the state of Missouri. While each school receives feedback annually from MO PLC regarding the results of its BAT, prior to this study, summary information about other participating schools was not available. Each of the buildings in the Cape Girardeau School District has schools in the region and across the state to which it compares itself based on similar demographics and programs. Having access to PLC implementation from those schools could provide valuable information to PLC leadership teams at each of our buildings. How does our BIS compare to comparable schools at comparable stages of implementation? What issues are those 
schools facing that are similar/different than ours? What solutions are other comparable schools implementing to address similar problems? These are exactly the kinds of questions collaborative teams of teachers in PLC schools need to be considering and researching.

The findings of this study will have implications for Cape Public Schools and beyond. One can speculate that the number of schools participating in the MO PLC organization is the minimum number of schools involved in PLC implementation. There are very likely a number of schools actively implementing PLC without utilizing the services of the MO PLC organization. Additionally, it is likely that there are schools intentionally only implementing parts of the concept based on resources or need. Even at the minimum number, there is a significant amount of resources in Cape Girardeau and across the state being directed at PLC implementation. To the extent that those schools are expecting the implementation process to have an impact on teacher influence, the results of this study gives them some sense of the effectiveness of their efforts. A positive finding reassures buildings (as well as their districts and, more broadly, the Department of Elementary and Education) that their efforts are succeeding, which would serve to justify additional resources for promoting PLC implementation. A negative finding would suggest additional research to determine reasons for the disconnect.

Although this dissertation discusses the limitations surrounding the interpretation of findings concerning the year of implementation and actual PLC implementation, this data must still be considered. In general, one would expect that, on average, participation in the MO PLC would result in greater PLC implementation. While the current study only looks at a snapshot of PLC implementation and is, therefore, not able to provide data 
to either support or refute that assumption, it seems a reasonable supposition that, on average, those schools that have participated the longest in the MO PLC implementation process should have the highest implementation scores. That is, one could argue that the average implementation score for all Year 4 schools should be higher than the average implementation score for all Year 1 schools, and that Year 2 and Year 3 schools should, on average, fall in between these two. As in the previous paragraph, a finding that verifies this assumption reassures buildings (as well as their districts and, more broadly, the Department of Elementary and Education) that their efforts are succeeding, which would serve to justify additional resources for promoting PLC implementation, and a negative finding would suggest additional research to determine reasons for the disconnect.

\section{Summary}

The Cape Girardeau School District, or any school district either considering the implementation of PLC or in the progress of implementing PLC, faces substantial organizational issues as it encounters the changes necessary to move from a traditional, top-down bureaucratic hierarchy to the flatter hierarchy required when teachers are organized to collaborate, perform action research, drive their own professional development, and become more empowered to be involved in decision-making in critical areas previously reserved for building- and district-level administrators (e.g., curriculum, hiring, behavior management programs, textbook selection, inservice content, and spending discretionary funds). However, decades of organizational research on distributive leadership, participatory management, and leadership styles indicates that the 
potential benefits of empowering teachers and embedding the capacity for change within an organization is worth the effort. 


\section{Section Three—Scholarly Review for the Study}

Educational reform has been a topic of intense interest since the 1950's (Brost, 2000; Lambert, 2003; Servage 2009; Watson, 2014). Researchers have routinely proposed that schools must evolve to be much more adaptable and much more responsive to students' needs (Brost, 2000; Servage, 2009). A great deal of educational research exists that indicates that, in order to accomplish educational reform, teachers must be more involved in decision-making processes (Brost, 2000; Conley, 1991; DuFour \& Eaker, 1998; Odden \& Wohlstetter, 1995; Liontos, 1993; Smylie et al., 1996; York-Barr \& Duke, 2004). Empowering teachers to reflect, collaborate, and act collectively as a means to enhance student achievement figures prominently in many current public school reform initiatives (Duffy et al., 2006; DuFour \& Eaker, 1998; Gates \& Watkins, 2010). Howey (1988) described teacher leadership as both natural and necessary in today's climate of increasing demands for excellence being placed on schools. His assertion that reform could only be effective if addressed by those who reside where the problems are is a common theme in educational research (Brost, 2000; Clark \& Clark, 2002; Liontos, 1993; Odden \& Wohlstetter, 1995 Smylie et al., 1996; York-Barr \& Duke, 2004).

One popular reform framework that schools have embraced that incorporates the idea of involving teachers in problem analysis and decision-making is "professional learning communities" (Clark \& Clark, 2002, Gates \& Watkins, 2010; Linder et al., 2012), defined by DuFour \& Eaker (1998) as an organizational model or framework "characterized by a shared mission, vision, and values; collective inquiry; collaborative teams; an orientation toward action and a willingness to experiment; commitment to continuous improvement; and a focus on results" (p. 45). Even though definitions vary 
somewhat, there are certain characteristics that are commonly cited by educational researchers: A collaborative culture based on the assumptions that groups of teachers are able to achieve more by working together than they can achieve individually (Bolam et al., 2005; Kruse et al., 1994), a commitment to improved student learning driven by data and mutual accountability (DuFour \& Eaker, 1998; Kruse et al., 1994), supportive and shared leadership in which administrators are committed to sharing decision-making with teachers (Roy \& Hord, 2006), and shared personal practice and collective inquiry between teachers that leads to continuous inquiry and reflective dialogue (Roy \& Hord, 2006; Stoll et al. 2006).

A central tenet of the PLC framework is that PLC can lead to greater teacher influence which then indirectly influences student achievement (DuFour \& Eaker, 1998 Linder et al., 2012; Thompson et al., 2004; Sigurðardóttir, 2010; Louis \& Marks, 1998). An important result of embedding collaboration into the structures of schools when PLCs are implemented is the incorporation of shared leadership and shared decision-making: "Collaboration can involve various stakeholders in making significant decisions about their school and its programs" (Clark \& Clark, 2002, p. 52). These authors go on to note that "collaborative decision-making can improve the school working environment and lead to instructional improvement and higher student achievement scores" (p. 56), a finding that is supported by other researchers (Hofman \& Dijkstra, 2010; Linder et al., 2012; Schechter, 2008; Thompson et al., 2004; Sigurðardóttir, 2010; Louis \& Marks, 1998). The observation that PLCs are designed to emphasize teacher-led data-informed decision-making is also well-documented in the literature (Linder et al., 2012; Thompson et al., 2004; Sigurðardóttir, 2010; Louis \& Marks, 1998). 
Given the abundance of research on proposed theoretical connections between PLC and teacher influence, one would expect there to be a body of research documenting the relationship between PLC and teacher involvement in decision-making using empirical evidence. In their 2004 comprehensive review of over two decades of empirical research related to teacher leadership, York-Barr \& Duke (2004) refer only to "numerous small-scale, qualitative studies that describe dimensions of teacher leadership practice, teacher leader characteristics, and conditions that promote and challenge teacher leadership" (p. 255). They reviewed 140 teacher leadership studies and reviews of studies. None of these were quantitative research studies examining the relationship between teacher leadership and PLCs. Similarly, although a review of research for this current paper revealed studies examining positive effects from increased collaboration in PLCs, like better informed teachers (White, 1992), improved teacher communication within and across schools (White, 1992; Wohlstetter, 1995), and reduced isolation of teachers (White, 1992) there were no quantitative studies directly examining whether the presence of PLCs predicts increased teacher influence in schools.

\section{Organization of Scholarly Review}

The current study was designed to fill that research gap in order to determine, quantitatively, if a relationship exists between PLC implementation and teacher involvement in decision-making. This chapter provides a review of the extant scholarship related to this study. It begins with a brief overview of reform in public education. This is followed by a summary of participatory management theory (which is used as the theoretical framework for the current study) which provides the context for the review of literature on teacher empowerment which follows. Literature on the 
concept of professional learning communities (PLC) is reviewed next, including literature pertaining to the attributes of PLC, leadership within PLC, the relationship between PLC and professional development, and the relationship between PLC and student

achievement. The literature pertaining to quantifying teacher influence is then reviewed. Reflecting the reliance on qualitative research in the study of teacher influence, Section 3 concludes with a summary of issues surrounding bias in self-reported data.

\section{History of Educational Reform}

In the late nineteenth century, schools were created in the image of the industrial factory, in which a small group of people could do the thinking for an entire organization, determining the one best way to accomplish a task and then providing the training and supervision necessary for workers to accomplish that task. It was a model that "demanded centralization, standardization, hierarchical top-down management, a rigid sense of time, and accountability based on adherence to the system" (DuFour \& Eaker, 1988, p. 20). As a result, uniformity, standardization, and bureaucracy became defining characteristics of the American school, with decisions flowing from state boards of education to local school boards and administrators, from which they were directed to teachers to be implemented. Students were viewed as raw material on the educational assembly line, emerging after thirteen years as a finished product. DuFour and Eaker (1998) summarized the inadequacy of the factory model and the need for reform in public schools in the United States.

The factory model is woefully inadequate for meeting the national education goals of today—goals that call for all students to master rigorous content, learn how to learn, pursue productive employment, and compete in a global economy. 
If educators are to meet these challenges, they must abandon an outdated model that is contrary to the findings of educational research, the best practices of both schools and industry, and common sense. They must embrace a new conceptual model for schools (DuFour \& Eaker, 1998, p. 23).

Researchers have consistently proposed that schools must evolve to be much more adaptable and much more responsive to students' needs, and the call for reform of U.S. schools is a widespread one (Brost, 2000; Howey, 1988; Lambert, 2003; Louis, Kruse, \& Raywid, 1996; Servage 2009; Watson, 2014; Zmuda, Kuklis, \& Kline, 2004). Concern over the quality of education in our country has also been ubiquitous in national/federal committees and commissions [e.g., Carnegie Forum on Education and the Economy Task Force on Teaching as a Profession (1986), The Education Commission of the States' Task Force on Education for Economic Growth (1983), The President's Commission on Industrial Competitiveness (1985)]. Research in educational reform has identified a number of specific areas of concern, including a complex and rapidly changing world, the increased complexity of organizations, work that is best accomplished by teams, and rapidly changing environments (Brost, 2000; Servage, 2009). In its publication, "A Nation Prepared: Teachers for the $21^{\text {st }}$ Century," the Task Force on Teaching as a Profession summed up the challenge facing our nation's schools: "The American mass education system, designed in the early part of the century for a mass-production economy, will not succeed unless it not only raises but redefines the essential standards of excellence and strives to make quality and equality of opportunity compatible with each other" (p. 21).

\section{The Excellence Movement.}


The second half of the twentieth century saw numerous efforts at reforming schools. In 1983, the National Commission on Excellence published A Nation at Risk which gave rise to a variety of school reform efforts collectively referred to as the Excellence Movement (Kingston, 1986; Bridgman, 1985). The focus of the Excellence Movement was on schools to do more: Require more credits for graduation, add more days to the school year, test students more frequently, have more expectations of teachers (Education Commission of the States, 1983). By most accounts, these efforts failed to achieve their intended results (Bridgman, 1985; DuFour \& Eaker, 1988).

\section{The Restructuring Movement.}

In response to the perceived failure of the Excellence Movement, the nation's governors convened to establish national goals for education, which were later amended by Congress to include two additional goals, all of which set high expectations on the scholastic achievement and workplace readiness of students. Subsequently, efforts were initiated at the federal and state levels to establish national standards for education (Lewis, 1995). Simultaneous to these efforts, and as a response by business interests and locally-elected officials to the perception that the failure of the Excellence Movement was the reliance on a top-down effort to mandate improvement, a movement emerged to give schools more freedom to develop the best methods to achieve educational goals. This new emphasis on site-based management (Brost, 2000; Conley, 1991; Liontos, 1993; Murphy, Evertson \& Radnofsky, 1991; Odden \& Wohlstetter, 1995; Smylie \& Denny, 1990; Smylie et al., 1996; Taylor \& Bogotch, 1994; White, 1992; Wohlstetter, 1995; Wohlstetter et al., 1994) came to be known as the Restructuring Movement. The Restructuring Movement called for individual schools to have meaningful authority over 
staffing, programming, and budget; shared decision-making; shared planning time for teams of teachers responsible for the instruction of a shared group of students; advisory groups; and heterogeneous grouping in core subjects. In spite of all of the research supporting the important role that involving teachers in decision-making processes plays in achieving meaningful and lasting school reform, there is a large body of evidence indicating that very little real progress has been made in this area. In their research on high involvement school based management (SBM), Wohlstetter, Smyer, and Mohrman (1994) described a disconnect between the ubiquitous implementation of SBM and the limited extent to which decision-making responsibility had actually devolved from the central office to the school building. This is a consistent finding in educational research (Ben-Peretz, 2001; Brost, 2000; Clark \& Clark, 2002; Howey, 1988; Lambert, 2003; Servage, 2006; Servage, 2009; Taylor \& Bogotch, 1994; White, 1992; Wilson, 2016; Wohlstetter et al., 1994). Clark \& Clark (2002) state it succinctly: "While there appears to be teacher and administrator support for collaborative decision-making and most schools have the structures such as leadership teams, most decision-making is still done by principals" (p. 54). Servage (2006) echoes that sentiment, observing that "school outsiders - government policy makers, corporate interests, and educational publishersare still calling most of the shots about what students will learn and what teachers will teach" (p. 16). In the end, the results of the Restructuring Movement fell short of expectations (DuFour \& Eaker, 1988), perhaps due to focusing on non-academic, administrative issues instead of the core issues of teaching and learning (Murphy, Evertson, \& Radnofsky, 1991, p. 146).

\section{Participatory Management Theory}


The theoretical framework that examines the directional relationship between PLC and teacher involvement is based on participatory management theory. The participatory management movement (also known as shared leadership, participative decision-making, and distributed leadership) has gained much popularity over the last three decades (Spillane et al., 2005). It stands in contrast to the seminal work of Frederick Taylor on scientific management (Taylor, 1911), which was based on controlling variables in the workplace and creating predictable outcomes for the organization. As such, Taylor's ideas clearly did not support the concepts of participation and empowerment, focusing instead on "centralization, standardization, hierarchical top-down management, a rigid sense of time, and accountability based on adherence to the system" (DuFour \& Eaker, 1988, p. 20). Application of the principles of Taylor's time and motion studies and assembly line cultures led to negative employee reactions which resulted, over time, in Taylor's ideas being largely discredited.

Spillane et al. (2005) described participatory management as a process that engages all members of an organization or organizational division in jointly identifying its vision, goals, and strategies, and involves them in key areas of decision-making. Sarafidou and Chatziioannidis (2013) state that "this empowerment of individuals is considered fundamental for enhancing their morale and motivation, increasing levels of job satisfaction and promoting a sense of responsibility and commitment to organizational effectiveness and improvement" (p. 170). Other researchers in the field of participatory leadership (MacBeath, 2005; Harris, 2010) emphasize the importance of collaborative decision-making as the focus of new organizational management practices that serve to cultivate synergistic creativity and facilitate the incorporation of high- 
performance practices into the workplace. Lange (1993) ascribed multiple benefits of decentralizing school governance with through participatory management, including a commitment to decisions, a perception that higher quality decisions were made, increased staff cohesion, and increased trust among staff members and principals.

\section{Teacher Empowerment}

Many current public school reform initiatives continue to hold empowering teachers to reflect, collaborate, and act collectively as a means to enhance student achievement as central tenets (Duffy et al., 2006; DuFour \& Eaker, 1998; Eaker, DuFour \& Burnette, 2002; Gates \& Watkins, 2010). In its 1986 report, “A Nation Prepared: Teachers for the $21^{\text {st }}$ Century," the Carnegie Forum's Task Force on Teaching as a Profession addressed the importance of involving teachers in making decisions in order to achieve necessary school reforms:

Properly staffed schools can only succeed if they operate on the principle that the essential resource is already inside the school: determined, intelligent, and capable teachers. Such schools will be characterized by autonomy for the school as a whole and collegial relationships among its faculty (p. 1).

It went on to call on districts to "restructure schools to provide a professional environment for teaching, freeing them to decide how best to meet state and local goals for children while holding them accountable for student progress" (p. 3). Howey (1988) described teacher leadership as both natural and necessary in today's climate of increasing demands for excellence being placed on schools. His assertion that reform could only be effective if addressed by those who reside where the problems are is a common theme in educational research (Brost, 2000; Odden \& Wohlstetter, 1995; Smylie 
et al., 1996; Wohlstetter et al., 1994; Clark \& Clark, 2002; Liontos, 1993; York-Barr \& Duke, 2004). Further, researchers have identified a number of positive results of incorporating teachers in the decision-making processes of a school, including improved teacher morale (Liontos, 1993; White, 1992); reduced isolation of teachers (White, 1992); enhanced self-esteem and staff morale, commitment, and teamwork (Liontos, 1993; White, 1992); better informed teachers (White, 1992); improved teacher communication within and across schools (White, 1992; Wohlstetter, 1995); improved student motivation (White, 1992); instructional improvement (Clark \& Clark, 2002; Smylie et al., 1996; Newmann \& Wehlage, 1995; Peterson, Marks, \& Warren, 1996); better student academic outcomes (Newmann \& Wehlage, 1995; Peterson, Marks \& Warren, 1996; Servage, 2008; Smylie et al., 1996; Wohlstetter, 1995); higher quality decisions (Clark \& Clark, 2002; Liontos, 1993); and increased incentives that serve to attract and retain quality teachers (White, 1992; Liontos, 1993; Smylie et al., 1996). Studies have also made it clear that involving teachers in decision-making processes requires more than simply giving them a voice. It requires a real transfer of power from principals and administration to teachers themselves (Brost, 2000; Odden \& Wohlstetter, 1995; Wohlstetter, 1995; Wohlstetter et al., 1994; Wilson, 2016). Further, to provide lasting and successful reform, decision-making authority must include the following areas: Budget, personnel, and instructional methods (Wohlstetter, 1995), as well as curriculum (Odden \& Wohlstetter, 1995).

\section{Results of teacher empowerment.}

In spite of the research cited in the previous paragraph and the efforts of educational reform movements, early 20th Century schools continued to be modeled on 
Taylor's design for industrial bureaucracy, where decisions were made by a few people at state governmental agencies, handed down to local Boards of Education, passed on to the superintendent and the building administrator, and finally delivered to teachers who were expected to carry out the decisions of their supervisors (Dufour \& Eaker, 1998). This process carried over into the classroom. DuFour and Eaker (1998) offer this assessment:

Students were simply the raw material transported along the educational assembly line. They would be moved to a station where a teacher would "pour" in mathematics until the bell rang; then they would be moved to the next station where another teacher would "assemble" the nuts and bolts of English until the next bell rang, and so on. Those who completed this 13 -year trek on the assembly line would emerge as finished products, ready to function efficiently in the industrial world (p. 22).

DuFour and Eaker referred to this as the "sorting and selecting" (p. 23) function of schools that was taking place during an era in which less than three percent of American students were actually graduating from high school. They went on to assert that the majority of students were dropping out of high school even into the 1950's. DuFour and Eaker concluded that, at a time when unskilled factory jobs were abundant, this arrangement seemed satisfactory, but it is not a delivery system that can adequately meet the demands of today's national educational goals which call for all students to master rigorous content and compete in a global economy.

\section{Growth of professional learning communities.}

Based on research from the business sector, Senge (1990) coined the term "learning organizations" to describe organizations that use systems thinking, emphasize 
personal mastery of its workforce through continuous staff development and training, challenge existing mental models, operate with a shared vision, and embrace team learning. During the era of the Restructuring Movement, Senge was studying organizational learning. He observed that many businesses focused their change efforts on hiring heroic leaders to inspire and lead change, resulting in top-down, grand strategies that were never fully implemented due to the resistance they create in employees. In order to create true change, Senge suggested that employees must identify results that truly matter to them, and then must continually expand their capacity to create those results. He called these organizations "learning organizations" where new and expansive patterns of thinking are nurtured, and in which there are collective efforts to see the organization in its entirety as a system. He argued that learning organizations would be able to adapt quickly and effectively.

Translating Senge's (1990) concept of the learning organization to the educational setting, DuFour and Eaker (1998) described the characteristics of the Professional Learning Community (PLC), a conceptual model that has become one of the most popular conceptual frameworks for reforming public schools (DuFour \& Eaker, 1998; Linder et al., 2012; Thompson et al., 2004; Sigurðardóttir, 2010; Louis \& Marks, 1998). PLC is a description of an ideal state, a vision of what schools should be like in order to "offer insight into steps that must be taken to transform a school into a learning community" (DuFour \& Eaker, 1998, p. 25). In their vision, the teacher is at the center of educational research and development. Synthesizing the findings of Senge with a number of educational and organizational researchers, DuFour and Eaker described six characteristics of a PLC: a shared mission, vision, and values; collective inquiry; the use 
of collaborative teams; teachers who have an action orientation and engage in experimentation; an attitude of continuous improvement; and a results orientation.

Other researchers have offered variations on these characteristics. In the business setting, Senge's learning organizations have evolved into "communities of practice" (Wenger \& Snyder, 2000), "groups of people informally bound together by shared expertise and passion for a join enterprise" (p. 139), and which Wenger \& Snyder refer to as "the hidden fountainhead of knowledge development" (p. 145). These groups bear a striking resemblance to their educational counterparts, PLCs. For example, Kruse et al. (1994) list five critical elements that are demonstrated in PLCs: Reflective dialogue, deprivatization of practice, collective focus on student learning, collaboration, and shared norms and values. Westheimer (1999) lists five characteristics that he found to be most often associated with PLC: Shared beliefs and understandings, meaningful relationships, interaction and participation, concern for individual and minority views, and interdependence. Some researchers have offered more descriptive definitions of PLC. While there are a number of definitions for PLC, it is essential to understand that it is a process, a conceptual framework, not a model or a program (DuFour \& Eaker, 1998). Even though definitions vary somewhat (see above), there are certain characteristics that are commonly cited by educational researchers: A collaborative culture based on the assumptions that groups of teachers are able to achieve more by working together than they can achieve individually (Bolam et al., 2005; Kruse et al., 1994, 1994); a commitment to improved student learning driven by data and mutual accountability (DuFour \& Eaker, 1998; Kruse et al., 1994, 1994); supportive and shared leadership in which administrators are committed to sharing decision-making with teachers (Roy \& 
Hord, 2006; Kruse et al., 1994, 1994); and shared personal practice and collective inquiry between teachers that leads to continuous inquiry and reflective dialogue (Roy \& Hord, 2006; Stoll et al. 2006). Grodsky and Gamoran (2003) view professional community as a mediating variable, defining it as "an important aspect of the school context that contributes to or stifles the ability of the school organization to address the needs of students" (p. 5). They go on to assert that "Professional community is the medium through which curricular and pedagogical innovations flow" (p. 5).

Comparing the characteristics of participatory management (from the Reference for Business website, www.referenceforbusiness.com) with those of PLCs shows remarkable similarities (Table 7). From Table 7, it is clear that the fundamental features of both PLC and participatory management research are collective inquiry/information Table 7

Comparing Characteristics of Participatory Management and Professional Learning Communities

\begin{tabular}{|c|c|}
\hline $\begin{array}{l}\text { Characteristics of } \\
\text { Participative Management }\end{array}$ & $\begin{array}{l}\text { Characteristics of } \\
\text { Professional Learning Communities }\end{array}$ \\
\hline Commitment & Commitment to student learning \\
\hline Information sharing & Collaboration \\
\hline Training/skill development & Collective inquiry \\
\hline Employee decision-making & $\begin{array}{l}\text { Supportive and shared decision- } \\
\text { making }\end{array}$ \\
\hline Rewards for performance & Focus on outcomes \\
\hline
\end{tabular}

sharing, collaboration, a focus on outcomes, and shared decision-making. This last feature, one of the defining characteristics of a PLC in which administrators are committed to sharing decision-making with teachers, is described by numerous PLC researchers (Roy \& Hord, 2006; Kruse et al., 1994, 1994; DuFour, Eaker \& DuFour, 
2005; Rosenholtz, 1989). These authors cite distributed leadership as a necessity in order to build an effective PLC. Similarly, in their study on creating and sustaining PLCs, Bolam, et al. (2005) stated that "school autonomy, as evidenced in site-based management, is seen as essential for the development of a learning community" (p. 25). The literature cited in the Introduction section is unequivocal in its call for increased participation of teachers in the implementation of PLCs, and participatory management theory provides the foundation for understanding the connection between PLC implementation and increased teacher influence.

\section{Attributes of professional learning communities.}

While Rick DuFour and Robert Eaker (1998) are most strongly associated with the concept of Professional Learning Communities in educational circles, the concept of teacher professional community has a long history. Little (1982) studied the difference between successful and unsuccessful schools, finding that more successful schools were marked by a movement away from skill improvement as an individual enterprise toward skill improvement as an "organizational phenomenon" (p. 338). She described successful schools as having a "norm of collegiality" which included shared discussions and shared work, interactions "by which teachers discuss, plan for, design, conduct, analyze, evaluate, and experiment with the business of teaching" (p. 338). She also described a "norm of continuous improvement" (p. 339) which pertained to the teachers' continuous pursuit of improvements in knowledge and practice about teaching.

Reviewing recent literature on PLCs, InPraxis Group Inc (2006) notes that much of the literature in the past 10 years emphasizes four key understandings: PLCs (1) emphasize the importance of inquiry and reflection; (2) build capacity for leadership, 
learning, and growth as a means for achieving success; (3) emphasize the ongoing learning of teachers and the knowledge and training necessary to function effectively in the classroom; and (4) serve to improve teacher quality and student achievement. Research has sought to identify attributes and processes required to start and maintain PLCs. Table 8 is a summary which shows a comparative examination of attributes that define PLCs [Adapted from InPraxis Inc, 2006)].

DuFour \& Eaker (1998) proposed that understanding PLCs requires more than compiling a list of descriptive characteristics: It is fundamental to PLCs that these attributes be embedded in the culture of the school organization (DuFour \& Eaker, 1988). This has made school culture an important area of research affiliated with PLCs. Carpenter (2015) defined school cultures as "complex webs of traditions and rituals that have been built up over time as teachers, students, parents and administrators work together on establishing a culture of collaboration focused on student achievement" ( $p$. 682). In her review of PLCs, Hord (1997) noted the importance of a school culture that nurtures a high level of staff collaboration. As she examined PLCs in action, she found that mutual respect and understanding were fundamental cultural requirements in order to build the support and trust between teachers necessary to support the collaborative nature of PLCs. Collaboration was the single-most identifiable characteristic of the PLC, and the defining mantra of the PLC was that teachers work more effectively when they work collaboratively (DuFour \& Eaker, 1988). The study of collaboration goes hand in hand with the study of culture (see previous paragraph), as is elucidated by Seashore, Anders, and Riedel (2003): 


\section{Table 8}

\section{Comparison of Attributes of Professional Learning Communities}

\begin{tabular}{|c|c|c|c|c|}
\hline $\begin{array}{l}\text { Attributes of } \\
\text { a PLC }\end{array}$ & Hord (1997) & DuFour \& Eaker (1998) & Senge (2000) & $\begin{array}{c}\text { Kruse, Seashore, Louis, } \\
\text { \& Bryk (1994) }\end{array}$ \\
\hline $\begin{array}{l}\text { Supportive } \\
\text { and Shared } \\
\text { leadership } \\
\text { capacity }\end{array}$ & $\begin{array}{l}\text { Shared leadership structures in } \\
\text { which administrators and } \\
\text { teachers question, investigate, } \\
\text { and seek solutions for school } \\
\text { improvement }\end{array}$ & & $\begin{array}{l}\text { Personal mastery: articulate a } \\
\text { coherent image of personal vision, } \\
\text { expanding personal capacity }\end{array}$ & $\begin{array}{l}\text { Teacher empowerment } \\
\text { and school autonomy, } \\
\text { supportive leadership }\end{array}$ \\
\hline $\begin{array}{l}\text { Shared } \\
\text { mission, } \\
\text { focus, goals }\end{array}$ & $\begin{array}{l}\text { Values are embedded in day- } \\
\text { to-day actions. Learning } \\
\text { community engages and } \\
\text { develops commitment and } \\
\text { talents. }\end{array}$ & $\begin{array}{l}\text { A solid foundation consisting } \\
\text { of collaboratively developed } \\
\text { and widely shared mission, } \\
\text { vision, values and goals. }\end{array}$ & $\begin{array}{l}\text { Shared vision: focus on mutual } \\
\text { purpose to nourish a sense of } \\
\text { commitment. }\end{array}$ & $\begin{array}{l}\text { Collective focus, shared } \\
\text { norms and values, trust } \\
\text { and respect. }\end{array}$ \\
\hline $\begin{array}{l}\text { Collective } \\
\text { learning and } \\
\text { application of } \\
\text { learning }\end{array}$ & $\begin{array}{l}\text { Collectively seeking new } \\
\text { knowledge and applying it to } \\
\text { work, resulting in } \\
\text { collaborative relationships. }\end{array}$ & $\begin{array}{l}\text { Collaborative teams that work } \\
\text { independently to achieve } \\
\text { common goals. }\end{array}$ & $\begin{array}{l}\text { Team learning: group interaction to } \\
\text { transform collective thinking and } \\
\text { learning and mobilize energies and } \\
\text { actions to achieve common goals. }\end{array}$ & $\begin{array}{l}\text { Collaboration, } \\
\text { deprivatization of } \\
\text { practice, socialization. }\end{array}$ \\
\hline $\begin{array}{l}\text { Continuous } \\
\text { inquiry and } \\
\text { practice }\end{array}$ & $\begin{array}{l}\text { Share personal practice } \\
\text { through inquiry-oriented } \\
\text { practice and collegial } \\
\text { coaching. }\end{array}$ & & $\begin{array}{l}\text { Mental Models: reflection and } \\
\text { inquiry skills focused around } \\
\text { developing awareness of attitudes } \\
\text { and perceptions. }\end{array}$ & Reflective learning. \\
\hline $\begin{array}{l}\text { Focus on } \\
\text { improvement }\end{array}$ & Continuous improvement. & $\begin{array}{l}\text { A focus on results as } \\
\text { evidenced by a commitment to } \\
\text { continuous improvement. }\end{array}$ & & $\begin{array}{l}\text { Openness to } \\
\text { improvement. }\end{array}$ \\
\hline $\begin{array}{l}\text { Supportive } \\
\text { conditions } \\
\text { and } \\
\text { environments }\end{array}$ & $\begin{array}{l}\text { Create supportive structures, } \\
\text { including a collaborative } \\
\text { environment-- structural } \\
\text { conditions and collegial } \\
\text { relationships. }\end{array}$ & & $\begin{array}{l}\text { Systems thinking: interdependency } \\
\text { and change to deal more effectively } \\
\text { with the forces that shape the } \\
\text { consequences of their actions. Find } \\
\text { the leverage needed to get } \\
\text { constructive change. }\end{array}$ & $\begin{array}{l}\text { Structural conditions: } \\
\text { time to meet and talk, } \\
\text { physical proximity }\end{array}$ \\
\hline
\end{tabular}


By using the term professional learning community we signify our interest not only in discrete acts of teacher sharing, but in the establishment of a school-wide culture that makes collaboration expected, inclusive, genuine, ongoing, and focused on critically examining practice to improve student outcomes (p. 3). In that same vein, Stoll et al. (2006) reference Fullan's (2001) conclusion that effective schools are those that establish professionally collaborative cultures. Bryk et al. (1999) studied the creation of cultural resources to support collaboration and found that social trust was the strongest facilitator of professional community: "When teachers trust and respect each other, a powerful social resource is available for supportive collaboration, reflective dialogue, and deprivatization" (p. 767). Stoll et al (2006) makes the compelling statement that "a goal of better teaching practices would be considered unachievable without collaboration" (p. 227). In her 1982 study on workplace conditions, Little determined specific collaborative behaviors in which teachers engage that create conditions for success. She found that teachers in successful schools: ...engage in frequent, continuous, and increasingly concrete and precise talk about teaching practice (as distinct from teacher characteristics and failings, the social lives of teachers, the foibles and failures of students and their families, and the unfortunate demands of society on the school) (p. 331).

She further categorized collaborative teacher interactions as planning, designing, researching, evaluating, and preparing materials, and identified four "critical practices of adaptability" (p. 332) in which teachers engaged collaboratively: discussions of classroom practice, mutual observation and critique, shared efforts to design and prepare curriculum, and shared participation in the business of instructional improvement. She 
concludes that successful, adaptable schools operate with an expectation of shared work, which describes as a "norm of collegiality" (p. 338).

As the body of research on PLC expanded, certain attributes/elements emerged with enough regularity to be formulated into general PLC frameworks. PLC frameworks created by Roy and Hord (2006), Louis, Marks, and Kruse (1996). and Bryk, Camburn, and Louis (1999) are representative of others found in the PLC literature. Roy and Hord, hereafter referred to as RH, reviewed 15 years of PLC research and proposed a PLC framework of five elements: Supportive \& shared leadership, collective learning and application, shared values and vision, supportive conditions, and shared practice (Table 9). Louis, Marks, and Kruse, hereafter referred to as LMK, identified five distinguishing elements of PLCs: Shared values, focus on student learning, collaboration, deprivatized practice, and reflective dialogue (Table 10). Bryk, Camburn, and Louis (1999), hereafter Table 9

Roy and Hord PLC Framework PLC elements Description

Supportive \& shared leadership

Collective learning and application Shared values and vision

Supportive conditions

Shared practice
Collegial and facilitated participation; shared decision-making and shared leadership in which principals "nurture the capacity of staff members to build a trustworthy, respectful, and collaborative environment" (p. 493)

Reflective dialogue leading to inquiry and application and collective assessment efforts

Used for decision-making and focused on student learning

Human capacities (trust, respect, feedback, collegiality, risktaking) and physical/structural components (schedules that facilitate collaboration, open communication structures, physical proximity of teachers within teams)

Peers helping peers; observation and feedback 
referred to as BCL, also identify five essential elements: Reflective dialog, deprivatized practice, collaborative/shared work, normative control, and socialization of new professional members (Table 11). These three PLC frameworks have similarities. All three include a reference to reflective dialogue (although $\mathrm{RH}$ include it as part of “collective learning and application"). "Shared values" appears in some form in all three frameworks: It is part of "normative control" in BCL; a stand-alone element, "shared values and expectations" in LMK; and a stand-alone element, "shared values and vision" in RH. Collaboration is another shared element between all three frameworks (again, given a different name, "shared practice," by RH). All three include "focus on student Table 10

Louis, Marks, and Kruse PLC Framework PLC elements Description

\begin{tabular}{|c|c|}
\hline $\begin{array}{l}\text { Shared values \& } \\
\text { expectations }\end{array}$ & $\begin{array}{l}\text { Common beliefs and values teachers hold "underlying their } \\
\text { assumptions about children, learning, teaching, and teachers' } \\
\text { roles, the nature of human needs, human activity, and human } \\
\text { relationships, and the organization's extended societal role, } \\
\text { including its relationship with the surrounding environment" (p. } \\
758 \text { ) }\end{array}$ \\
\hline $\begin{array}{l}\text { Collective focus on } \\
\text { student learning }\end{array}$ & $\begin{array}{l}\text { Discussed by teachers; drives instruction that enhances } \\
\text { intellectual growth and development }\end{array}$ \\
\hline Collaboration & $\begin{array}{l}\text { Shared expertise that benefits students' opportunity to learn and } \\
\text { is related to implementation of practice; enhances teachers' } \\
\text { affiliation to each other }\end{array}$ \\
\hline $\begin{array}{l}\text { Deprivatized } \\
\text { practice }\end{array}$ & $\begin{array}{l}\text { Interchanging roles (e.g., mentor, advisor, specialist) and } \\
\text { practices like peer coaching, teamed teaching, structured } \\
\text { classroom observations that also increase affiliation and mutual } \\
\text { support between teachers }\end{array}$ \\
\hline Reflective dialogue & $\begin{array}{l}\text { Conversations between teachers about teaching and learning } \\
\text { that lead to "deepened understanding of the process of } \\
\text { instruction and the products of teaching and learning" (p. 761) }\end{array}$ \\
\hline
\end{tabular}


learning" as an element as well, although in different ways: BCL include this as part of "normative control," which also includes shared social norms guiding teachers to take collective responsibility for student learning; LMK list "focus on student learning" as a stand-alone element; RH include it as an outcome of "shared values and vision".

In addition to differences in element terminology described above, there are also other important differences to note between the frameworks. "Deprivatized practice" is included as an element by BCL and LMK, but is not an element in RH (although LMK describe deprivatized practice as increasing affiliation and mutual support between teachers, which is an important part of the "human capacities" component of the Table 11

Bryk, Camburn, and Louis PLC Framework PLC elements Description

Reflective Regular conversations between teachers about their work, beliefs dialogue about teaching and learning, and instructional practice

Deprivatized practice

Interchanging roles (e.g., mentor, advisor, specialist) and practices like peer coaching, teamed teaching, structured classroom observations allowing teachers to share methods and philosophies

Cooperative relationships that lead to shared work and expertise Collaboration on schoolwide projects, reform efforts, and practice; leads to heightened "sense of mutual support and responsibility for effective instruction" (p. 755)

Set of shared norms focusing on student learning and enhancing students' opportunities to learn; results in a social control

Normative control mechanism guiding teacher behavior and fostering a "collective sense of responsibility for school operations and improvement" (p. 755)

Socialization of new professional members

Induction process; deliberately maintained to socialize new members into the school 
"supportive conditions" element included in RH). "Socialization of new professional members" in the BCL framework has no counterpart in either of the other two frameworks. Likewise, "supportive and shared leadership" and "supportive conditions" from the RH framework have no counterparts in LMK or BCL (other than a common reference to affiliation and mutual support between teachers that appears in both LMK's “deprivatized practice" and RH's "supportive conditions").

The widespread adoption of PLCs has made it an international movement: After reviewing 25 years of international research on school improvement, Stoll et al (2006) refer to PLCs as a "hot topic in many countries" that holds "considerable promise for capacity building for sustainable improvement" (p. 221). A search of the literature for the term "professional learning communities in schools" returns over three million references from a wide assortment of countries. Huffman (2011) described research on PLCs as "an international phenomenon with scholars and practitioners in Australia, Canada, China, Taiwan, United States, and United Kingdom engaging in longitudinal and cross-cultural studies" (p. 321). Toole and Louis (2002) reference the presence of PLCs in countries as diverse as Canada, South Africa, the Netherlands, Japan, and Mexico. Roy and Hord (2006), in an article titled, "It's Everywhere, but What Is It? Professional Learning Communities," describe PLCs as being in "village schools, city schools, rural settings, and suburban and urban locales" (p. 490). Hord (1997) attested to its prevalence in the United States. He conducted a literature review in order to define and describe PLCs and observed that the term learning community was "well integrated into the lexicon of American education" (p. 1). With 254 schools currently participating in a 
statewide PLC organization in Missouri (MO PLC Organization, see www.moplc.org), it is clear that PLCs have been widely adopted across the state.

\section{Leadership and professional learning communities.}

A great deal of literature emphasizes the importance of leadership in a school's ability to implement and maintain an effective PLC (Carpenter, 2015; Hord, 1997; Stoll et al, 2006; Sackney \& Walker, 2006; Wiley, 2001). Referencing Mulford \& Silins (2003), Stoll, et al (2006) state it simply: "It is difficult to see how a PLC could develop in a school without the active support of leadership at all levels" (p. 235). Leadership in PLCs effects student academic achievement, as Wiley (2001) documented by finding a significant positive relationship on students' math scores resulting from PLC, but only in schools in which administrators were above average in transformational leadership. Specific leadership behaviors related to effective PLCs have also been received attention in the literature. Carpenter (2015) found that how teachers engaged in the collaborative culture of a school and to what degree they engaged in that collaborative structure was shaped by the authority and power position of the building administrator. He noted that the shared and supportive leadership that demonstrated trust and respect enhanced the collaborative culture. Hord (1997) observed that leaders in schools with effective PLCs "actively supported a culture of inquiry through constant scanning and bringing in of new ideas and people to help teachers reflect on their teaching practice and to develop; increased skills" (p. 37). Further, she noted the importance of leaders who model collaborative behaviors for keeping the PLC culture alive and visible.

A series of studies based on data from the Chicago Public School system examined teacher leadership and student achievement through its relationship to principal 
leadership in order to determine the pathways of influence used by principals to impact student achievement and classroom instruction. Sebastian and Allensworth (2012) studied principal influence on classroom instruction and student achievement to determine the pathways of influence used by principals to impact student achievement and classroom instruction. Findings demonstrated that the most important pathways of influence for principals for improving classroom instruction and impacting student achievement were quality of professional development, program coherence and learning climate. In a 2014 study, Sebastian, Allensworth, and Stevens adopted a configurationsbased approach in an effort to achieve a more holistic view focused on patterns related to outcomes as opposed to individual variables in isolation. While the study did not attempt to connect leadership behaviors to student achievement, it did determine that leadership is a necessary condition for student classroom participation. Sebastian, Allensworth, and Huang (2016) took a systems approach to the examination of the effect of school leadership on student learning, proposing a model of shared leadership that impacts student learning through multiple mediating factors (e.g., school climate, program coherence, professional development, and parental involvement) as a means for understanding the mechanisms through which leadership impacts student achievement. The study showed that principals' influence on student learning depends almost entirely on empowering teachers with greater decision-making responsibilities.

\section{Professional learning communities and professional development.}

Professional development (also referred to as "collective learning" in PLC literature) in the structures and skills necessary for PLCs to function effectively has also received attention in the research (Dufour \& Eaker, 1998; Hord, 1997; Hord \& Boyd, 
1995). Hord (1997) states it simply: “Acquiring and applying new knowledge is an intellectual task and a high priority in a professional learning community" (p. 37). DuFour \& Eaker (1998) put learning at the center of the PLC, identifying it as a collective activity through which teachers "are relentless in questioning the status quo, seeking new methods, testing those methods, and then reflecting on the results" (p. 25). They emphasize the importance of professional development with the provocative assertion that "the process of searching for answers is more important than having an answer" (pp. 25-26). Further, they were clear that professional development that meets the above description must be continuous and job-embedded, part of teachers' daily routine. These views are well-supported in the literature (Carpenter,2015; Lieberman, 1995; Talbert \& McLaughlin, 1994). Hord (1997) made observations about the function of leadership associated with professional development. She observed that leaders in successful PLC schools actively identify needs of their teachers and provide resources to help them reflect on their practice and develop new skills. The need for professional development does not just refer to the acquisition of new skills. Carpenter's (2015) case study of three high schools led her to conclude that teachers needed year-long training in PLC processes, structure, and functions as well as follow-up after that training year. Grodsky and Gamoran's (2003) work articulated the relationship between professional development and professional community, citing two ways that professional development enhances professional community: (1) enhancing the professional skill of teachers, which increases the availability of highly trained teachers for sharing their training with others, ultimately leading to increased student achievement; and (2) strengthening the social ties between educators as they share their expertise with one another. According to 
Grodsky and Gamoran, underlying these effects is the necessity that the professional development be reflective, requiring teachers to communicate openly with each other about instructional issues.

Fundamental to the research question in the current study is the understanding that DuFour and Eaker (1998) envisioned schools as organizations that embed shared decision-making in their processes and procedures. Issues concerning curriculum, instruction, and classroom management are collectively researched by the instructional staff, and potential solutions are processed through the collaborative team for review, selection, and implementation. Completing the problem-solving cycle, the collaborative team has the responsibility to review data to evaluate the outcome and make a final determination on whether or not to continue, modify, or terminate each project. Other researchers (Linder et al., 2012; Thompson et al., 2004; Sigurðardóttir, 2010; Louis \& Marks, 1998) have also observed that PLCs are designed to emphasize teacher-lead datainformed decision-making.

\section{Professional learning communities and student achievement.}

The goal of PLCs, like the goal of all school reform efforts, is to improve student achievement (DuFour \& Eaker, 1998; Linder et al., 2012 Thompson et al., 2004; Sigurðardóttir, 2010; Louis \& Marks, 1998). However, a number of issues make it difficult to relate PLC directly to student achievement. Burns, et al. (2014) cite a variety of factors contributing to the limited amount research that directly relates PLC to student achievement: The difficulties encountered by collaborative teams of generating common assessments; a lack of agreement on criteria on which to judge student proficiency; the difficulty of defining a process for a team of teachers to collaboratively analyze data; the 
impact of the No Child Left Behind (NCLB) legislation of 2001 (PL 107-110, 2001), which shifted the focus of schools from structures and school culture to utilizing data to document improvement for accountability purposes. Further, studies have confounding issues related to research design and data which limit the degree to which generalizations can be drawn: They rely on teacher perceptions (Andrews \& Louis, 2007); increases in test student achievement scores can be explained by teachers' technical instructional skill ("authentic pedagogy") of the teacher without relying on PLC attributes (Louis \& Marks, 1998); and sample populations tend to be limited and homogeneous (see Sigurðardóttir, 2010).

In spite of these difficulties, studying the relationship between PLC and teacher involvement in decision-making can help resolve a contradiction in PLC research as it pertains to student achievement outcomes. Some research supports the idea that PLC is positively related to student achievement. Research studies by Andrews \& Louis (2007), Louis \& Marks (1998), and Sigurðardóttir (2010) all show slight to moderate impacts of PLC on student achievement. Burns, et al (2014) found moderate relationships between attributes of PLC and student achievement. In his study of PLCs in Alabama Black Belt schools, Stewart (2014) found a positive relationship between PLC and student achievement. This study stands out by virtue of its design, exploring the effects of professional learning communities (PLC) on student achievement in a selected school district experiencing sustained high student achievement in spite of high poverty rates. In this qualitative case study of a rural school in a high poverty area, Stewart found a positive relationship between PLC and student achievement. Additionally, he found that the increase in test scores was, in part, attributable to teachers' involvement in decision- 
making. Research studies by Andrews \& Louis (2007), Berry et al. (2005), Bolam et al. (2005), Hollins et al. (2004), Louis \& Marks (1998), Phillips (2003), Sigurðardóttir (2010), Strahan (2003), Supovitz (2002), and Supovitz \& Christman (2003) all show slight to moderate impacts of PLC on student achievement. The studies by Bolam et al. (2005), Louis and Marks (1998), Supovitz (2002), and Supovitz and Christman (2003) provide important information about the impact of specific aspects of PLC on achievement. Both the Bolam et al. (2005) and the Louis and Marks (1998) studies reported positive gains in student achievement related to the strength of the PLC in the schools studied. The studies by Supovitz (2002) and Supovitz and Christman (2003) found significant gains in student achievement in schools where teachers engaged in focused instructional discussions concerning the relationships between teaching practices and student work. Cooper, et al (2005), in their study on schools with records of high performance on state assessments, found collaboration between teachers to be one of the themes common to each of the schools. The authors concluded that "the support systems for students and teachers at these schools enabled collaborative instructional improvement" (p. 12).

However, findings to the contrary can also be found in the literature. Studies by Louis \& Marks (1998) and Smylie et al. (1996) found the reported effects of PLCs on student achievement to be small. Further, some research shows no effect, especially when accounting for other school factors such as school climate (Andrews \& Louis 2007; Louis \& Marks, 1998; Sigurðardóttir, 2010; Burns, et al, 2014; Stewart, 2014). Given the importance of teacher influence to the overall framework of PLCs, empirically examining 
this pathway can help explain why the effects of PLC on student achievement that are reported in the research are either small or non-existent.

\section{Quantifying Teacher Influence}

Given the importance of involving teachers in decision-making processes to the effective implementation of PLCs in schools, one would expect there to be literature specifically documenting the degree to which teachers are involved in decision-making in schools identifying themselves as PLCs. Those studies are conspicuously lacking. One can find studies in the literature that examine issues surrounding a variety of different types of decisions in PLCs, for example, staffing/hiring (Butcher \& Kritsonis, 2007; Berry et al, 2008), use of discretionary school funds (Leech 1999), books and instructional materials (Kim, 2016), curriculum and instructional decisions (Griffith et al, 2013; DeNeve et al, 2015; Kim, 2016), professional development (Abbott \& Wren, 2016; Griffith et al, 2013; Nelson, et al., 2012; Poekert, 2012; Skalski \& Romero, 2011; Turner, 2012), and student behavior standards (Priest 2015; Turner, 2012; Maag, 2009). Further, there is abundant literature relating the benefits of PLCs for teachers. Benefits include reduced isolation and increased collaboration between teachers (Hord, 1997; Lieberman, 1995); increased instructional effectiveness and collective responsibility (Lee, Smith, \& Croninger, 1995; Louis, et al., 1996); increased morale and job satisfaction (Lee, Smith, \& Croninger, 1995); enhanced commitment to change and increased involvement in decision-making (Bryk, et al., 1993); increased student achievement (Lee, Smith, \& Croninger, 1995; Smith, Lee, \& Newmann, 2001); increased leadership capacity (Lambert, 1998); improved instruction (Kruse \& Louis, 1995); and a focus on continuous improvement (Newmann \& Wehlage, 1995). One can also find studies examining the 
quality of decisions made in PLCs (Clark \& Clark, 2002; Liontos, 1993). However, these studies identify the quality of the decisions based on their relation to instructional and learning issues that have historically been considered as part of the domain of the classroom teacher; they do not attempt to quantify the degree to which teachers are involved in broader decisions (hiring of staff, discretionary spending, choice of instructional materials, establishing curricula, determining content of professional development, setting standards for student behavior) typically considered to be part of participatory decision-making reforms. In spite of the breadth and depth of the studies described above, none specifically link professional learning communities to teacher influence: Currently, there appears to be no quantitative research directly examining whether or not the degree of professional learning community implementation predicts teachers' involvement in decision-making.

\section{Teacher leadership, teacher influence, and directionality.}

Many researchers have used teacher influence in decision-making as a proxy variable for teacher leadership. York-Barr and Duke (2004) give the following definition of teacher leadership: "The process by which teachers, individually or collectively, influence their colleagues, principals, and other members of school communities to improve teaching and learning practices with the aim of increased student learning and achievement” (pp. 287-88).

The body of research on teacher leadership includes two additional categories of study that merit attention concerning their impact on the relationship between PLCs and teacher influence. Both of these categories involve directionality, i.e., they involve research designed to determine the direction of causality: Do PLCs lead to greater teacher 
influence, or does increased teacher influence predict the process of PLC implementation, or both? Studies by Carpenter (2015) and Moller (2006) examine the relationship between PLCs and teacher influence in the opposite direction to the current study, i.e., they theorized that teacher leadership influences PLC in schools. In his qualitative study of three secondary schools, Carpenter (2015) explored school culture policies and procedure and leadership structures to determine their impact on the effective function of professional learning community practice and found that "the manner in which teachers engaged in the collaborative culture was greatly shaped by shared and supportive leadership trust and respect for teachers as professionals" (p. 689). Carpenter's study was intentionally designed to examine whether or not teacher influence impacted the effective implementation of PLCs. His positive finding does not preclude the possibility that the relationship also moves in the opposite direction (which is the question being studied in the current study). In fact, in his conclusions, the author couches his results in a discussion of the "continuous improvement cycle" (p. 691), which suggests that he expected that influence moved in both directions. Moller's qualitative study of 19 schools found similar results.

The second category of research on teacher leadership involves "reciprocal models" (Carpenter, 2015; Heck \& Hallinger, 2005; Hallinger and Heck, 1996b; Heck and Hallinger, 2009a, 2009b; Hallinger \& Heck, 2010). These studies are based on the premise that findings from studies that are based on correlational relationships do not preclude the possibility that, in reality, the causal relationship also exists in the opposite direction. In fact, in his conclusions, Carpenter (2015) couches his results in a discussion of the "continuous improvement cycle" (p. 691), which suggests that he expected that 
influence moved in both directions. For theoretical reasons, it is important to examine the relationship from the other direction, i.e., to see if PLC leads to teacher leadership. Based on a demonstration of a bias in research for framing leadership as the causal agent of change in organizations (Heck \& Hallinger, 2005), Hallinger and Heck conducted a series of studies (Hallinger \& Heck, 1996b; Heck \& Hallinger, 2009a, 2009b, and Hallinger \& Heck, 2010) that conceptualized leadership effects as a process of mutual influence. In their 2010 study, they developed a series of multilevel longitudinal models to test notion that "the empirical study of school improvement leadership requires dynamic models that take into account changing relationships among relevant variables over time" (p. 230). They tested a reciprocal model for describing the relationship between collaborative leadership and school improvement and concluded that it offered "a new empirical description of collaborative leadership and academic capacity building as mutually reinforcing, parallel change processes" (p. 246). The current study could provide support for empirically examining reciprocal relationships between school processes such as leadership and PLC, similar to studies conducted by Hallinger and Heck.

\section{Reliance on qualitative research.}

A review of the research on teacher involvement in decision-making reveals a reliance on qualitative research designs. Early research studies in this area focused on the contrast between teachers' perceptions of the extent to which they are actually involved and the extent to which they desire to be involved. Alutto and Belasco conceptualized the variable "decisional participation" as the difference between the number of decisions in which a teacher desires to participate and the number of decisions in which the teacher actually participates. They identified a continuum of decisional participation from 
deprivation (wanting more decision-making participation) to equilibrium (satisfaction with the amount of decision-making participation) to saturation (wanting less decisionmaking participation) by describing a variety of decision-making situations and asking subjects whether they currently participated in the decision-making process in each situation and whether they wished to participate. By analyzing their results against demographic characteristics (age, sex, seniority, teaching level), they concluded that decisionally-deprived teachers tended to be young, males at the secondary level in rural settings who perceived high levels of role conflict, were supportive of collective bargaining, strikes, and unions, felt that decisions were made in a top-down fashion, and wanted to see superintendents and principals have less influence. Teachers experiences decisional saturation were older, female at the elementary level in urban settings who perceived moderate levels of role conflict, were moderately unsupportive of collective bargaining, strikes and unions.

Ferrara (1992) built on the work of Alutto and Belasco to measure the difference between teachers' perceptions of actual involvement and desired involvement in decision-making in eight categories: Policy, planning, curriculum/instruction, pupil personnel, staff personnel, staff development, school/community, and budget/management. She found that on average, teachers reported deprivation on all eight of these categories with the largest degree of difference between actual and desired involvement in the areas of curriculum/instruction, pupil personnel, policy, staff development, and planning. Also using the typology of deprivation, equilibrium, and saturation established by Alutto and Belasco (1972), Keung (2008) focused on teachers' perceptions of their workloads, their commitment to their school, and their job 
satisfaction related to their participation in the three dimensions of instruction,

curriculum, and management. Keung found that teachers perceived themselves to be in a state of decision deprivation in all of the dimensions included in the study. Further, he found that these teachers had a greater desire to be involved in instructional decisions than they did in curricular or managerial decisions. Smylie and Denny (1990) also found that teachers expressed more desire to participate in decisions related to classroom instruction than participation in administrative/managerial decisions.

\section{Categories of Qualitative Research about Teacher Influence.}

According to Conley (1991), a review of research concerning the involvement of teachers in school-based decision-making shows that studies fall into four broad categories.

Expectations of teachers.

A number of studies (e.g., Sarafidou \& Chatziioannidis, 2013; Taylor \& Bogotch, 1994) follow the design originally devised by Alutto \& Belasco (1972) to investigate teachers' perceptions on the degree to which they are involved in decision-making. These studies ask teachers to describe their involvement in a number of categories (e.g., textbook selection, interview and hiring, selection of classroom management methods) as "deprivation" (not enough involvement), "equilibrium" (satisfied with the amount of involvement), or "saturation" (too much involvement). Studies of this type also investigate various dimensions (categories) and content associated with each of the three

decisional states. These studies do not answer the question of whether or not PLC predict teach influence.

Changing rationales for teacher participation. 
A second category of research into teacher decision-making seeks to frame participation in terms of the real, daily work experience of teachers, capturing the working relationships, structures, and organizational roles unique to schools (e.g., Conley, et al, 1988; Mohrman, 1978; Shedd, 1988). These studies find that in terms of both scope and intensity, teachers' involvement in decision-making is restricted to teachers' classroom responsibilities, leaving administrators to make decisions focused on the organizational level. Findings indicate that, while teachers are constantly making decisions, most of these decisions occur in a context of coordinating with the activities of fellow teachers (lateral participation), or between teachers and their supervisors (vertical participation). Overall, research in this category supports the notion that the majority of organizational-level decisions are being made managerially. While these studies do investigate the degree to which teachers are involved in decision-making, they do not look at the role played by PLC implementation.

\section{Forms of participation.}

Examining the forms of participation in decision-making comprises a third category of research. Research on forms has divided between examining traditional forms of participation (departments, teacher teams, grade-level teams, school councils, see Duke, 1980; Conley, et al, 1988) and new forms of participation (school councils, educational policy trust agreements, career ladders and mentor/master teacher plans, interdisciplinary teaming, see Malen \& Ogawa, 1988; Griffin, 1985; Malen \& Hart, 1987; Smylie \& Denny, 1990). Studies on traditional forms of participation identified both benefits (successful coordination and information exchange) and barriers (restrictive time schedules, teacher suspicion, insular school structures) of their use as means to increase 
teacher participation in decision-making. Studies on new forms of participation indicate that most are extending decision-making influence to teachers (i.e., creating opportunities for input) rather than granting them decision-making authority. Again, PLC are not considered in these research studies.

\section{Issues of teacher power.}

The final category of research into teacher participation in decision-making addresses the dimensions of power. This research examines how teachers use authority and influence as a means of participating in decision-making. Research in this category finds that teachers are exerting authority in a variety of ways (e.g., demanding involvement in selecting agendas, determining guidelines, designing solutions) and using that involvement to influence decisions being made at the administrative level (see Bacharac et al, 1986; Benson \& Malone, 1987; Blasé, 1989; Bridges, 1967; Firestone, 1977; Lieberman, 1988; Malanowski et al, 1986; Malen \& Ogawa, 1988; Mertons \& Yarger 1988). In this context, teachers have authority over various stages of the decisionmaking process, while administrators/managers retain final decision-making responsibility. To that end, teachers' participation actually preserves traditional managerial authority (Malanowski et al, 1986).

\section{Bias in Self-Reported Data}

The preponderance of the studies in the categories of research just reviewed rely on data that is self-reported. Studies examining PLC in schools generally rely on teacher perceptions of different aspects of PLC. Perceptual studies have focused on topics such as shared decision-making (Leech, 1999); leadership behaviors (Berry et al, 2008; Leech, 1999), empowerment (Berry et al, 2008), the authenticity of implementation of PLC 
structures (Kim, 2016), driving forces of instructional decision-making (Griffith et al, 2013), the interplay between PLC and teacher self-efficacy (DeNeve et al, 2015; Turner, 2012; Priest, 2015), the impact of professional development on teacher practice (Griffith et al, 2013; Nelson, et al., 2012; Poekert, 2012), the use of performance assessments (Abbott \& Wren, 2016; Nelson, et al., 2012; Skalski \& Romero, 2011), and overcoming barriers for dealing with disruptive student behavior (Maag, 2009), to name a few. However, self-reports of organizational constructs can be biased and must be interpreted with caution. Donaldson \& Grant-Vallone (2002) identify measurement in organizational settings as a significant shortcoming of organizational research due to the reliance on self-reports. Camburn, Han, and Sebastian (2017) noted that, while surveys have advantages (e.g., generally less expensive and burdensome, allow for data collection over a large number of participants), their research produced mixed evidence about the validity of using an annual survey as a measuring tool. Rosenman, Tennekoon, \& Hill (2011) describe the reasons individuals offer biased estimates of self-assessed behavior, "ranging from a misunderstanding of what a proper measurement is to social-desirability bias, where the respondent wants to 'look good' in the survey, even if the survey is anonymous" (p. 321). Donaldson \& Grant Vallone (2002) cite "shared method variance" - a contamination of data when all variables in a study are based on one method of measurement — as the primary problem, but do acknowledge that the extent to which this affects research conclusions is still hotly debated. Their study examined the problem of self-report bias in relation to specific constructs in order to elucidate the probability that bias was occurring. They gave the example of a research participant who was abusing drugs at work and was asked to report on his/her level of drug abuse. 
Because the question was directed at a potentially sensitive construct about which the participant perceived that a true response could jeopardize his/her employment, the participant had a strong propensity to bias his/her response to be socially desirable. The study concluded that "the nature of the construct (e.g., level of sensitivity) in combination with employee characteristics (e.g., actual behavior or true score and propensity to give socially desirable responses) and situational pressures must be considered to fully understand and account for self-report bias in organizational behavior research" (p. 256). Donaldson \& Grant-Vallone (2002) argue that current approaches for controlling response bias in self-reported data are inadequate, explaining that "the problem of selfreport bias is compounded by the fact that when all variables in an organizational behavior study are based on one method of measurement, substantive findings are likely to be contaminated by shared method variance" (p. 247). In educational research on PLCs, few studies have used an external objective assessment of PLC implementation as it relates to other important organizational constructs such as teacher leadership or involvement in decision-making.

\section{Summary}

Educational reform has been a topic of intense interest since the 1950's.

Researchers have consistently proposed that schools must evolve to be much more adaptable and much more responsive to students' needs. A great deal of research exists that indicates that teachers must be more involved in decision-making in order for school reform to be effective and lasting. One recent reform framework that schools have embraced to accomplish this is Professional Learning Communities (PLC). PLC have been widely adopted by schools in the USA and around the world as a means to reform 
public schools, and a major assumption of the PLC framework is that PLCs lead to greater teacher influence which then indirectly influences student achievement.

Given this assumption, one would expect there to be a body of research documenting whether or not teachers in PLC perceive themselves to be more involved in decision-making. While there are studies examining whether involvement in PLCs leads to higher quality decisions, as well as studies that show positive effects from increased collaboration in PLCs, like better informed teachers and improved teacher communication within and across schools, and reduced isolation of teachers, none of these studies are designed to determine if PLCs predict teacher involvement in decisionmaking. Further, studies examining PLC in schools generally rely on teacher perceptions of different aspects of PLC. Unfortunately, self-reports of organizational constructs can be biased. Few studies have used an external objective assessment of PLC implementation as it relates to other important organizational constructs such as teacher leadership or involvement in decision-making. There is overwhelming support in the literature for the benefits of substantively involving teachers in decision-making in terms of achieving sustainable reform in educational practices. The literature also clearly documents that in spite of decades of supportive research, very little progress has been made at increasing teacher's involvement in decision-making. As one considers the "failure" of school reform efforts over the years, this lack of progress looms large as a likely culprit. As such, it is important for document whether or not PLC implementation actually predicts teacher involvement. In districts and buildings where PLC has been implemented, the answer to the question, "Are teachers more involved in decision- 
making due to PLC?" offers an assessment of the probability that PLC implementation efforts will successfully accomplish their desired goals. 


\section{Section 4 - Contribution to Practice}

\section{Type of Document}

I have written a journal article to be submitted to Educational Leadership (EL), a widely-read practitioner's journal in the field of education. Articles published in $E L$ have a practitioner-oriented style and are read by a much broader field of educators, especially teachers and building-level administrators, which are the educators for whom this research will has the greatest importance.

\section{Rationale for this Contribution Type}

EL is published by the Association for Supervision and Curriculum Development (ASCD), a highly esteemed organization whose mission is to empower educators "to achieve excellence in learning, teaching, and leading so that every child is healthy, safe, engaged, supported, and challenged" (http://www.ascd.org/about-ascd.aspx). It is a mission that has much in common with the mission of the PLC movement itself, which by itself is an excellent justification for choosing this journal, but certainly not the only one. The ASCD website indicates that the association has 113,000 members that include superintendents, principals, teachers, preservice teachers, professors of education, members of Boards of Education, and other educational advocates representing more than 128 countries. As indicated in the Introduction of this paper, PLC is an international phenomenon that involves the efforts of educators and support staff at every level. The congruence of the membership of the association with all of the various individuals involved with implementing and sustaining PLCs makes readers of $E L$ the target market for an article about PLCs. 
The ASCD website provides this description of EL: "Educational Leadership magazine is ASCD's flagship publication. With a circulation of $135,000, E L$ is acknowledged throughout the world as an authoritative source of information about teaching and learning, new ideas and practices relevant to practicing educators, and the latest trends and issues affecting prekindergarten through higher education" (http://www.ascd.org/publications/educational-leadership.aspx). An article about the relationship between PLC implementation and teacher influence certainly fits that description. Additionally, EL is distinguished from other educational journals by primarily publishing authors who are practitioners and are writing for other practitioners (as opposed to authors who are journalists or pure researchers). Further, $E L$ has an extensive reach and influence among educators: It has a high pass along rate to go with its circulation of 135,000 . The ASCD website indicates that 75 percent of $E L$ article submissions are unsolicited pieces (http://www.ascd.org/Publications/EducationalLeadership/Write-for-Educational-Leadership/Write-for-Educational-Leadership.aspx).

Finally, PLCs have received a great deal of interest from ASCD, another reason for choosing $E L$ as my target journal. A search of "professional learning communities" on the ASCD website yields 9420 results, including books, individual journal articles, entire magazine issues, and institute and conference notifications. ASCD also supports a "Professional Learning Communities" professional interest community (i.e., a memberinitiated, special interest groups designed to unite people around a common area of interest in the field of education).

\section{Outline for Proposed Contents}


EL solicits articles that offer research-based solutions to current educational problems according to the following guidelines for articles: Between 1,500 and 2,500 words; written in a conversational style; offering debate on controversial subjects; opinion pieces that meld experiences and ideas; program descriptions; a focus on explaining and interpreting as opposed to methodology. My article begins with an abbreviated form of the Introduction and Theoretical Framework sections followed by a summary of the results. The remainder of the article is dedicated to a discussion of the findings, offering possible explanations, and sharing practical suggestions for increasing teacher involvement in decision-making.

The following is a copy of my submission-ready journal article. 


\section{Professional Learning Communities and Teachers' Involvement in Decision- Making: \\ A Study of Missouri Public Schools}

\section{Educational Reform, Teacher Empowerment, and PLCs}

Educational reform has been a topic of intense interest since the 1950's. ${ }^{1}$

Researchers have routinely proposed that schools must evolve to be much more adaptable and much more responsive to students' needs ${ }^{2}$, and a great deal of educational research indicates that, in order to accomplish educational reform, teachers must be more involved in decision-making processes. ${ }^{3}$ Empowering teachers to reflect, collaborate, and act collectively as a means to enhance student achievement figures prominently in one of the more widespread reform initiatives currently being implemented by school districts around the globe, professional learning communities (PLCs), and while definitions vary somewhat, there are certain characteristics of PLCs that are commonly cited by educational researchers: A collaborative culture based on the assumptions that groups of teachers are able to achieve more by working together than they can achieve individually ${ }^{4}$, a commitment to improved student learning driven by data and mutual accountability ${ }^{\mathbf{5}}$, supportive and shared leadership in which administrators are committed to sharing decisionmaking with teachers ${ }^{6}$, and shared personal practice and collective inquiry between teachers that leads to continuous inquiry and reflective dialogue ${ }^{7}$.

Clark and Clark (2002) concluded that "Collaboration can involve various stakeholders in making significant decisions about their school and its programs" (p. 52), acknowledging that shared leadership and shared decision-making go hand in hand when teacher collaboration occurs as part of PLC implementation. These authors go on to note that "collaborative decision-making can improve the school working environment and lead to instructional improvement and higher student achievement scores" (p. 56), a finding that is supported by other researchers. ${ }^{8}$

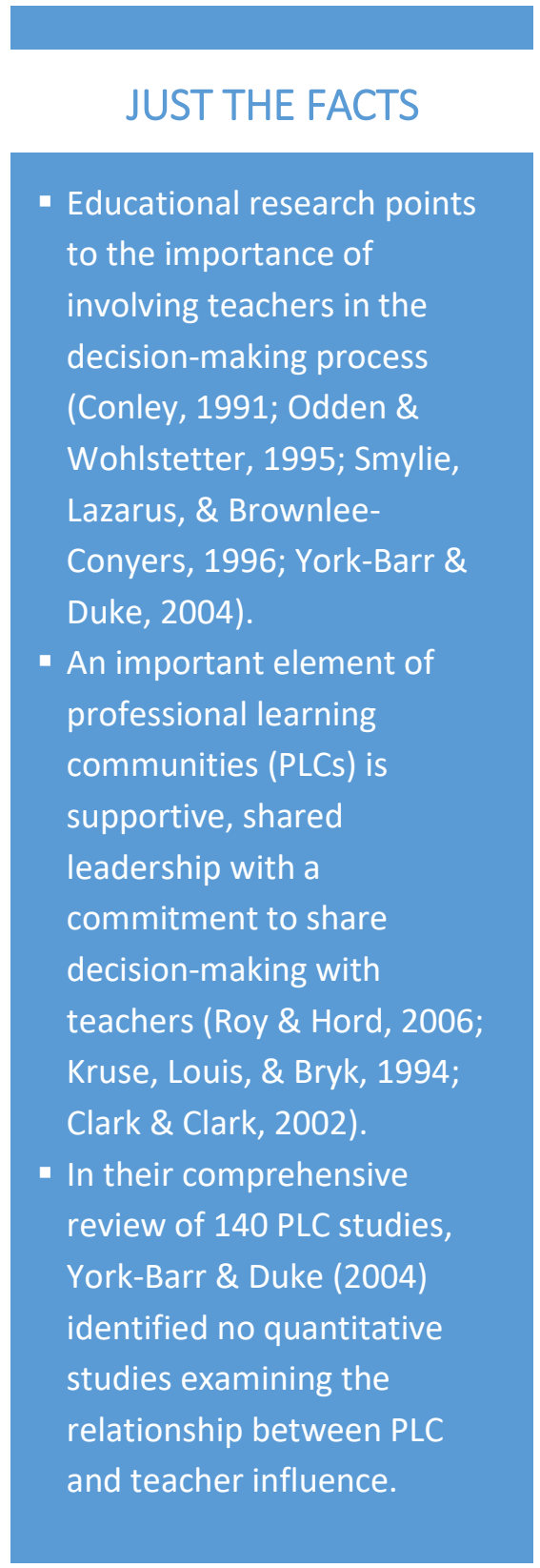


These are important results that are reflected in the mission statement of virtually all of our nation's schools, which would suggest that increasing teacher involvement in decision-making (commonly referred to as "teacher influence") would be a crucial goal for any building or district seriously involved in implementing PLC concepts.

Consequently, one would assume that there would be a body of research examining the relationship between PLC implementation and teacher influence. Surprisingly, that is not the case. In the abstract of their 2004 comprehensive review of over two decades of empirical research related to teacher leadership, York-Barr \& Duke (2004) refer to "numerous small-scale, qualitative studies that describe dimensions of teacher leadership practice, teacher leader characteristics, and conditions that promote and challenge teacher leadership" (p. 257). They reviewed 140 teacher leadership studies and reviews of studies. None of these were quantitative research studies examining the relationship between PLC implementation and teacher influence. A thorough review of more recent publications also failed to produce quantitative research into this relationship.

The bottom line in school reform is improved student achievement. Are schools that have implemented PLCs seeing improved student achievement? The results are mixed. A variety of research studies show slight to moderate impacts of PLC on student achievement. Studies by Bolam et al. (2005) and Louis and Marks (1998) reported positive gains in student achievement related to the strength of the PLC in the schools studied. Supovitz (2002) and Supovitz and Christman (2003) found significant gains in student achievement in schools where teachers collaborated through focused discussions

General research into teacher empowerment paints a grim picture concerning any real progress towards authentially involving teachers in decision-making processes. In fact, there is a large body of evidence indicating that very little real progress has been made in this area. of the relationships between teaching practices and student work. However, findings to the contrary can also be found in the literature. Studies by Louis and Marks (1998) and Smylie, Lazarus and Brownlee-Conyers (1996) found the reported effects of PLCs on student achievement to be small. Further, some research shows no effect, especially when accounting for other

school factors. 9 Given the importance of teacher influence to the overall framework of PLCs, empirically examining this pathway could help shed some light on why some researchers are finding that the effects of PLCs on student achievement are either small or non-existent.

General research into teacher empowerment paints a grim picture concerning any real progress towards authentically involving teachers in decision-making processes. In fact, there is a large body of evidence indicating that very little real progress has been made in this area. In their research on school based management (SBM), Wohlstetter, Smyer, and Mohrman (1994) described a disconnect between the widespread 
implementation of SBM and the limited extent to which decision-making responsibility had actually moved from the central office to the school building. This is a consistent finding in educational research. ${ }^{\mathbf{1 0}}$ Clark \& Clark (2002) state it succinctly: "While there appears to be teacher and administrator support for collaborative decision-making and most schools have the structures such as leadership teams, most decision-making is still done by principals" (p. 54). Servage (2006) echoes that sentiment, observing that "school outsiders - government policy makers, corporate interests, and educational publishersare still calling most of the shots about what students will learn and what teachers will teach" (p. 16).

\section{PLCs and Teacher Empowerment}

To explore whether PLCs are faring any better, we asked, "Is there a relationship between PLC implementation and teacher involvement in decision-making?" We tackled that question with the help of the Missouri Professional Learning Communities organization (MO PLC), a school improvement initiative sponsored by the Missouri Department of Elementary and Secondary Education from 2003-2019. Its mission was to provide support to its member schools in order to build and sustain PLCs, engaging participating schools in a four-year training process with regional PLC consultants. Participating schools committed to include all certificated instructional staff on collaborative teams, attend trainings, provide time during the day for collaborative teams to meet, and participate in annual MO PLC assessments. MO PLC provided staff survey results reflecting staff members' perceptions on the degree to which various aspects of PLCs had been implemented in their respective schools. This data allowed the computation of an index score quantifying the extent of each school's actual PLC implementation on a scale from 0 to 105 .

Teachers' perceptions of their involvement in decision-making was measured using a part of a larger instrument, the UChicago Consortium on School Research 5Essentials School Reports "My School, My Voice" survey that asked teachers to indicate how much influence they have over policy in each of six areas: Hiring new professional personnel, planning how discretionary school funds should be used, determining books and other instructional materials used in The finding after statistical analysis of the data was that there was no significant relationship between the degree of PLC implementation in a school and the degree to which teachers are involved in decisionclassrooms, establishing the curriculum making.

and instructional program, determining the content of in-service programs, and setting standards for student behavior. The finding after statistical analysis of the data was that there was no statistically significant relationship between the degree of PLC implementation in a school and the degree to which teachers are involved in decision-making. 
In the light of the research on the relationship between collaboration and decisionmaking, as well as research showing the positive effects of involving teachers in the decision-making process, finding no significant relationship between PLC

implementation and teacher influence in this study is unexpected. Clark \& Clark (2002) specifically state that teacher collaboration (a defining feature of PLCs) leads to involving teachers in significant decision-making about programs, an assertion that is not supported by the results of this study. Instead, the findings of the current study are consistent with other general research (i.e., not PLC-related) that has been done on the extent to which teachers are involved the decision-making processes at their school buildings. ${ }^{11}$ These studies share the finding that little has changed in the decision-making processes of schools since the Industrial Era: Teachers continue to be tasked with implementing decisions that have been made by central office administrators or districtwide committees (e.g., selection of curricula, articulation of course objectives, choice of instructional and classroom management methods).

\section{Explaining the Disconnect}

Research suggests several reasons for these findings. Short \& Greer (1989) examined teacher participation in decision-making in several specific areas (budgets, teacher selection, scheduling, curriculum, other programmatic areas) and found that, in order for teacher involvement in decision-making to happen, teachers must believe that their involvement is genuine and that their opinion has critical impact in the outcome of the decision. Anything interfering with teachers' beliefs that their involvement in decision-making is not geniune or critical could, therefore, undermine their perception of their influence.

Regardless of specific cause, the results of this study are clear: Whatever the original intent of schools for embedding PLC characteristics into the fabric of their school processes, there appears to be a failure to translate those efforts into empowering teachers to be more involved in decision-making. Building leadership teams, district administrators, and Boards of Education working with schools already involved in PLC implementation need to examine carefully, candidly, and authentically the barriers that exist in their districts and in their school buildings that prevent teachers from greater involvement in decision-making in those areas that make a difference in student achievement.

One of the defining characteristics of a PLC is supportive and shared leadership in which administrators are committed to sharing decision-making with teachers. ${ }^{12}$ These authors cite distributed leadership as a necessity in order to build an effective PLC. Research by Odden and Wohlstetter (1995) and Wohlstetter, et al. (1994) demonstrated the critical importance of principals' leadership in determining if teacher involvement in decision-making will impact student achievement and in developing visions, setting 
goals, and establishing high expectations. Murphy (1994) identified facilitating groups, directing group processes, and managing change processes as necessary skills for principals in schools where shared decision-making is occurring. It is reasonable to infer that principal leadership style in this regard could have a signicant influence on teacher's beliefs about the authenticity of their involvement in decision-making. Stated succinctly, it is possible that a significant number of the schools involved in the MO PLC organization have principals who struggle with sharing or delegating decision-making power.

In addition to individual principals' leadership skills, it is certainly possible that district level leadership could be influencing the process of teacher empowerment either directly or indirectly. In their study on creating and sustaining PLCs, Bolam, et al. (2005) stated that "school autonomy, as evidenced in site-based management, is seen as essential for the development of a learning community" (p. 25). Central office administration or Boards of Education might be applying pressure directly to building principals to exercise more autocratic leadership styles. Indirectly through their ultimate approval of budgets, staffing decisions, and course schedules, central office administrators and Boards of Education wield significant power over both PLC implementation and efforts to incorporate teachers in decision-making processes, and the specific exercise of that power could be impacting PLC implementation.

\section{Next Steps}

Regardless of specific cause, the results of this study are clear: Whatever the original intent of schools for embedding PLC characteristics into the fabric of their school processes, there appears to be a failure to translate those efforts into empowering teachers to be more involved in decision-making processes. Building leadership teams, district administrators, and Boards of Education working with schools already involved in PLC implementation need to examine carefully, candidly, and authentically the barriers

that exist in their districts and in their school buildings that prevent teachers from greater involvement in decision-making in those areas that make a difference in student achievement. Further, school leaders considering PLC implementation would be wellserved to have these same candid, authentic conversations at the front end of the process and be very clear about their intentions for empowering teachers to increase their influence in decision-making processes. It takes little imagination to envision the disillusionment, discouragement, and feelings of betrayal felt by teachers who make extraordinary efforts to embrace PLCs by working together to establish shared mission, vision, values, and goals; working interdependently in collaborative teams; conducting action research; engaging in processes of continuous improvement; and adopting resultsoriented practices; only to find their expectations of greater involvement in decisionmaking unfulfilled. 


\section{Endnotes}

$1 \quad$ Howey, 1988; Lambert, 2003; Louis, Kruse, \& Raywid, 1996; Watson, 2014

2 Brost, 2000; Servage, 2008

3 Conley, 1991; Odden \& Wohlstetter, 1995; Smylie, Lazarus, \& BrownleeConyers, 1996; York-Barr \& Duke, 2004

$4 \quad$ Bolam et al., 2005; Kruse, Louis, \& Bryk, 1994

$5 \quad$ DuFour \& Eaker, 1998; Kruse, Louis, \& Bryk, 1994

$6 \quad$ Roy \& Hord, 2006; Kruse, Louis, \& Bryk, 1994

7 Roy \& Hord, 2006; Stoll et al. 2006

8 Louis \& Marks, 1998; Schechter, 2008; Sigurðardóttir, 2010; Thompson, Gregg, \& Niska, 2004

$9 \quad$ Andrews \& Louis 2007; Louis \& Marks, 1998; Sigurðardóttir, 2010; Stewart, 2014

10 Brost, 2000; Clark \& Clark, 2002; Lambert, 2003; Taylor \& Bogotch, 1994; White, 1992; Wohlstetter, Smyer \& Mohrman, 1994

11 Costa, 2012; Darling-Hammond, Bullmaster, \& Cobb, 1995; Duffy, Mattingly, \& Randolph, 2006; Fitzgerald \& Gunter, 2006; Gates \& Watkins, 2010

12 DuFour, Eaker \& DuFour, 2005; Rosenholtz, 1989; Roy \& Hord, 2006 


\section{References}

Andrews, D. \& Lewis, M. (2007). Transforming practice from within: the power of the professional learning community. In: Professional learning communities: divergence, depth and dilemmas. Professional Learning. Open University Press, Maidenhead, UK, pp. 132-147. ISBN 0335 22031Bolam, et al. 2005.

Brost. P. (2000). Shared decision-making for better schools. Principal Leadership (High School Ed.), 1(3), 58-63.

Clark, S. N. \& Clark, D. C. 2002. Collaborative decision-making: A promising but underused strategy for middle school improvement. Middle School Journal, 33(4), 52-57.

Conley, S. 1991. Review of research on teacher participation in school decision-making. Review of Research in Education, 17, 225-266.

Costa A. M. 2012. A mixed methods program evaluation on the effectiveness of a school redesign model on teacher empowerment and student achievement (Doctoral dissertation). Retrieved from https://scholarworks.waldenu.edu/dissertations/1026/.

Darling-Hammond, L., Bullmaster, M. L., \& Cobb, V. L. 1995. Rethinking teacher leadership through professional development schools. The Elementary School Journal, 96(1), 87-106.

Duffy, E., Mattingly, K., and Randolph, D. 2006. A culture of learning. Independent School, 65(4), 24-28.

DuFour, R. \& Eaker, R. 1988. Professional learning communities at work: Best practices for enhancing student achievement. Bloomington, IN: National Education Service.

DuFour, R., Eaker, R., \& DuFour, R. (2005). On common ground: The power of professional learning communities. Bloomington, IN: National Education Service.

Fitzgerald, T. \& Gunter, H. 2006. Leading learning: Middle leadership in schools in England and New Zealand. Management in Education, 20(3), 6-8.

Gates, S. G. and Watkins, M. 2010. The place of autonomy in school community: Taking a closer look at teacher collaboration. Journal of School Leadership, 20(3), 272303.

Howey, K. R. 1988. Why teacher leadership? Journal of Teacher Education, 39(1), 2831.

Kruse, S., Louis, K., and Bryk, A. 1994. Building professional community in schools. Madison, WI: Center on Organization and Restructuring Schools.

Lambert, L. (2003). Leadership capacity for lasting school improvement. Alexandria, VA: Association for Supervision and Curriculum Development.

Louis, K. S., Kruse, S., \& Raywid, M. A. 1996. Putting teachers at the center of reform: Learning schools and professional communities. NASSP Bulletin, 80(580), 9-12.

Louis \& Marks. 1998. Does professional community affect the classroom? Teachers' work and student experiences in restructuring schools. American Journal of Education, 106(4), 532-575.

Murphy, J. (1994). Transformational change and the evolving role of the principal: Early empirical evidence. In J. Murphy \& K. S. Louis (Eds), Reshaping the 
principalship: Insights from transformational reform efforts (pp. 20-53). Thousand Oaks, CA: Corwin Press.

Odden, E. R. and Wohlstetter, P. 1995. Making school-based management work. Educational Leadership, 52(5), 32-37.

Rosenholtz, S. 1989. Teacher's workplace: The social organization of schools. New York: Longman.

Roy, P. \& Hord, S. M. 2006. It's everywhere, but what is it? Professional learning communities. Journal of School Leadership, 16(5), 491-501.

Schechter, C. 2008. Organizational learning mechanisms: The meaning, measure and implications for school improvement. Educational Administration Quarterly, 44(2), 155-186.

Sebastian, J. \& Allensworth, E. 2012. The influence of principal leadership on classroom instruction and student learning: A study of mediated pathways to learning. Educational Administration Quarterly, 48(4), 626-663.

Servage, L. 2008. Critical and transformative practices in professional learning communities. Teacher Education Quarterly, 35(1), 63-77.

Short, P. M. \& Greer, J. T. 1989. Increasing teacher autonomy through shared governance: Effects on policy making and student outcomes. Retrieved from ERIC database. (ED319096)

Sigurðardóttir, A. K. 2010. Professional learning community in relation to school effectiveness. Scandinavian Journal of Educational Research, 54(5), 395-412.

Smylie, M. A., Lazarus, V., \& Brownlee-Conyers, J. 1996. Instructional outcomes of school-based participative decision-making. Educational evaluation and policy analysis, 18(3), 181-198.

Stewart, K. A. 2014. Effects of professional learning communities in Alabama black belt schools: Case study (Doctoral dissertation, Grand Canyon University). Retrieved from https://pqdtopen-proquestcom.proxy.mul.missouri.edu/doc/1537385034.html?FMT=AI\&pubnum=3619414

Stoll, L., Bolam, R., McMahon, A., Wallace, M., \& Thomas, S. 2006. Professional learning communities: A review of the literature. Journal of Educational Change, 7(4), 221-258.

Supovitz, J. A. (2002). Developing communities of instructional practice. Teachers College Record, 104(8), 1591-1626.

Supovitz, J. A. \& Christman, J. B. (2003). Developing communities of instructional practice: Lessons for Cincinnati and Philadelphia. Retrieved from ERIC database. (ED498331)

Taylor, D. L. \& Bogotch, I. E. 1994. School-level effects of teachers' participation in decision-making. Educational Evaluation and Policy Analysis, 16(3), 302-319.

Thompson, S. C., Gregg, L., \& Niska, J. M. 2004. Professional learning communities, leadership, and student learning. Research in Middle Level Education Online, 28(1). Retrieved from https://www.tandfonline.com/doi/abs/10.1080/19404476.2004.11658173.

Watson, C. 2014. Effective professional learning communities? The possibilities for teachers as agents of change in schools. British Educational Research Journal, 40(1), 18-29. 
White, P. A. 1992. Empowerment under "ideal" school-site autonomy. Educational Evaluation and Policy Analysis, 14)1, 69-82.

Wohlstetter, P., Smyer, R., \& Mohrman, S. A. (1994, April). New boundaries for schoolbased management: The high involvement model. Paper presented at the annual meeting of the American Educational Research Association, New Orleans, LA.

York-Barr, J. \& Duke, K. 2004. What do we know about teacher leadership? Findings from two decades of scholarship. Review of Educational Research, 74(3), 255316. 


\section{Section Five-Contribution to Scholarship}

Target Journal (highest level journal appropriate for the topic)

Educational Administration Quarterly

\section{Rationale for this Target}

Educational Administration Quarterly (EAQ) is peer-reviewed educational journal that had a 2018 Impact Factor of 2.313 and was ranked $47^{\text {th }}$ out of 243 in the category of "Education and Educational Research" (Journal Citation Reports, web of Science Group, 2019). It is described as publishing "prominent empirical and conceptual articles focused on timely and critical leadership and policy issues of educational organizations" (see https://us.sagepub.com/en-us/nam/journal/educational-administrationquarterly\#description). This same website indicates that the editorial team encourages manuscripts that "consider how the organizational structure of districts and schools impacts leadership and improvement processes" (see https://us.sagepub.com/enus/nam/journal/educational-administration-quarterly\#aims-and-scope). Both of these quotations are apt descriptions of the current study.

\section{Outline of Proposed Contents}

Introduction

Theoretical Framework and Research Questions

Methods

Results

Discussion

Implications for Future Research

Limitations

Summary 


\title{
Is There a Relationship between Professional Learning Community Implementation and Teacher Influence? A Quantitative Study of the Relationship between PLC Implementation and Teacher Influence in Missouri PLC Schools
}

\begin{abstract}
"Shared leadership" is listed as an essential element of professional learning communities (PLCs). There is also an abundance of research on proposed theoretical connections between PLCs and teachers' involvement in decisionmaking (also referred to as "teacher influence"). However, there is an absence of quantitative research providing empirical evidence concerning the relationship between PLC implementation and teacher involvement in decision-making: A comprehensive review of over two decades of empirical research related to teacher leadership (York-Barr \& Duke, 2004) found only small-scale, qualitative studies describing various aspects and characteristics of teacher leadership practice. This current study makes its contribution to the body of research surrounding public schools and PLCs by examining quantitative evidence concerning the relationship between PLC implementation and teacher influence based on information provided by the Missouri Professional Learning Community organization and surveys returned by 782 teachers in 76 Missouri schools.
\end{abstract}

\section{Introduction}

Educational reform has been a topic of intense interest since the 1950's (Brost, 2000; Lambert, 2003; Servage 2009; Watson, 2014). Researchers have routinely proposed that schools must evolve to be much more adaptable and much more responsive to students' needs (Brost, 2000; Servage, 2009). A great deal of educational research exists that indicates that, in order to accomplish educational reform, teachers must be more involved in decision-making processes (Brost, 2000; Conley, 1991; DuFour \& Eaker, 1998; Liontos, 1993; Odden \& Wohlstetter, 1995; Smylie, Lazarus \& BrownleeConyers, 1996; York-Barr \& Duke, 2004); and empowering teachers to reflect, collaborate, and act collectively as a means to enhance student achievement figures prominently in many current public school reform initiatives (Duffy, Mattingly, \& Randolph, 2006; DuFour \& Eaker, 1998; Gates \& Watkins, 2010). According to Howey 
(1988), teacher leadership is both natural and necessary in today's climate of increasing demands for excellence being placed on schools. His assertion that reform can only be effective if addressed by those who reside where the problems are is a common theme in educational research (Brost, 2000; Clark \& Clark, 2002; Liontos, 1993; Odden \& Wohlstetter, 1995; Smylie et al., 1996; York-Barr \& Duke, 2004).

One popular reform framework that schools have embraced that incorporates the idea of involving teachers in problem analysis and decision-making is "professional learning communities" (Clark \& Clark, 2002, Gates \& Watkins, 2010; Linder et al., 2012). It is defined by DuFour \& Eaker (1998) as an organizational model or framework "characterized by a shared mission, vision, and values; collective inquiry; collaborative teams; an orientation toward action and a willingness to experiment; commitment to continuous improvement; and a focus on results" (p. 45). Even though definitions vary somewhat, there are certain characteristics that are commonly cited by educational researchers: A collaborative culture based on the assumptions that groups of teachers are able to achieve more by working together than they can achieve individually (Bolam et al., 2005; Kruse, Louis, \& Bryk, 1994), a commitment to improved student learning driven by data and mutual accountability (DuFour \& Eaker, 1998; Kruse et al., 1994), supportive and shared leadership in which administrators are committed to sharing decision-making with teachers (Roy \& Hord, 2006), and shared personal practice and collective inquiry between teachers that leads to continuous inquiry and reflective dialogue (Roy \& Hord, 2006; Stoll et al. 2006).

Hord (1997) observed that the term learning community was "well integrated into the lexicon of American education" (p. 1). It is an movement that has had an 
international impact: After reviewing 25 years of international research on school improvement, Stoll et al (2006) refer to PLCs as a "hot topic in many countries" that holds "considerable promise for capacity building for sustainable improvement" (p. 221). Toole and Louis (2002) referenced the presence of PLCs in countries as diverse as Canada, South Africa, the Netherlands, Japan, and Mexico. A search of the literature for the term "professional learning communities in schools" returned over three million references from a wide assortment of countries. Educational research has followed this trend: Huffman (2011) described research on PLCs as "an international phenomenon with scholars and practitioners in Australia, Canada, China, Taiwan, United States, and United Kingdom engaging in longitudinal and cross-cultural studies” (p. 321, abstract). Additionally, Roy and Hord (2006), in an article suitably titled, "It's Everywhere, but What Is It? Professional Learning Communities," noted that PLCs can be found across the spectrum of school settings as they observed PLCs as being in "village schools, city schools, rural settings, and suburban and urban locales" (p. 490). The current study focused on PLCs in Missouri (United States), and with 254 schools currently participating in a statewide PLC organization in Missouri (MO PLC Organization, see www.moplc.org), it is clear that PLCs have been widely adopted across the state.

A central tenet of the PLC framework is that PLC can lead to greater teacher influence which then indirectly influences student achievement (DuFour \& Eaker, 1998; Linder et al., 2012; Louis \& Marks, 1998; Sigurðardóttir, 2010; Thompson, Gregg, and Niska, 2004). An important result of embedding collaboration into the structures of schools when PLCs are implemented is the incorporation of shared leadership and shared decision-making: "Collaboration can involve various stakeholders in making significant 
decisions about their school and its programs" (Clark \& Clark, 2002, p. 52). These authors go on to note that "collaborative decision-making can improve the school working environment and lead to instructional improvement and higher student achievement scores" (p. 56), a finding that is supported by other researchers (Hofman \& Dijkstra, 2010; Linder et al., 2012; Louis \& Marks, 1998; Schechter, 2008;

Sigurðardóttir, 2010; Thompson et al., 2004). The observation that PLCs are designed to emphasize teacher-led data-informed decision-making is also well-documented in the literature (Linder et al., 2012; Louis \& Marks, 1998; Sigurðardóttir, 2010; Thompson et al., 2004).

Given the abundance of research on proposed theoretical connections between PLC and teacher influence, one would expect there to be a significant/substantial body of quantitative research documenting the relationship between PLC implementation and teacher involvement in decision-making using empirical evidence. However, in their 2004 comprehensive review of over two decades of empirical research related to teacher leadership, York-Barr \& Duke (2004) referred only to "numerous small-scale, qualitative studies that describe dimensions of teacher leadership practice, teacher leader characteristics, and conditions that promote and challenge teacher leadership" (p. 255). They reviewed 140 teacher leadership studies and reviews of studies, and none of these were quantitative research studies examining the relationship between teacher leadership and PLCs. Similarly, although a review of research for this current paper revealed studies examining a wide variety of positive effects from increased collaboration in PLCs [e.g., like better informed teachers (White, 1992), improved teacher communication within and across schools (White, 1992; Wohlstetter, 1995), and reduced isolation of 
teachers (White, 1992)], there were no quantitative studies directly examining whether or not there is a relationship between PLC implementation and increased teacher influence in schools.

In a number of studies, teacher influence (a term used interchangeably with the concept of teacher involvement in decision-making processes) is used as a proxy variable for teacher leadership (e.g., Brost, 2000; Bryk, Cambrun, \& Louis, 1997; Liontos, 1993; Marks \& Printy, 2003), which makes research on teacher leadership a possible source of data on the relationship being examined in the current study. Teacher leadership studies typically examine correlational relationships between the presence of PLC and various aspects of teacher leadership. Because correlational relationships do not imply directionality, a number of researchers have investigated the correlation between PLC and teacher leadership from different directional points of view. There are studies that examine this relationship in the opposite direction of the current study, examining the possibility that creating leadership opportunities for teachers drives the implementation of PLCs. For example, Kruse et al. (1994) stated that enhancing teacher leadership and teacher autonomy was a critical part of establishing a PLC in a school. This directional finding was also found in studies by Bolam et al. (2005), Carpenter (2015), Louis \& Marks (1998), Maag (2009), Moller (2006), Sackney \& Walker (2006), and Servage (2008). The importance of having the principal's support in creating leadership opportunities for teachers was underscored by Carpenter (2015), who found that "the manner in which teachers engaged in the collaborative culture was greatly shaped by shared and supportive leadership trust and respect for teachers as professionals" (p. 689). This finding was supported by Stoll, et al. (2006) who found that distributed leadership 
ensures that leaders were working collaboratively with teachers to create opportunities for teacher leadership roles, and Hord (1997) listed the incorporation of shared leadership as one of the distinguishing factors of a PLC. In essence, the strong positive correlational findings of teacher leadership studies suggest that teachers' involvement in leadership and decision-making roles enhances the effective implementation of PLCs. A different conceptualization of the directional relationship between collaborative leadership and school improvement emerged from a series of studies conducted by Hallinger and Heck (Hallinger \& Heck, 1996b; Heck \& Hallinger, 2009a, 2009b, and Hallinger \& Heck, 2010). Based on a demonstration of a bias in research for framing leadership as the causal agent of change in organizations (Heck \& Hallinger, 2005), these authors conceptualized leadership effects as a process of mutual influence, i.e., influence in both directions between collaborative leadership and school improvement. In their 2010 study, Hallinger and Heck developed a series of multilevel longitudinal models to test notion that "the empirical study of school improvement leadership requires dynamic models that take into account changing relationships among relevant variables over time" (p. 230). They tested a reciprocal model for describing the relationship between collaborative leadership and school improvement and concluded that it offered "a new empirical description of collaborative leadership and academic capacity building as mutually reinforcing, parallel change processes" (p. 246). As noted earlier, what is missing from the literature are studies like the current study which can provide evidence that could be used to support theory that proposes a directional relationship from PLC implementation to teacher involvement in decision-making and could also support theories of reciprocal influence. 
It is important to note that studies examining PLC in schools generally rely on teacher perceptions of different aspects of PLC. Perceptual studies have focused on topics such as shared decision-making (Leech, 1999); leadership behaviors (Berry et al, 2008; Leech, 1999), empowerment (Berry et al, 2008), the authenticity of implementation of PLC structures (Kim, 2016), driving forces of instructional decision-making (Griffith et al, 2013), the interplay between PLC and teacher self-efficacy (DeNeve et al, 2015; Priest, 2015; Turner, 2012), the impact of professional development on teacher practice (Griffith et al, 2013; Nelson, et al., 2012; Poekert, 2012), the use of performance assessments (Abbott \& Wren, 2016; Nelson, et al., 2012; Skalski \& Romero, 2011), and overcoming barriers for dealing with disruptive student behavior (Maag, 2009), to name a few. However, self-reports of organizational constructs can be biased and must be interpreted with caution. Donaldson \& Grant-Vallone (2002) identified measurement in organizational settings as a significant shortcoming of organizational research due to the reliance on self-reports. Camburn, Han, and Sebastian (2017) noted that, while surveys have advantages (e.g., generally less expensive and burdensome, allow for data collection over a large number of participants), their research produced mixed evidence about the validity of using an annual survey as a measuring tool. Rosenman, Tennekoon, \& Hill (2011) described the reasons individuals offer biased estimates of self-assessed behavior, "ranging from a misunderstanding of what a proper measurement is to social-desirability bias, where the respondent wants to 'look good' in the survey, even if the survey is anonymous" (p. 321). Donaldson \& Grant Vallone (2002) cited "shared method variance" - a contamination of data when all variables in a study are based on one method of measurement - as the primary problem, but acknowledged that the extent to 
which this affects research conclusions is still hotly debated. Their study examined the problem of self-report bias in relation to specific constructs in order to elucidate the probability that bias was occurring. They gave the example of a research participant who was abusing drugs at work and was asked to report on his/her level of drug abuse. Because the question was directed at a potentially sensitive construct about which the participant perceived that a true response could jeopardize his/her employment, the participant had a strong propensity to bias his/her response to be socially desirable. The study concluded that "the nature of the construct (e.g., level of sensitivity) in combination with employee characteristics (e.g., actual behavior or true score and propensity to give socially desirable responses) and situational pressures must be considered to fully understand and account for self-report bias in organizational behavior research" (p. 256). Comparing the findings of this study to the current study suggest that the likelihood of self-report bias in the current study was small. The survey protocol ensured anonymity. (The fact that the protocol replicated the protocol of the annual MO PLC BAT, with which the participants were familiar, reinforced the assurance of anonymity). The construct in question was not potentially sensitive: Providing one's perception of the degree to which one is involved in decision-making as part of a larger involvement in a PLC implementation project posed little risk of being job threatening. Finally, the items themselves were part of a larger survey, the UChicago Consortium on School Research (CCSR) 5Essentials School Reports "My School, My Voice" survey (Appendix A) that has undergone extensive testing for validity and reliability (Bryk, 2010; Levenstein, R., 2014; Appendix C), further diminishing the concern about self-report bias. 
Finally, studying the relationship between PLC and teacher involvement in decision-making can help resolve a contradiction in PLC research as it pertains to student achievement outcomes. While there are methodological difficulties in connecting PLC to student achievement (see Burns et al., 2014), a great deal of research has been conducted to determine what impact, if any, PLC implementation is having on student achievement. In a meta-analysis of three decades of studies investigating the effects of PLC on student achievement, Lomos et al. found a small but significant effect $(3=.25, \mathrm{p}<.05)$. Research studies by Andrews \& Louis (2007), Berry and Montgomery (2005), Bolam et al. (2005), Hollins et al. (2004), Louis \& Marks (1998), Phillips (2003), Sigurðardóttir (2010), Strahan (2003), Supovitz (2002), and Supovitz \& Christman (2003) all showed slight to moderate impacts of PLC on student achievement. The studies by Bolam et al. (2005), Louis and Marks (1998), Supovitz (2002), and Supovitz and Christman (2003) provided important information about the impact of specific aspects of PLC on achievement. Both the Bolam et al. (2005) and the Louis and Marks (1998) studies reported positive gains in student achievement related to the strength of the PLC in the schools studied. The studies by Supovitz (2002) and Supovitz and Christman (2003) found significant gains in student achievement in schools where teachers engaged in focused instructional discussions concerning the relationships between teaching practices and student work. However, findings to the contrary can also be found in the literature. Studies by Louis \& Marks (1998) and Smylie et al. (1996) found the reported effects of PLCs on student achievement to be small. Further, some research shows no effect, especially when accounting for other school factors such as school climate (Andrews \& Louis 2007; Burns, et al, 2014; Louis \& Marks, 1998; Sigurðardóttir, 2010; Stewart, 
2014). Given the importance of teacher influence to the overall framework of PLCs, empirically examining this pathway could help explain why the effects of PLC on student achievement that are reported in the research are contradictory.

\section{Present Study.}

The present study examined whether or not there is a relationship between PLC implementation and teacher involvement in decision-making. This required a measure of PLC implementation as well as data concerning the degree to which teachers perceive themselves to be involved in decision-making. PLC implementation (the independent variable) was quantified by calculating a Benchmark Assessment Tool Implementation Score (BIS) for each participating school from data provided by the Missouri Professional Learning Community organization, (MO PLC, described below). Teacher involvement in decision-making (the dependent variable) was measured by a statewide survey of teachers on their perceptions of their involvement in six decision-making areas. As with the BIS, these scores averaged to provide a building-level measurement. Multiple regression analysis was used to determine if a significant relationship existed between these two measures.

As indicated above, PLC implementation was quantified using annual survey results obtained from the MO PLC for all its participating schools. Following the calculation originally created by MO PLC, the BIS was calculated for each school participating in the current study. (See the Methods section for a detailed description of this calculation.) Using items from the UChicago Consortium on School Research 5Essentials School Reports Survey designed to assess teachers' involvement in decisionmaking, a survey was created (MO PLC Teacher Influence Survey) to determine 
teachers' perceptions of their involvement in decision-making. These were distributed to all participating MO PLC schools. Surveys were received from 76 schools, and an overall teacher involvement score was calculated for each of these schools.

\section{Theoretical Framework and Research Questions}

There are two theories underlying the present study: PLC (which as indicated in the introduction, is described by multiple frameworks in the literature), and participatory management theory.

\section{Professional Community}

It is important to consider various PLC frameworks in order to compare them to the instruments used by the MO PLC organization to measure PLC implementation. For the 2017-18 school year, the BAT was redesigned to align with six "strands" corresponding to an implementation rubric developed by MO PLC: The process of identifying the school's mission and vision, the nature of their building's culture (collaborative culture and shared decision-making), the use of SMART goals and priority goals, the nature of collaborative teams, and the implementation of school-wide tiered interventions (Table 1). PLC frameworks created by Roy and Hord (2006) and Louis, Marks, and Kruse (1996) are representative of others found in the PLC literature. Roy and Hord, hereafter referred to as RH, reviewed 15 years of PLC research and proposed a PLC framework of five elements: Supportive \& shared leadership, collective learning and application, shared values and vision, supportive conditions, and shared practice (Table 2). Louis et al. (1996), hereafter referred to as LMK, identified five distinguishing elements of PLCs: Shared values, focus on student learning, collaboration, deprivatized practice, and reflective dialogue (Table 3 ). 
Table 1

MO PLC Implementation Strands

MO PLC Strands

Description

Learning community Mission, vision, and values are articulated and collectively culture \& continuous constructed; SMART goals are regularly revised and improvement sustained; the PLC culture is assessed regularly

Effective leadership teams

Staff are involved in leadership roles; meetings are proactive and responsive to specific needs; feedback data is used for improvement and communication about decisions is transparent; progress of collaborative teams is continuously monitored and feedback is provided; support needed by collaborative teams is solicited

Regular meetings using protocols with a record of discussions How effective teams work that is provided to leadership teams for review and feedback; regular and systematic reflection on the four corollary questions with focus on results from data; use of a method of monitoring trust and participation

What do students need to know and do?

Essential learning terminology and standards are implemented and regularly reviewed/revised; students are able to articulate their progress in each subject area; instructional timelines are adjusted based on assessment data

How will we know

Appropriate assessments are collaboratively developed and when students have learned? collectively scored; students are involved in assessments, and timely and specific feedback is provided to students; assessments are data driven and grading practices are collaboratively developed

Success for all is implemented school-wide with adaptations Systematic process for and modifications made for individual students; there is a school-wide communication system that includes vertical and intervention/student success horizontal communications; Tier 1, 2, and 3 interventions are provided and monitored for success; enrichment work is included

These PLC frameworks have similarities: References to reflective dialogue (although RH include it as part of "collective learning and application"); shared values; collaboration (referred to as "shared practice," by RH); focus on student learning (included as part of "shared values and vision in RH"). There are, however, important 
Table 2

Roy \& Hord PLC Framework

PLC elements

Description

Supportive \& shared leadership

Collegial and facilitated participation; shared decisionmaking and shared leadership in which principals "nurture the capacity of staff members to build a trustworthy, respectful, and collaborative environment" (p. 493)

Collective learning and Reflective dialogue leading to inquiry and application and application collective assessment efforts

Shared values and vision

Used for decision-making and focused on student learning

Human capacities (trust, respect, feedback, collegiality, Supportive conditions risk-taking) and physical/structural components (schedules that facilitate collaboration, open communication structures, physical proximity of teachers within teams)

Shared practice Peers helping peers; observation and feedback

differences to note between the frameworks. "Deprivatized practice" is included as an element by LMK, but is not included by RH (although it is suggested as part of "supportive conditions" in RH); "supportive and shared leadership" and "supportive conditions" from the RH framework have no counterparts in LMK (other than a common reference to affiliation and mutual support between teachers that appears in both LMK's “deprivatized practice” and RH’s “supportive conditions”).

\section{Participatory Management}

The theoretical framework that examines the directional relationship between PLC and teacher involvement is based on participatory management theory. The participatory management movement (also known as shared leadership, participative decision-making, and distributed leadership) has gained much popularity over the last 
Table 3

Louis, Marks, and Kruse (1996) PLC Framework

\begin{tabular}{ll}
\multicolumn{1}{c}{ PLC elements } & $\begin{array}{l}\text { Common beliefs and values teachers hold "underlying their } \\
\text { assumptions about children, learning, teaching, and teachers' } \\
\text { roles, the nature of human needs, human activity, and human } \\
\text { relationships, and the organization's extended societal role, } \\
\text { including its relationship with the surrounding environment" (p. } \\
\text { 758) }\end{array}$ \\
$\begin{array}{l}\text { Collective focus on } \\
\text { student learning }\end{array}$ & $\begin{array}{l}\text { Discussed by teachers; drives instruction that enhances } \\
\text { intellectual growth and development }\end{array}$ \\
Collaboration & $\begin{array}{l}\text { Shared expertise that benefits students' opportunity to learn and } \\
\text { is related to implementation of practice; enhances teachers' } \\
\text { affiliation to each other }\end{array}$ \\
$\begin{array}{l}\text { Interchanging roles (e.g., mentor, advisor, specialist) and } \\
\text { practices like peer coaching, teamed teaching, structured } \\
\text { classroom observations that also increase affiliation and mutual } \\
\text { support between teachers } \\
\text { practice }\end{array}$ & $\begin{array}{l}\text { Conversations between teachers about teaching and learning that } \\
\text { lead to "deepened understanding of the process of instruction } \\
\text { and the products of teaching and learning" (p. 761) }\end{array}$ \\
Reflective dialogued &
\end{tabular}

three decades (Spillane et al., 2004). It stands in contrast to the seminal work of Frederick Taylor on scientific management (Taylor, 1911), which was based on controlling variables in the workplace and creating predictable outcomes for the organization. As such, Taylor's ideas clearly did not support the concepts of participation and empowerment, focusing instead on "centralization, standardization, hierarchical top-down management, a rigid sense of time, and accountability based on adherence to the system" (DuFour \& Eaker, 1998, p. 20). Application of the principles of Taylor's time and motion studies and assembly line cultures led to negative employee reactions which resulted, over time, in Taylor's ideas being largely discredited. 
Spillane et al. (2005) described participatory management as a process that engages all members of an organization or organizational division in jointly identifying its vision, goals, and strategies, and involves them in key areas of decision-making. Sarafidou and Chatziioannidis (2013) stated that "this empowerment of individuals is considered fundamental for enhancing their morale and motivation, increasing levels of job satisfaction and promoting a sense of responsibility and commitment to organizational effectiveness and improvement" (p. 170). Other researchers in the field of participatory leadership (MacBeath, 2005; Harris, 2010) emphasized the importance of collaborative decision-making as the focus of new organizational management practices that served to cultivate synergistic creativity and facilitate the incorporation of highperformance practices into the workplace. Lange (1993) described multiple benefits of decentralizing school governance through participatory management, including a commitment to decisions, a perception that higher quality decisions were made, increased staff cohesion, and increased trust among staff members and principals.

Comparing the characteristics of participatory management (from the Reference for Business website, www.referenceforbusiness.com) with those of PLCs shows remarkable similarities (Table 4). From Table 4, it is clear that the fundamental features of both PLC and participatory management research are collective inquiry/information sharing, collaboration, a focus on outcomes, and shared decision-making. The similarity between the characteristics and outcomes of participative management and PLCs is evidence of the utility of participative management as the theoretical framework of this study, especially in terms of increasing involvement in employees in decision-making 
Table 4

Comparing Characteristics of Participatory Management and Professional Learning Communities

\begin{tabular}{ll}
\hline $\begin{array}{l}\text { Characteristics of } \\
\text { Participative Management }\end{array}$ & $\begin{array}{l}\text { Characteristics of } \\
\text { Professional Learning Communities }\end{array}$ \\
\hline Commitment & Commitment to student learning \\
Information sharing & Collaboration \\
Training/skill development & Collective inquiry \\
Employee decision-making & Supportive and shared decision- \\
Rewards for performance & Focus on outcomes \\
\hline
\end{tabular}

processes as an outcome: As noted earlier in the problem statement section, one of the defining characteristics of a PLC is supportive and shared leadership in which administrators are committed to sharing decision-making with teachers (Roy \& Hord, 2006; Kruse et al., 1994, 1994; DuFour, Eaker \& DuFour, 2005; Rosenholtz, 1989). These authors cite distributed leadership as a necessity in order to build an effective PLC. Similarly, in their study on creating and sustaining PLCs, Bolam, et al. (2005) stated that "school autonomy, as evidenced in site-based management, is seen as essential for the development of a learning community" (p. 25). The literature cited in the Introduction section is unequivocal in its call for increased participation of teachers in the implementation of PLCs, and participatory management theory provides the foundation for understanding the connection between PLC implementation and increased teacher influence (Figure 1).

Based on the above information about PLCs and participatory management and its theoretical connections to greater stakeholder involvement, applied to the educational setting, the current study was designed to investigate the following. 
Hypothesis. PLC implementation and increased teacher participation in decision-making have a positive relationship.

Figure 1

Participatory Management Theoretical Framework
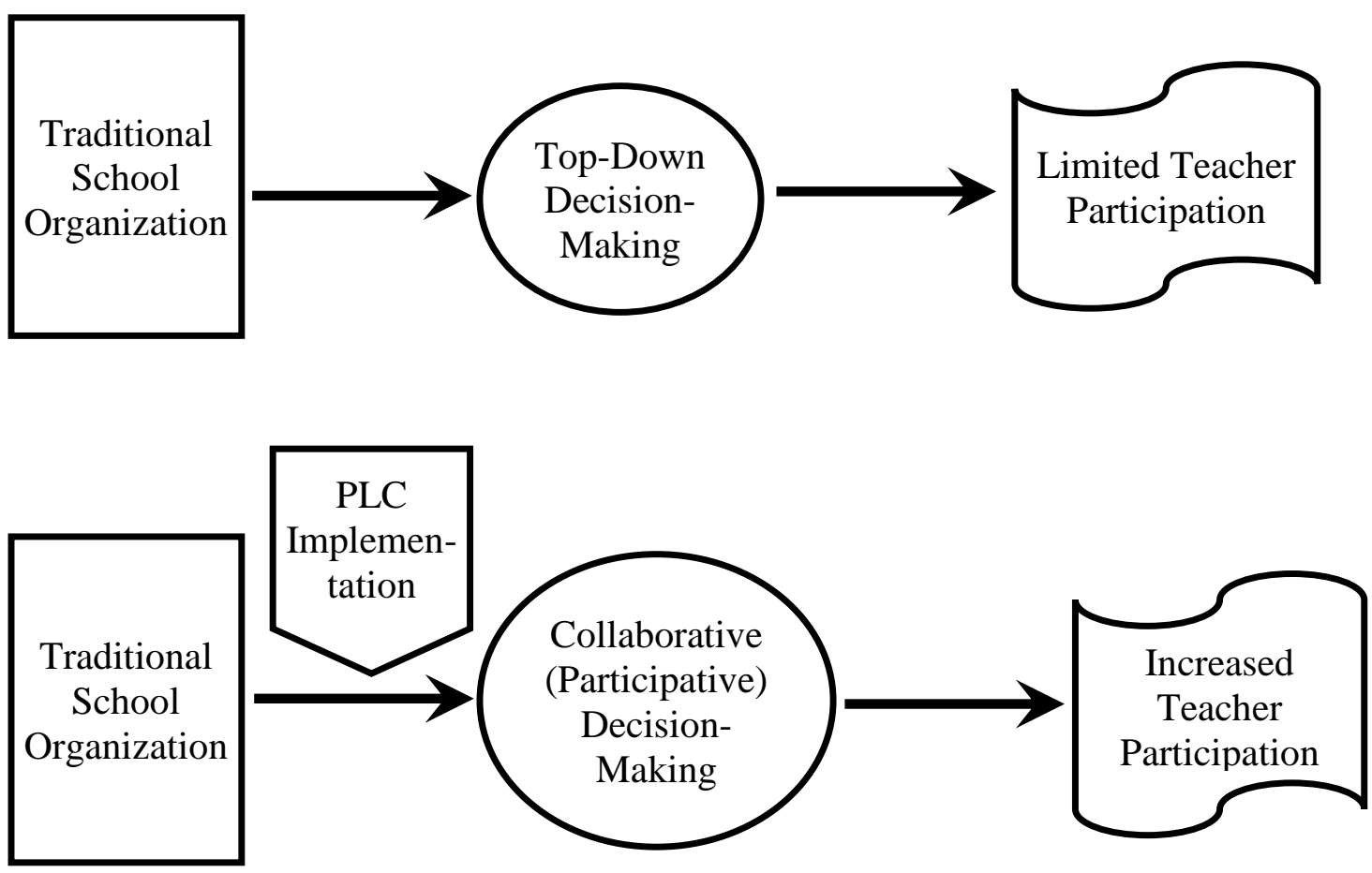

\section{Methods}

\section{Sample and Data Sources}

The sample for this study included the instructional staff of the 202 schools participating in the Missouri Professional Learning Community organization (MO PLC, see www.moplc.org) during the spring semester of the 2017-18 school year. Descriptive information about all of the variables included in the study is given in Table 5. Data on involvement in decision-making (the independent variable) was collected using items from the UChicago Consortium on School Research (CCSR) 5Essentials School Reports "My School, My Voice" survey (Appendix A) that asked teachers to indicate how much 
Table 5

Descriptions of Study Variables

\begin{tabular}{|c|c|c|}
\hline Variable & Type & Classification \\
\hline PLC implementation (BIS) & Independent Variable & Continuous \\
\hline Teacher influence & Dependent Variable & Continuous \\
\hline Attendance rate & Covariate & Continuous \\
\hline$\%$ Free/reduced lunch & Covariate & Continuous \\
\hline School size & Covariate & Continuous \\
\hline $\begin{array}{l}\text { Student achievement (MAP } \\
\text { Performance Index (MPI) } \\
\text { for Math and } \\
\text { English/Language Arts } \\
\text { (2017-18 school year) }\end{array}$ & Covariate & Continuous \\
\hline$\%$ Minority students & Covariate & Continuous \\
\hline Expenditures per ADA & Covariate & Continuous \\
\hline $\begin{array}{l}\text { School grade configuration } \\
\text { (Elementary, Middle, High) }\end{array}$ & Covariate & Categorical \\
\hline Rural/Urban & Covariate & Categorical \\
\hline $\begin{array}{l}\text { Year of MO PLC } \\
\text { implementation }\end{array}$ & Covariate & Categorical \\
\hline
\end{tabular}

influence they have over policy in each of six areas: Hiring new professional personnel, planning how discretionary school funds should be used, determining books and other instructional materials used in classrooms, establishing the curriculum and instructional program, determining the content of in-service programs, and setting standards for student behavior. The 5Essentials School Reports Survey has been widely used in educational research (e.g., Bryk, et al., 2010; Lee, Robinson, \& Sebastian, 2012) and undergone testing for validity and reliability (Bryk, et al., 2010; Levenstein, R., 2014; Appendix C). The final nine-item survey used in the current study (which added three demographic questions for subsequent disaggregation) was constructed in Qualtrics and named "MO PLC Teacher Influence Survey" (Appendix B). Items were rated on a fourpoint Likert scale: "None," "A little," "Some," and "A Great Deal." 
The independent variable in this study was a building-level calculated index (number between 0 and 105), the Benchmark Assessment Tool Index Score (BIS) that reflects the extent to which each school building has implemented PLC. The BIS was calculated based on responses to an annual online survey, the Benchmark Assessment Tool (BAT) that is administered online each spring. There are three components of the BAT: The Leadership Team Survey, completed by the Building Leadership Team, the Administrative Survey, completed only by building administrators, and the PLC Staff Survey. For the purposes of this study, only the final component was utilized. The BAT survey included 15 questions and assessed the perspectives of these staff members on the degree to which the following aspects of PLC had been implemented in their respective buildings: The process of identifying the school's mission and vision, the nature of their building's culture, the use of SMART goals and priority goals, the nature of collaborative teams, and the implementation of school-wide tiered interventions (see Appendix F). The BIS was developed when the MO PLC organization was created in 2003 as part of their annual assessment of participating schools. It was calculated (described below) and reported to each participating school from 2003 until the BAT was redesigned in 2017. The BIS was used as a feedback tool for the buildings to determine the extent to which they had implemented the essential features of PLC. Higher values of the BIS indicated greater PLC implementation. Since the BIS was calculated each year, Dr. Rob Gordon (former State Field Director of MO PLC) indicated that it was a very useful index for schools to use as an indication of their progress towards PLC implementation.

Because the extent to which the BAT items correspond to the six strands of PLC implementation identified by MO PLC as well as existing PLC frameworks reflects on its 
ability to accurately assess PLC implementation, a comparison of the items on the redesigned BAT to the strands and the frameworks was necessary (see Table 6). All survey items reflect some element of at least one of the PLC frameworks. Still, there are omissions that stand out. A match for the item, "How is shared decision-making encouraged in your building," can only be found in one PLC framework-RH's "supportive \& shared leadership." Further, there are some elements from the frameworks that are not represented by any of the 15 questions in the survey. RH's "supportive conditions" doesn't neatly fit any of the survey items, although it includes the attributes of trust, respect, feedback, collegiality, and risk-taking that are commonly referred to as outcomes of collaboration. "Deprivatized practice," included as an element of PLC by LMK, isn't specifically referenced by any of the survey items.

With the redesign of the BAT in 2017, the MO PLC discontinued calculating the BIS, replacing it with an evaluation process that included the collection of artifact data demonstrating implementation of PLC practices related to each of the six strands, and the evaluation of this artifact data by a site visit of educators trained in PLC implementation. When the organization reorganized their PLC implementation elements around six strands in 2018 (described below), it also shifted its focus away from the BIS in favor of evaluating artifact data on a site visit. When this was implemented in 2017, the BIS was discontinued.

The calculation of the BIS from the redesigned 2017-18 BAT for the current study duplicated the mathematical calculations utilized with the original BAT. As indicated above, the new BAT replaced the original three response choices with four response choices (written as rubric-style statements) reflecting the following: Deep 
Table 6

Comparison of MO PLC Implementation Survey with PLC Implementation Frameworks

\begin{tabular}{|c|c|c|c|c|}
\hline Survey items & Full implementation & MO PLC Strands & RH & LMK \\
\hline $\begin{array}{l}\text { Choose the best descriptor of } \\
\text { your building's } \\
\text { collaboratively developed } \\
\text { mission. }\end{array}$ & $\begin{array}{l}\text { The mission focuses on student } \\
\text { learning and is referred to regularly. }\end{array}$ & $\begin{array}{l}\text { Learning } \\
\text { community culture } \\
\text { \& continuous } \\
\text { improvement }\end{array}$ & $\begin{array}{l}\text { Shared } \\
\text { values and } \\
\text { vision }\end{array}$ & $\begin{array}{l}\text { Shared values } \\
\& \text { expectations }\end{array}$ \\
\hline $\begin{array}{l}\text { Choose the best descriptor of } \\
\text { your building's vision. }\end{array}$ & $\begin{array}{l}\text { Our vision was collaboratively } \\
\text { developed, is reviewed regularly, } \\
\text { and we have commitments aligned } \\
\text { to our vision. }\end{array}$ & $\begin{array}{l}\text { Learning } \\
\text { community culture } \\
\text { \& continuous } \\
\text { improvement }\end{array}$ & $\begin{array}{l}\text { Shared } \\
\text { values and } \\
\text { vision }\end{array}$ & $\begin{array}{l}\text { Shared values } \\
\text { \& expectations }\end{array}$ \\
\hline $\begin{array}{l}\text { Choose the best descriptor of } \\
\text { your building's collaborative } \\
\text { culture. }\end{array}$ & $\begin{array}{l}\text { Collaborative teams share ideas and } \\
\text { resources for problem-solving and } \\
\text { decision-making within and across } \\
\text { teams. }\end{array}$ & $\begin{array}{l}\text { Learning } \\
\text { community culture } \\
\& \text { continuous } \\
\text { improvement }\end{array}$ & $\begin{array}{l}\text { Shared } \\
\text { practice }\end{array}$ & Collaboration \\
\hline $\begin{array}{l}\text { Which best describes } \\
\text { building level SMART goals } \\
\text { in your school? }\end{array}$ & $\begin{array}{l}\text { Our building has measurable, } \\
\text { SMART goals around student } \\
\text { learning that influence my } \\
\text { instruction. }\end{array}$ & $\begin{array}{l}\text { What do students } \\
\text { need to know and } \\
\text { do? }\end{array}$ & $\begin{array}{l}\text { Shared } \\
\text { values and } \\
\text { vision }\end{array}$ & $\begin{array}{l}\text { Focus on } \\
\text { student } \\
\text { learning }\end{array}$ \\
\hline $\begin{array}{l}\text { Describe the level of trust in } \\
\text { your team. }\end{array}$ & $\begin{array}{l}\text { I am comfortable sharing my } \\
\text { strengths and weaknesses about } \\
\text { teaching and learning with all } \\
\text { members of my team. }\end{array}$ & $\begin{array}{l}\text { How effective } \\
\text { teams work }\end{array}$ & $\begin{array}{l}\text { Supportive } \\
\text { conditions }\end{array}$ & Collaboration \\
\hline $\begin{array}{l}\text { I believe that collaboration } \\
\text { through teacher teams is } \\
\text { improving the education we } \\
\text { provide to all our students. }\end{array}$ & Yes, and this happens in my team. & $\begin{array}{l}\text { How effective } \\
\text { teams work }\end{array}$ & $\begin{array}{c}\text { Shared } \\
\text { practice/ } \\
\text { Shared } \\
\text { values and } \\
\text { vision }\end{array}$ & $\begin{array}{l}\text { Collaboration/ } \\
\text { Focus on } \\
\text { student } \\
\text { learning }\end{array}$ \\
\hline
\end{tabular}


How is shared decisionmaking encouraged in your building?

Which best describes your collaborative team meetings. your team uses meeting protocols such as roles, norms, timed agendas,
Which best describes how

Collaborative teams directly contribute to decision-making about critical issues impacting instruction and directly contribute to plans for addressing those issues.

Collaborative teams meet weekly during the contract day and are teacher-led, focusing on student learning and data-driven decisionmaking.

Our team makes effective use of all meeting protocols. need to know and priority standards?

How does your team utilize identified priority standards?

Choose the best descriptor of your team.
All teachers are directly involved in identifying priority standards for the subject areas they teach.

Our team uses priority standards as the basis for determining our formative assessments on a regular basis.

My team collaboratively identifies instructional strategies which are aligned with priority standards and we are committed to implementing them.
How effective teams work

What do students do?

\section{Effective leadership \\ Supportive \& \\ shared \\ leadership}

\section{How effective teams work}

\section{Shared}

practice/

Collective

learning and

applications

Collaboration

Shared

practice

Collaboration

Shared

values and

vision/

Supportive

and shared

leadership

Shared

What do students need to know and do?

values and

vision/

Shared

practice

Shared

How will we know values and vision/

when students have learned?

Collective

learning and applications
Focus on student

learning

Collaboration/

Focus on

student

learning

Focus on

student

learning 
I am a member of a collaborative team that uses student data to drive problem-solving and decisions.

As a team we collaboratively establish SMART goals and implement strategies and action plans based on student data. Choose the best descriptor of your team's use of SMART goals.

What is the level of implementation of school-
My team routinely reviews student data to inform problem-solving and decisions.

Our team has established SMART goals and action plans based on student data.

School-wide implementation with review of targeted data points for all students.
Systematic process for

intervention/student success

How will we know when students have learned?

Systematic process for intervention and student success
Shared values and vision

Focus on student learning Shared values and Focus on

Focus on student learning

learning and applications

vision 
implementation, proficient implementation, partial implementation, and minimal implementation, respectively. In order to convert teacher responses to a building-level BIS score, all responses for each question were converted to numeric equivalents $($ minimal implementation $=1$, partial implementation $=2$, proficient implementation $=3$, deep implementation $=4$ ), which allowed a building-wide average to be calculated for each question. Subsequently, these average scores were examined in order to distinguish between scores that showed a great deal of agreement and those that were widely dispersed. For each survey item, the total number of responses for each of the choices (i.e., no implementation, minimal implementation, moderate implementation, exemplary implementation) were tallied and percentages calculated. On each item, the response that received the highest percentage was designated as the categorical response for that particular survey item. If that percentage was $80 \%$ or greater, that response category was considered to show "consensus." Any percentage less than $80 \%$ was designated "without consensus." For example, Table 7 shows the responses given by the 10 teachers who returned BAT surveys from a hypothetical school (ABC Elementary) on item 1: Choose the best descriptor of your building's collaboratively developed mission.

Table 8 shows the conversion of these responses percentages in order to determine the categorical response (the response with the highest percentage) and to determine if that response reflected consensus for this item. In this example, the majority of teachers at $\mathrm{ABC}$ Elementary rated the best descriptor of their building's collaboratively developed mission as "exemplary," so this item was rated a 4 (fully implemented) in the BIS calculation. However, since that rating was chosen by less than $80 \%$ of the teachers, it was designated "without consensus." 
Table 7

Teacher Responses at ABC Elementary School for BAT Item 1

\begin{tabular}{cc} 
Teacher & Response \\
\hline 1 & 3 \\
2 & 4 \\
3 & 4 \\
4 & 3 \\
5 & 4 \\
6 & 4 \\
7 & 4 \\
8 & 4 \\
9 & 3 \\
10 & 3 \\
\hline
\end{tabular}

The final BIS is a weighted score calculated by totaling the number of practices in each category, multiplying each by a factor reflecting the degree of implementation (ranging from 7 for the greatest implementation with the highest degree of consensus to 0 for the least implementation with the lowest degree of consensus), and then summing all of the results. (See Table 9 for a sample calculation.) In that example, BAT items 1, 3, and 9 received over $80 \%$ " 4 " ratings by teachers at ABC Elementary. Items 7 and 10 received a majority of " 4 " ratings, but the percentage was less than $80 \%$. Items $2,4,5,6$, and 11 through 14 received over $80 \%$ "3" ratings. Item 9 received a majority of " 3 " ratings, but the percentage was less than $80 \%$. Item 15 received over $80 \%$ " 2 " ratings. No survey items received a majority of "1" ratings. Building-level BIS scores range from 0 to a "perfect" score of 105 . This score was originally designed to be reported to schools participating in MO PLC to provide them with a numerical representation of their progress towards PLC implementation. Followed longitudinally, it gave schools a straightforward sense of their progress. Because the score included weighting to reflect 
Table 8

Determination of Consensus for BAT Item 1 at ABC Elementary School

\begin{tabular}{lcc}
\multicolumn{1}{c}{ Response } & $\begin{array}{c}\text { Number of } \\
\text { responses }\end{array}$ & $\%$ of response \\
\hline 4 (fully implemented) & 6 & $60 \%$ \\
3 (partially implemented) & 4 & $40 \%$ \\
2 (minimally implemented) & 0 & $0 \%$ \\
1 (not implemented) & 0 & $0 \%$ \\
\hline
\end{tabular}

Table 9

Sample Benchmark Index Score (BIS) Calculation

\begin{tabular}{|c|c|c|c|c|c|c|c|c|}
\hline \multirow{2}{*}{ Question } & \multicolumn{2}{|c|}{$\begin{array}{c}\text { Fully } \\
\text { implemented }\end{array}$} & \multicolumn{2}{|c|}{$\begin{array}{c}\text { Partially } \\
\text { implemented }\end{array}$} & \multicolumn{2}{|c|}{$\begin{array}{c}\text { Minimally } \\
\text { implemented }\end{array}$} & \multicolumn{2}{|c|}{$\begin{array}{c}\text { Not } \\
\text { implemented }\end{array}$} \\
\hline & $\begin{array}{l}\text { with } \\
\text { cons. }\end{array}$ & $\begin{array}{l}\text { without } \\
\text { cons. }\end{array}$ & $\begin{array}{l}\text { with } \\
\text { cons. }\end{array}$ & $\begin{array}{l}\text { without } \\
\text { cons. }\end{array}$ & $\begin{array}{l}\text { with } \\
\text { cons. }\end{array}$ & $\begin{array}{l}\text { without } \\
\text { cons. }\end{array}$ & $\begin{array}{l}\text { with } \\
\text { cons. }\end{array}$ & $\begin{array}{c}\text { without } \\
\text { cons. }\end{array}$ \\
\hline 1 & 1 & 0 & 0 & 0 & 0 & 0 & 0 & 0 \\
\hline 2 & 0 & 0 & 1 & 0 & 0 & 0 & 0 & 0 \\
\hline 3 & 1 & 0 & 0 & 0 & 0 & 0 & 0 & 0 \\
\hline 4 & 0 & 0 & 1 & 0 & 0 & 0 & 0 & 0 \\
\hline 5 & 0 & 0 & 1 & 0 & 0 & 0 & 0 & 0 \\
\hline 6 & 0 & 0 & 1 & 0 & 0 & 0 & 0 & 0 \\
\hline 7 & 0 & 1 & 0 & 0 & 0 & 0 & 0 & 0 \\
\hline 8 & 0 & 0 & 0 & 1 & 0 & 0 & 0 & 0 \\
\hline 9 & 1 & 0 & 0 & 0 & 0 & 0 & 0 & 0 \\
\hline 10 & 0 & 1 & 0 & 0 & 0 & 0 & 0 & 0 \\
\hline 11 & 0 & 0 & 1 & 0 & 0 & 0 & 0 & 0 \\
\hline 12 & 0 & 0 & 1 & 0 & 0 & 0 & 0 & 0 \\
\hline 13 & 0 & 0 & 1 & 0 & 0 & 0 & 0 & 0 \\
\hline 14 & 0 & 0 & 1 & 0 & 0 & 0 & 0 & 0 \\
\hline 15 & 0 & 0 & 0 & 0 & 1 & 0 & 0 & 0 \\
\hline Subtotals & 3 & 2 & 8 & 1 & 1 & 0 & 0 & 0 \\
\hline $\begin{array}{l}\text { Factor } \\
\text { weighting }\end{array}$ & 7 & 6 & 5 & 4 & 3 & 2 & 1 & 0 \\
\hline Totals & 21 & 12 & 40 & 4 & 3 & 0 & 0 & 0 \\
\hline BIS & & & & & & & & \\
\hline
\end{tabular}


the degree of agreement among teachers' ratings for each question (i.e., with or without consensus), it conveyed more information than a simple mean and served as an important policy tool for MO PLC (reflecting the effectiveness of their training and support) as well as the building (serving as an evaluation of the relative success of their implementation efforts). In the current study, this score provided a comparative measure of PLC implementation that was used to answer the study's research questions.

Because schools vary in size, rural versus urban setting, student socioeconomic status, percentage of minority students, attendance rate, expenditures per student, and prior academic performance, these variables were all included as covariates. Individual school data for these covariates was obtained from the Missouri Department of Elementary and Secondary Education (see https://dese.mo.gov/school-data). Schools also vary on the length of time they have been involved in the MO PLC organization (i.e., divided into four categories: Year 1, Year 2, Year 3, and Year 4 \& Continuing schools). This information was provided by the MO PLC organization.

\section{Survey Procedure}

As indicated above, teachers' perceptions of their involvement in decision-making was measured using a part of a larger instrument, the UChicago Consortium on School Research 5Essentials School Reports "My School, My Voice" survey. To encourage a high response rate, the support of the director of the MO PLC organization, Dr. Rob Gordon, was solicited. He agreed to allow the format and distribution of the decisionmaking survey to imitate that of the BAT, as follows. The building principal in each school participating in the MO PLC organization was sent an email from Dr. Gordon in September 2019 in which he invited them to encourage their teachers to complete the 
survey (Appendix D). The email contained a link to the survey. Attached to the email was an informed consent document (see Appendix E). Participation in the survey was optional. As a further means to achieve a high response rate, the survey was kept to nine items and an anticipated completion time of less than two minutes. Reminder emails were sent weekly for the following two weeks, and a thank you email was sent the third week after survey distribution. Surveys were received from 16 of the 51 Year 1 schools (31\%), 16 of the 53 Year 2 schools (30\%), 23 of the 40 Year 3 schools (58\%), and 18 of the 58 Year 4 and Continuous schools (31\%). Overall, 36\% of the schools participating in MO PLC at the time of the survey distribution responded to the survey.

Responses to the survey about teacher decision-making were collected as ordinal data $($ None $=1$, A little $=2$, Some $=3$, A great deal $=4)$, and means were calculated for each teacher and, subsequently, for each building. Schools were assigned to one of four groups based upon the number of years they had completed in their involvement with MO PLC training (Year 1, Year 2, Year 3, and Year 4/Continuing). For the purpose of regression analysis, this data was converted into binary “dummy” variables, with binary variables created for all four categories. A similar process was used for each of the other categorical variables involved in the study: Grade configuration (elementary, middle, and high school) and setting (rural and urban). In the regression equations for each of the research questions (see below), one of the categories of each of the categorical variables was omitted from the equation: Year 1 schools, elementary school configuration, and rural setting. This allowed $\beta_{0}$ (the y-intercept) to have meaning when all other coefficients were 0 - a rural elementary school in its first year of participation with MO PLC. (A complete description of this instance is given in the explanation of the 
regression equations below in Analytical Procedures.) Procedures for calculating the BIS from the April 2018 administration of the BAT were provided by the MO PLC, and a BIS was calculated as described in the Sample and Data Sources section (above) for each school that participated in the MO PLC Teacher Influence Survey.

\section{Analytical Procedures}

As indicated in the Introduction, this study investigated three research questions. First, this study asked whether or not there was a relationship between year of implementation of PLC reforms (as determined by year of involvement in the MO PLC organization) and actual PLC implementation (as determined by the BIS score). The regression model used to examine this relationship was as follows.

PLC implementation $=\beta_{0}+\beta_{1}$ Year 2 of PLC implementation +

$\beta_{2}$ Year 3 of PLC implementation $+\beta_{3}$ Year 4 of PLC implementation $+\beta_{4}$ School size + $\beta_{5} \%$ Minority students $+\beta_{6}$ Average $\%$ attendance $+\beta_{7} \%$ students on $F / R$ lunches +

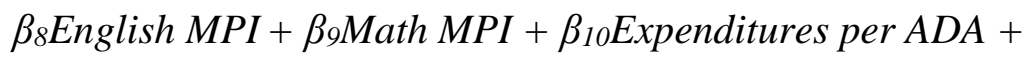
$\beta_{11}$ Middle school grade configuration $+\beta_{12}$ High School grade configuration + $\beta_{13}$ Urban setting $+\varepsilon_{i}$

There are three categorical variables in this equation: Year of PLC implementation (Y1, Y2, Y3, and Y4), school configuration (elementary, middle, and high school), and setting (rural and urban). The intercept, $\beta_{0}$, represents the expected value of the BIS when all predictors are zero. Because it is not possible to have a school in this study that has no year of implementation, school configuration, or setting (i.e., if all categorical variables 
are equal to 0), one variable from each category was removed from the equation: Year 1 (for year of PLC implementation), elementary school (for configuration), and rural (for setting). With these values of the categorical variables removed from the equation, $\beta_{0}$ represented the BIS in a rural elementary school in its first year of participation in MO PLC with no students, $0 \%$ minority, $0 \%$ attendance rate, $0 \%$ of students on free or reduced lunches, MPI's of 0 in math and English, and \$0 expenditures per ADA. The coefficient, $\beta_{1}$, was the expected change in the BIS when the predictor, year of implementation of PLC reforms, increases by one unit (i.e., year 2 of PLC implementation), holding all other predictors constant. Similarly, $\beta_{2}$ was the expected change in the BIS for schools in their third year of PLC implementation, and $\beta_{3}$ was the expected change in the BIS for schools in their in their fourth (or greater) year of PLC implementation.

The second research question of this study constituted the primary focus of the research: What is the relationship between PLC implementation (BIS) and teacher involvement in $\mathrm{v}$ ? The following regression model was used to examine the relationship between PLC implementation and teachers' perceptions of their involvement in decisionmaking.

Teacher influence $=\beta_{0}+\beta_{1}$ PLC Implementation $+\beta_{2}$ School size +

$\beta_{3} \%$ Minority students $+\beta_{4}$ Average $\%$ attendance $+\beta_{5} \%$ students on $F / R$ lunches + $\beta_{6}$ English MPI $+\beta_{7}$ Math MPI $+\beta_{8}$ Expenditures per $A D A+\beta_{9}$ Year 2 of Implementation $+\beta_{10}$ Year 3 of Implementation $+\beta_{11}$ Year 4 of Implementation + 
$\beta_{12}$ Middle school grade configuration $+\beta_{13}$ High school grade configuration $+\beta_{14}$ Urban setting $+\varepsilon_{i}$

Here, the outcome was the average building-level numerical score associated with teachers' perceptions of their involvement in decision-making. The intercept, $\beta_{0}$, represented the expected value of teacher influence when all predictors were zero. Specifically, it represented teacher influence in a rural elementary school in its first year of participation in MO PLC with no students, $0 \%$ minority, $0 \%$ attendance rate, $0 \%$ of students on free or reduced lunches, MPI's of 0 in math and English, and $\$ 0$ expenditures per ADA. The coefficient, $\beta_{1}$, was the expected change in the outcome, teacher influence, when the predictor, PLC implementation (as measured by the BIS) increased by one unit, holding all other predictors constant.

Finally, this study explored a third research question: What is the relationship between year of implementation of PLC reforms and teacher influence? The equation for this research question was substantially the same as equation (2). However, in both instances, simple regression analysis was conducted first (without including additional covariates) to allow us to compare the unique correlations of BIS with teacher influence [equation (2)] and year of implementation with teacher influence [equation (3)]. The regression model used to examine the relationship between PLC implementation and teachers' perceptions of their involvement in decision-making was as follows.

Teacher influence $=\beta_{0}+\beta_{1}$ Year 2 of PLC implementation + 
$\beta_{2}$ Year 3 of PLC implementation $+\beta_{3}$ Year 4 of PLC implementation $+\beta_{4} P L C$

Implementation $+\beta_{5}$ School size $+\beta_{6} \%$ Minority students $+\beta_{7}$ Average $\%$ attendance + $\beta_{8} \%$ students on F/R lunches $+\beta_{9}$ English MPI $+\beta_{10}$ Math MPI $+\beta_{12}$ Expenditures per $A D A+\beta_{12}$ Middle school grade configuration $+\beta_{13}$ High School grade configuration + $\beta_{14}$ Urban setting $+\varepsilon_{i}$

Here, the outcome, as in the second research question, was the average building-level numerical score associated with teachers' perceptions of their involvement in decisionmaking, this time using year of implementation as the predictor variable. The intercept, $\beta_{0}$, represented the expected value of teacher influence when all predictors were zero. Specifically, it represented the teacher influence in a rural elementary school in its first year of participation in MO PLC with no students, $0 \%$ minority, $0 \%$ attendance rate, $0 \%$ of students on free or reduced lunches, MPI's of 0 in math and English, and $\$ 0$ expenditures per ADA. The coefficient, $\beta_{l}$, was the expected change in teacher influence when the predictor, year of implementation of PLC reforms, increased by one unit (i.e., year 2 of PLC implementation), holding all other predictors constant. Similarly, $\beta_{2}$ was the expected change in teacher influence for schools in their third year of PLC implementation, and $\beta_{3}$ was the expected change in teacher influence for schools in their fourth (or greater) year of PLC implementation.

\section{Results}

Descriptive information for each of the teacher decision-making categories on the MO PLC Teacher Influence Survey is provided in Table 10. Table 11 summarizes the correlations 
Table 10

Descriptive Statistics for MO PLC Teacher Influence Survey Items

\begin{tabular}{lrrrr}
\hline Decision-Making Category & \multicolumn{1}{c}{ Min. } & \multicolumn{1}{c}{ Max. } & \multicolumn{1}{c}{ Mean } & Std. Dev. \\
\hline Hiring & 1.20 & 4.00 & 2.34 & 0.710 \\
Spending discretionary funds & 1.00 & 3.50 & 1.96 & 0.549 \\
Book selection & 1.67 & 4.00 & 3.25 & 0.491 \\
Curriculum & 1.78 & 4.00 & 3.38 & 0.510 \\
Content of in-service & 1.50 & 4.00 & 2.67 & 0.529 \\
Student behavior standards & 2.00 & 4.00 & 3.06 & 0.485 \\
\hline
\end{tabular}

among the variables of interest. BIS was significantly correlated with math achievement scores $(\mathrm{p}<.05)$, expenditures per student $(\mathrm{p}<.01)$, configuration $(\mathrm{p}<.01)$, and setting (rural v. urban, $\mathrm{p}<.05$ ). Teacher influence in decision-making was significantly related to percentage of students on free/reduced lunches $(\mathrm{p}<.01)$. School size was significantly related to attendance $(\mathrm{p}<.01)$, expenditures per student $(\mathrm{p} .<.01)$, and setting (rural v. urban, p. <.01). Minority percentage was significantly related to setting (rural v. urban, $\mathrm{p}<.01)$. In addition to school size, attendance was significantly related to math achievement scores $(\mathrm{p}<.01)$ and configuration $(\mathrm{p}<.01)$. In addition to teacher influence on decision-making, percentage of students on free/reduced lunch was significantly related to English/language arts achievement scores $(\mathrm{p}<.01)$, math achievement scores $(\mathrm{p}<.01)$, and setting (rural v. urban, $\mathrm{p}<.01)$. In addition to the relationships already noted, configuration was also significantly related to math achievement scores $(\mathrm{p}<.05)$. Because these correlations represent pairwise relationships and do not control for other factors that may be influencing teacher influence, they must be interpreted with caution. Prior to performing regression analysis, the data was examined for standard regression assumptions. A histogram of regression standardized residuals showed even distribution, confirming multivariate normality. The probability-probability plot of 
Table 11

Descriptive Statistics and Correlations

\begin{tabular}{|c|c|c|c|c|c|c|c|c|c|c|c|c|c|c|}
\hline & Mean & Median & SD & 1 & 2 & 3 & 4 & 5 & 6 & 7 & 8 & 9 & 10 & 11 \\
\hline 1. BIS & 85.794 & 88.500 & 13.260 & & & & & & & & & & & \\
\hline $\begin{array}{l}\text { 2. Mean } \\
\text { influence }\end{array}$ & 2.768 & 2.747 & .408 & -.010 & & & & & & & & & & \\
\hline 3. Size & 322.137 & 282.000 & 172.497 & .194 & -.090 & & & & & & & & & \\
\hline 4. $\%$ Minority & 12.640 & 7.100 & 17.263 & .071 & -.056 & .141 & & & & & & & & \\
\hline 5. Attendance & 90.195 & 91.100 & 4.437 & .210 & .154 & $-.410^{\mathrm{b}}$ & .019 & & & & & & & \\
\hline 6. $\% \mathrm{~F} / \mathrm{R}$ & 55.675 & 53.400 & 21.577 & .010 & $-.321^{b}$ & -.209 & .004 & -.048 & & & & & & \\
\hline 7. Engl/LA & 357.423 & 360.700 & 30.417 & .030 & .154 & .037 & -.147 & .069 & $-.412^{b}$ & & & & & \\
\hline 8. Math & 329.872 & 328.000 & 41.436 & $.287^{\mathrm{a}}$ & .147 & .048 & -.111 & $.396^{\mathrm{b}}$ & $-.338^{b}$ & $.764^{b}$ & & & & \\
\hline $\begin{array}{l}\text { 9. Expend/ADA } \\
10 .\end{array}$ & 9905.96 & 9500.07 & 1539.43 & $-.320^{b}$ & .075 & $-.309^{b}$ & .105 & $\begin{array}{r}.093 \\
-\end{array}$ & .039 & -.191 & -.223 & & & \\
\hline Configuration & & & & $-.361^{b}$ & .008 & .023 & -.228 & $.374^{\mathrm{b}}$ & -.171 & .102 & $-.253^{\mathrm{a}}$ & .153 & & \\
\hline 11. Year & & & & .232 & .045 & .047 & 1.018 & .123 & .000 & -.001 & .113 & -.130 & -.088 & \\
\hline 12. Rural/Urban & & & & $.257^{\mathrm{a}}$ & .092 & $.593^{\mathrm{b}}$ & $.393^{\mathrm{b}}$ & -.037 & $-.365^{b}$ & .186 & .208 & -.225 & -.224 & -.040 \\
\hline
\end{tabular}


observed probability versus theoretical probabilities revealed no extreme deviations from linearity. Regression standardized residuals were plotted against the regression standardized predicted values to examine for equal variances and homogeneity; observations were equally distributed across the regression line. Analysis for multicolinearity generated no VIF values of 10 or greater, indicating no significant multicollinearity. Thus, the data satisfied expectations for independent observations, normality, linearity, homogeneity of errors, and multicollinearity.

Results of regression analysis are shown in Tables 12-14. Table 12 results address research question 1: Is the number of years of participation in the MO PLC organization related to PLC implementation? The simple regression model shows that none of the implementation years is significantly related to PLC implementation (BIS score), with $84\left(\beta_{0}\right)$ the expected value of BIS for year 1 (Y1) schools when all other predictors are zero. None of the correlations for year of PLC implementation (Y2, Y3, and Y4) were statistically significant ( $p>.05$ ). In the multiple regression model, there was no significant predictor of PLC implementation.

Table 13 results address research question number 2: Is the degree of implementation of PLC related to teacher involvement in decision-making? The simple regression model shows that PLC implementation is not significantly related to teacher influence, with $2.8\left(\beta_{0}\right)$ the expected value of teacher's perception of their decisionmaking involvement (2 reflecting "a little" involvement and 3 reflecting "some" involvement) when all other predictors are zero. Analysis indicates that there is 0.000 change on teacher influence when the BIS score increases by 1 point, but this was not a 
Table 12

Regression Analysis for Year of MO PLC Participation on PLC Implementation

\begin{tabular}{|c|c|c|c|c|c|c|}
\hline \multirow{3}{*}{ Model } & \multicolumn{3}{|c|}{ Simple Regression Model } & \multicolumn{3}{|c|}{ Multiple Regression Model } \\
\hline & \multicolumn{2}{|c|}{$\begin{array}{l}\text { Unstandardized } \\
\text { Coefficients }\end{array}$} & \multirow[t]{2}{*}{ Sig. } & \multicolumn{2}{|c|}{$\begin{array}{c}\text { Unstandardized } \\
\text { Coefficients } \\
\end{array}$} & \multirow[t]{2}{*}{ Sig. } \\
\hline & $\mathrm{B}$ & Std. Error & & $\mathrm{B}$ & Std. Error & \\
\hline (Constant) & 84.000 & 3.357 & 0.000 & 76.548 & 56.891 & 0.185 \\
\hline $\mathrm{Y} 2$ & -2.938 & 4.672 & 0.532 & -0.379 & 5.136 & 0.941 \\
\hline Y3 & 2.190 & 4.395 & 0.620 & 5.020 & 4.498 & 0.270 \\
\hline Y4 & 7.687 & 4.672 & 0.105 & 3.991 & 5.171 & 0.444 \\
\hline Size & & & & 0.005 & 0.015 & 0.760 \\
\hline$\%$ Minority & & & & 0.004 & 0.106 & 0.967 \\
\hline Attendance & & & & 0.182 & 0.533 & 0.735 \\
\hline$\% \mathrm{~F} / \mathrm{R}$ & & & & 0.035 & 0.091 & 0.700 \\
\hline Engl/LA & & & & -0.119 & 0.108 & 0.274 \\
\hline Math & & & & 0.122 & 0.087 & 0.163 \\
\hline Exp/ADA & & & & -0.001 & 0.001 & 0.243 \\
\hline Middle & & & & 0.584 & 4.967 & 0.907 \\
\hline HS & & & & -4.779 & 5.020 & 0.346 \\
\hline Rural/Urban & & & & 2.987 & 5.526 & 0.591 \\
\hline
\end{tabular}

statistically significant finding. In the multiple regression model, there is no significant predictor of teacher influence.

The results in Table 14 address research question number 3: Is the number of years of participation in the MO PLC organization related to teacher decision-making influence? The simple regression model shows that none of the implementation years is significantly related to teacher influence, with $2.68\left(\beta_{0}\right)$ the expected value of teacher influence for year 1 (Y1) schools when all other predictors are zero. In this model, 0.01, 0.24 , and -0.04 were the expected changes in the average teacher influence rating when a school reached the end of its second, third, and fourth year of PLC implementation, respectively, but none of these findings were statistically significant. In the multiple regression model, there was no significant predictor of PLC implementation. (Note that 
Table 13

Regression Analysis for PLC Implementation on Teacher Influence

\begin{tabular}{|c|c|c|c|c|c|c|}
\hline \multirow{3}{*}{ Model } & \multicolumn{3}{|c|}{ Simple Regression Model } & \multicolumn{3}{|c|}{ Multiple Regression Model } \\
\hline & \multicolumn{2}{|c|}{$\begin{array}{l}\text { Unstandardized } \\
\text { Coefficients }\end{array}$} & \multirow[t]{2}{*}{ Sig. } & \multicolumn{2}{|c|}{$\begin{array}{l}\text { Unstandardized } \\
\text { Coefficients }\end{array}$} & \multirow[t]{2}{*}{ Sig. } \\
\hline & $\mathrm{B}$ & Std. Error & & $\mathrm{B}$ & Std. Error & \\
\hline (Constant) & 2.769 & 0.332 & 0.000 & 1.242 & 1.797 & 0.493 \\
\hline BIS & 0.000 & 0.004 & 0.935 & 0.000 & 0.005 & 0.979 \\
\hline Size & & & & $-5.176 \mathrm{E}-06$ & 0.000 & 0.989 \\
\hline$\%$ Minority & & & & -0.002 & 0.003 & 0.542 \\
\hline Attendance & & & & 0.016 & 0.017 & 0.333 \\
\hline$\% \mathrm{~F} / \mathrm{R}$ & & & & -0.007 & 0.003 & 0.019 \\
\hline Engl/LA & & & & 0.000 & 0.003 & 0.895 \\
\hline Math & & & & 0.001 & 0.003 & 0.735 \\
\hline Exp/ADA & & & & $8.380 \mathrm{E}-06$ & 0.000 & 0.833 \\
\hline Y2 & & & & 0.211 & 0.163 & 0.201 \\
\hline Y3 & & & & 0.289 & 0.146 & 0.053 \\
\hline Y4 & & & & 0.013 & 0.162 & 0.937 \\
\hline Middle & & & & 0.161 & 0.159 & 0.316 \\
\hline HS & & & & 0.069 & 0.156 & 0.662 \\
\hline Rural/Urban & & & & 0.023 & 0.18 & 0.898 \\
\hline
\end{tabular}

the multiple regression model in this analysis contains the same variables as the multiple regression shown in Table 12, explaining why both tables contain the same information, just in different order based on the arrangement of the variables in the respective tables.)

\section{Discussion}

Participatory management theory (discussed above in the Theoretical Framework and Research Questions section) describes the importance of engaging all members of an organization or organizational division in jointly identifying its vision, goals, and strategies, and involving them in key areas of decision-making. Considerable educational research attests to the positive effects of involving teachers in the decision-making model (Linder et al., 2012; Louis \& Marks, 1998; Sigurðardóttir, 2010; Thompson et al., 2004). 
Table 14

Regression Analysis for Year of MO PLC Participation on Teacher Influence

\begin{tabular}{|c|c|c|c|c|c|c|}
\hline \multirow{3}{*}{ Model } & \multicolumn{3}{|c|}{ Simple Regression Model } & \multicolumn{3}{|c|}{ Multiple Regression Model } \\
\hline & \multicolumn{2}{|c|}{$\begin{array}{l}\text { Unstandardized } \\
\text { Coefficients }\end{array}$} & \multirow{2}{*}{ Sig. } & \multicolumn{2}{|c|}{$\begin{array}{l}\text { Unstandardized } \\
\text { Coefficients }\end{array}$} & \multirow{2}{*}{ Sig. } \\
\hline & $\mathrm{B}$ & Std. Error & & $\mathrm{B}$ & Std. Error & \\
\hline (Constant) & 2.678 & 0.108 & 0.000 & 1.242 & 1.797 & 0.493 \\
\hline $\mathrm{Y} 2$ & 0.009 & 0.151 & 0.955 & 0.211 & 0.163 & 0.201 \\
\hline Y3 & 0.236 & 0.140 & 0.098 & 0.289 & 0.146 & 0.053 \\
\hline Y4 & -0.045 & 0.153 & 0.772 & 0.013 & 0.162 & 0.937 \\
\hline BIS & & & & 0.000 & 0.005 & 0.979 \\
\hline Size & & & & $-5.176 \mathrm{E}-06$ & 0.000 & 0.989 \\
\hline$\%$ Minority & & & & -0.002 & 0.003 & 0.542 \\
\hline Attendance & & & & 0.016 & 0.017 & 0.333 \\
\hline$\% \mathrm{~F} / \mathrm{R}$ & & & & -0.007 & 0.003 & 0.019 \\
\hline $\mathrm{Engl} / \mathrm{LA}$ & & & & 0.000 & 0.003 & 0.895 \\
\hline Math & & & & 0.001 & 0.003 & 0.735 \\
\hline Exp/ADA & & & & $8.380 \mathrm{E}-06$ & 0.000 & 0.833 \\
\hline Middle & & & & 0.161 & 0.159 & 0.316 \\
\hline HS & & & & 0.069 & 0.156 & 0.662 \\
\hline Rural/Urban & & & & 0.023 & 0.18 & 0.898 \\
\hline
\end{tabular}

Shared leadership and shared decision-making is a defining characteristic of PLC

(DuFour, Eaker, \& DuFour, 2005; Rosenholtz, 1989; Roy \& Hord, 2006). Clark \& Clark (2002) specifically state that teacher collaboration, another defining characteristic of PLC, leads to involving teachers in significant $\mathrm{v}$ about programs. In light of this, finding no significant relationship between PLC implementation and teacher influence in this study was unexpected.

Research suggests several reasons for the findings of the current study. Short \& Greer (1989) examined teacher participation in decision-making in several specific areas (budgets, teacher selection, scheduling, curriculum, other programmatic areas) and found that, in order for teacher involvement in decision-making to happen, teachers must 
believe that their involvement is genuine and that their opinion has critical impact in the outcome of the decision. Grindle (1982) made the same finding: "It is important to emphasize that simply having a voice in decision-making is meaningless unless each team perceives the involvement as genuine and important. Teachers... must perceive their roles as being important and as having a significant impact on the decision outcomes" (p. 31). Somech (2010) identified the following as a central properties of participatory decision-making: “...the role of the involved parties is more than advisory: They have the right to make, or heavily influence, the final decision" (p. 177). In his qualitative study on particpatory decision-making in South African schools, Mokoena (2011) observed that teachers questioned whether or not their involvement in decisionmaking was genuine: "They [the teachers] had to weigh up whether it meant real changes in having a say in the school" (p. 127). He noted that teachers' perception on this issue impacted their involvement in decision-making processes. Benson and Malone (1987) determined that teachers' reluctance to take advantage of decision-making opportunities was related to their awareness that involvment in decision-making "did not bring meaningful influence in decision-making" (p. 250). Although not research-based, a perusal of online blogs also reflects this sentiment. In his February 24, 2013 post (http://jaxkidsmatter.blogspot.com/2013/02/john-meeks-danger-of-professional.html), John Louis Meeks, Jr. states, "Many administrators use the PLC movement as a guise under which they can mandate conformity among their faculty." In another blog post (https://www.cultofpedagogy.com/plc-problems/), Chase Mielke voices a similar sentiment: "To put it in classroom terms, too many administrators treat PLCs more as homework than project-based learning. If you want us to simply do your bidding, call it a 
committee, not a PLC.” In summary, teachers' perceptions of their involvement as genuine and meaningful is critical to their decision to take advantage of decision-making opportunities. The absence of a measure of the genuine involvement of teachers in decision-making as a variable in the current study could explain the failure to find a relationship between PLC implementation and teacher influence.

One of the defining characteristics of a PLC is supportive and shared leadership in which administrators are committed to sharing decision-making with teachers (DuFour, Eaker \& DuFour, 2005; Rosenholtz, 1989; Roy \& Hord, 2006). These authors cite distributed leadership as a necessity in order to build an effective PLC. Similarly, research by Odden and Wohlstetter (1995) and Wohlstetter, et al. (1994) demonstrated the critical importance of principals' leadership in determining if teacher involvement in decision-making will impact student achievement and in developing visions, setting goals, and establishing high expectations. Murphy (1994) identified facilitating groups, directing group processes, and managing change processes as necessary skills for principals in schools where shared decision-making is occurring. Bird et al. (2009) found that the authenticity of the school principal has a significant positive correlation on the levels of trust and engagement among teachers. All of this research suggests that the role of the principal has a significant influence on teachers' involvement in decision-making, making it reasonable to infer that principals' leadership skills could have significant influence on the degree to which teachers are involved in decision-making. Smylie and Denny (1990) found that teachers willingness to participate in shared decision-making processes in schools was influenced primarily by their relationships with their principals; that teachers were more willing to participate if they perceived their relationships with 
their principals as "more open, collaborative, facilitative and supportive," and less willing if those relationships were characterized as "closed, exclusionary, and controlling" (p. 63). Streck (2009), studying the impact of leadership practices and shared decisionmaking in schools, identified the two most frequently mentioned practices that needed improvement as establishing a trusting environment and maintaining open lines of communication. The literature cited above suggests that the leadership of the principal or the extent to which distributed leadership systems are in place are critical to teachers' willingness to participate in decision-making opportunities. The current study did not include a measure of distributed leadership, which could explain why no relationship was found between PLC implementation and teacher influence.

In addition to individual principal's leadership skills, it is certainly possible that district-level leadership could be inhibiting the process of teacher empowerment. Leech (2019) concluded that "individual leadership behaviors of school principals may have less influence on the decision-making culture than the organizational structure and culture of the schools and school district" (pp. xiii-xiv). One can readily speculate that the organizational structure and culture Leech describes refers to the pressure applied by central office administration or Boards of Education directly on building principals to exercise more autocratic leadership styles. Geraci (1996) attributes part of the responsibility of the failure of decentralizing decision-making in Rochester, NY schools to school board policy "placing far too many restrictions on schools for them to be very creative," and indicates that teachers "can get in a good deal of trouble if [they] challenge the wrong authority" (p. 51). Lindle (1995), reviewing several years of implementing school School-Based Decision-Making (SBDM) Councils in Kentucky, made the 
following observation about decisions concerning curriculum, staff assignment, student assignment, school schedules, instructional practices, disipline, extracurricular programs, and alignment with state standards.

Because decisions in these areas epitomize the essential issues of educating students, they are sources of contention... between schools and district personnel. A few school boards have even taken their disputes over local control to court. At some schools, councils have "delegated" these decisions back to the principals, thus preserving the status quo. In effect, the superintendent and the board, by working through the principal, maintain their influence over the building (p. 21). Lindle also reported instances in which central office personnel, superintendents, or school boards simply blocked the decisions of SBDM Councils. Through budget processes, staffing decisions, and through the process of approving building schedules, central office administration and Boards of Education wield significant power over all aspects of school district operations, including the general process of PLC implementation and specific efforts to incorporate teachers in decision-making processes to a greater degree, and the exercise of that power could be impacting PLC implementation.

Each of the considerations above shares the underlying assumption that, if done correctly, PLCs should be related to increased teacher involvement in decision-making. This is reflected in the literature which invariably offers a number of common reasons for PLC failure: Insufficient access to data, lock of scheduled time for teacher collaboration, lack of teacher buy-in, lack of teacher ownership, and a competitive (as opposed to collaborative) building culture, leadership failure (DuFour \& Reeves, 2015; Provini, 
2013). Provini (2013) makes the claim that the "potential of PLCs is well documented" (https://www.educationworld.com/a_admin/professional-learning-community-pitfallsbest-practices.shtml). Determining the effectiveness of a reform movement, however, requires evidence. Research on the efficacy of PLCs is not universally positive. Shetzer (2011) found no correlation between teachers' self-efficacy beliefs and dimensions of PLC. He followed up that survey data with a phenomenological qualitative design to create a composite description of teachers' experiences with PLC and documented a sense of frustration, lack of vision and direction, and a lack of collaboration. A number of studies have found the reported effects of PLCs on student achievement to be small or non-existent (Andrews \& Louis 2007; Burns, et al, 2014; Sigurðardóttir, 2010; Smylie et al., 1996; Stewart, 2014). Even positive results must be interpreted with caution: Louis and Marks (1998) document that students in schools with PLC achieved at high levels, but found the beneficial influence "proved to be explained by authentic pedagogy at the technical core of the classrooms within these schools" (p. 558) and not directly attributable to PLC. These equivocal results on various aspects of PLC suggest another interpretation of the findings of the current study: PLCs do not influence teacher leadership.

\section{Implications for Future Research}

The results of this study suggest a number of follow-up studies that could help shed light on the lack of a relationship between PLC implementation and teachers' perceptions of being involved in decision-making. The work of Short \& Greer (1989) suggests the importance of teachers' perceptions about whether or not their involvement in decision-making is genuine. Grindle (1982) made the same finding: "It is important to 
emphasize that simply having a voice in decision-making is meaningless unless each team perceives the involvement as genuine and important. Teachers... must perceive their roles as being important and as having a significant impact on the decision outcomes" (p. 31). Bird et al. (2009) found that the authenticity of the school principal has a significant positive correlation on the levels of trust and engagement among teachers. Given the important role of the building principal's leadership style on teacher's beliefs about the authenticity of their involvement in decision-making reflected in the above studies, a study that identified the leadership styles of principals of MO PLC schools to see if there was a relationship between leadership style and scores on the MO PLC Implementation Survey could shed light on the results of the current study. A qualitative research design could also uncover influences coming from the Central office administration or Boards of Education.

Additionally, one could explore the issue of geniuneness of participation. While we couldn't locate any studies utilizing a survey instrument to gather this information, Aston and Lambert (2010) utilized a qualitative research design to explore young people's views about how best to achieve their genuine involvement in educational decision-making which could be applied to the current study. Aston and Lambert used focus groups and asked three questions: "What would it look like if young people's views were fully included in all decision-making?, What are the barriers that make this difficult at the moment?, What steps could be taken to overcome these barriers?" (p. 43). One could modify these questions to reflect a focus on teachers in PLCs, select schools from the 76 that participated in the current study, and present these questions to focus groups of teachers from those buildings to develop a valid measure of genuine 
participation. It would be important to add a fourth question, "Do you feel that your involvement in school wide decision-making is genuine?" Additional questions could be added to direct discussions towards the decision-making areas investigated in the current study by asking the question, "Do you feel that your involvement in decisions about is genuine?" and filling in the gap with "hiring new professional personnel," "planning how discretionary school funds should be used," "determining books and other instructional materials used in classrooms," "establishing the curriculum and instructional program," "determining the content of in-service programs," and "setting standards for student behavior," respectively. Given the volume of research already in existence on the importance of teachers feeling that their involvement is genuine, one could consider developing items to add to the MO PLC Teacher Influence survey to measure this construct directly. That would allow "genuine involvement" to be included as a covariate in the study. It would also allow one to conduct separate analyses of teachers based on their score on this measure.

\section{Limitations}

In spite of several steps taken to increase the return rate on the MO PLC Teacher Influence Survey (see description in the Methodology section above), a higher return rate would have served this study well. When the BAT was administered in the spring of 2019, 1,551 surveys were returned for Year 1 schools; 1,268 surveys were returned for Year 2 schools; 1,038 surveys were returned for Year 3 schools; and 1,869 surveys were returned from Year 4 (Continuing and Sustaining) schools, for a total of 5,726 surveys. The number of MO PLC Teacher Influence Surveys returned were as follows: Year 1205; Year 2-281; Year 3-302; Year 4 (Continuing and Sustaining) -319. The total 
number of MO PLC Teacher Influence Surveys returned was 1,107. Compared to responses on the BAT, the return rate for the MO PLC Teacher Influence Survey was: Year 1-13.2\%; Year 2-22.1\%; Year 3-29.1\%; Year 4-17.1\%; for an overall return rate of $19.3 \%$ compared to the return rate for the same sample of teachers. The voluntary nature of this survey seems to be an obvious explanation for the lower response rate. When arranging to receive resources from the MO PLC, participating schools give assurance of their intention to participate in the annual BAT. That assurance did not extend to the MO PLC Teacher Influence Survey. The BAT is administered during the spring; the MO PLC Teacher Influence Survey was administered at the end of September. Although the Director of the MO PLC program graciously distributed the MO PLC Teacher Influence Survey with wording similar to that of the BAT, there was no concealing the fact that the MO PLC Teacher Influence Survey was not a required component of involvement in the MO PLC program. Including the questions from the MO PLC Teacher Influence Survey with the BAT (or as an attached supplement to the BAT) may have made a significant difference in the response rate.

In addition to concerns about the return rate on the MO PLC Teacher Influence Survey, the questions themselves may impact the findings of the study: It is possible that the decision-making categories reflected on the survey may not be related to teacher influence in ways addressed by PLC implementation. Some support for this possibility is suggested by the descriptive data in Table 10 . The variance in the scores might be explained if the categories with higher mean scores (e.g., choice of curriculum, textbook selection, and establishing student behavior standards) are more closely related to decision-making issues one encounters when implementing PLCs. An additional analysis 
of these questions is offered in Appendix G, which provides regression analyses of PLC implementation on each of the categories separately. Although none demonstrated a significant relationship with PLC implementation, more research needs to be done to investigate the kinds of decision-making issues that are most closely related to PLC implementation.

Additional considerations affect the generalizability of the current study. Field (2013) defines generalizability in terms of drawing conclusions beyond the sample in a research study. The current study included only Missouri schools, which limits its generalizability to the State of Missouri. Another consideration concerning generalizability is sample size. Field (2008) gives as a rule of thumb that there should be between 10 and 15 cases of data for each predictor in a research model. Surveys were received from a total of 76 MO PLC schools (38\% of all schools participating in MO PLC). With one predictor variable in each research question, that corresponds to an $\mathrm{R}$ value of $1 /(73-1)$ or 0.014 , well within the benchmark for a small effect size (Field, 2013). This would suggest that the sample in the current study is sufficient to allow a generalization to other Missouri PLC schools not included in the study. The overall response rate on the survey must also be considered. Using the total number of BAT surveys returned in the spring of $2017(5,726)$ as an estimate of the total number of teachers in MO PLC schools, the response rate on the MO PLC Teacher Influence Survey was $1107 / 5726=19.3 \%$. It is difficult from the research to determine if this is large enough return rate to support generalization of the results of this study to the population of MO PLC schools. The American Association for Public Opinion Research (AAPOR) in an online post titled, "Response Rates-An Overview 
(https://www.aapor.org/Education-Resources/For-Researchers/Poll-Survey-

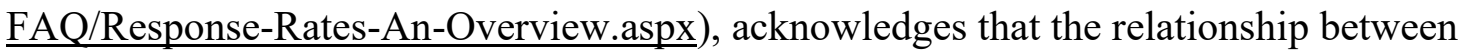
response rates and survey quality are much less clear than they have been historically, undermining the role of the response rate as the main criterion of survey quality. The AAPOR cites two reasons for this: Increasing refusals across all modes of survey administration, and increasing costs associated with additional efforts being made in survey administration. Visser, Krosnick, Marquette, and Curtin (1996) concluded that viewing "a high response rate as a necessary condition for accuracy is not necessarily sensible, nor is the notion that a low response rate necessarily means low accuracy" (p. 216). One can still get a sense of the comparative return rate from the current study by comparing it to an average survey response rate. Lindemann (2018, at https://surveyanyplace.com/average-survey-response-rate/) indicates that the overall average survey response rate is $33 \%$ for all methods. Email surveys have an average response rate of $30 \%$. Compared to these numbers, the return rate of the current study is low and constitutes a limitation.

The timing of the survey gives rise to another limitation in this study. Both the BAT and the MO PLC Teacher Influence Survey are collecting perceptual data. This study compared teachers' perceptions as reported on the BAT in March and April to their perceptions as reported on the MO PLC Teacher Influence Survey in September and October. Although this is a matter of a few weeks on the 9-month academic calendar, it reflects several months on the 12-month yearly calendar. It also represents the difference between the end of one school year and the beginning of another. To the extent that teachers' attitudes in March and April of one year are different than their attitudes in 
September and October of the subsequent year, this could lead to variations in the data. Other issues related to the use of self-report surveys were addressed previously in the Introduction section.

Several limitations fall under the general category of personnel. As was mentioned above in the Conclusions section, central office administration and Boards of Education exert a great deal of influence over activities in school buildings within a district. Although one might assume that in order to gain approval for their buildings to participate in the MO PLC organization, a building principal would first secure the blessings of the central office and the Board of Education, that might not be universally true. Further, since participation spans several years, it is possible that changing attitudes or changing personnel in the central office or on a Board of Education could result in a change in the support for this initiative. Similarly, anything that might cause a change in building-level instructional staff-either a large turnover of teachers or a small turnover of influential teachers - could impact the overall attitude of a building to change in general and to PLC implementation in particular. This is especially true concerning the role of the building principal: Horton (2009) observed that PLC is most successful "when it... becomes institutionalized so that when a leader leaves, the process continues" (p. 103). Data were not available to indicate which buildings in the MO PLC organization had experienced changes in principals at some point during their participation. One might expect that the search process for a new principal for a building involved in PLC implementation would place a priority on finding a candidate capable of picking up the PLC implementation process where the previous principal left off. There was no available evidence to evaluate that assumption. 
Care must be taken when making comparison of BIS scores between schools in different implementation year cohorts. BIS scores were designed to provide longitudinal feedback to schools on their PLC implementation progress: Schools are able to compare BIS scores year-to-year as they progress through the MO PLC implementation process as one measure of their progress. In the current study, we collected only current year BIS scores. This cross-sectional data limits our interpretation of the BIS data. It is true that one could compare BIS scores between two schools and draw comparisons about the degree to which each school had implemented PLC. It is not, however, possible from the cross-sectional data provided in the current study to draw any conclusions about the progress being made by each school. To make this inference would require knowledge of the BIS from at least the previous year. For this same reason, one cannot draw any conclusions about PLC implementation between implementation year cohorts: Doing so would require all schools in each implementation cohort to start with a common baseline BIS, which is not reflected in the data. This limitation prevents any measurement of longitudinal progress in PLC implementation, which could explain the lack of findings between year of implementation and BIS.

The use of the BAT as the source of data from which the BIS was calculated is limited to the degree that it reflects accepted PLC frameworks. Table 6 in the Methods section listed each of the 15 questions from the BAT and cross referenced them to existing PLC frameworks. Although there were areas of overlap, there was not a complete correspondence between the questions and the frameworks. While all survey items reflected some element of at least one of the three PLC frameworks, there were salient omissions. "How is shared decision-making encouraged in your building," can 
only be found in Roy \& Hord (2006) as "supportive \& shared leadership." Neither Roy and Hord's (2006) “supportive conditions" nor Louis, Marks, and Kruse's (1996) "deprivatized practice" were referenced by any of the survey items. This raises a question about the validity of the BIS as an accurate representation of the implementation of PLC: It is possible that a study using a PLC implementation measure based entirely on any one of the frameworks may have yielded different results.

Finally, because the statistical analysis utilized in this study examined correlational relationships, it is important to acknowledge that no causal relationships can be conferred. Field (2013) describes correlational research (also referred to as crosssectional research) as an observation of what is naturally occurring in the world without directly interfering with it. That is contrasted with experimental research, in which natural events are manipulated. Price, Jhangiani, and Chiang (adapted by the Saylor Foundation without attribution) defined correlational research as "a type of nonexperimental research in which the researcher measures two variables and assesses the statistical relationship (i.e., the correlation) between them with little or no effort to control extraneous variables” (p. 130). Bleske-Rechek, Morrison, and Heidtke (2015) observed that humans have a tendency to "conflate correlation with causation" (p. 49), although they went on to acknowledge that, in social science research, the distinction between the two is not obvious. An interesting example of this is provided by Baumeister, Campbell, Krueger, and Vohs (2003), who found that it was easier for individuals to assume that self-esteem enhances high academic performance than to assume the opposite (that high academic performance results in increased self-esteem). Their data indicated that much of the incorrect inference of causation resulted from 
associations that coincided with their preconceived notions. Price et al. (adapted by the Saylor Foundation without attribution) listed two reasons for conducting a correlational study instead of an experiment: The researcher does not believe the relationship is causal, and the researcher cannot manipulate the independent variable. In the current study, both of these reasons apply and it is not, therefore, possible to infer causality (or the lack of it) from the data. 


\section{Appendices}

\section{Appendix A}

Survey Items from the UChicago Consortium on School Research 5Essentials School Reports Survey

Items

How much influence do teachers have over school policy in each of the areas below?

Hiring new professional personnel

Planning how discretionary school funds should be used

Determining books and other instructional materials used in classrooms

Establishing the curriculum and instructional programs

Determining the content of in-service programs

Setting standards for student behavior 


\section{Appendix B}

\section{MO PLC Teacher Influence Survey}

1. Please choose your region.

- Southeast (Cape Girardeau)

- Heart of Missouri (Columbia)

○ Kansas City

- Northeast (Kirksville)

- Northwest (Maryville)

- South Central (Rolla)

○ Southwest Agency for Teaching, Leading and Learning (Springfield)

$\circ$ EdPlus (St. Louis)

$\circ$ Central (Warrensburg)

2. Choose your [name of region] area school. [Pull-down menu of all schools in the region]

3. What is your primary role?

$\circ$ Building administrator

- General education teacher

- Special education teacher

○ Other role

4. In your school, how much influence do teachers have over school policy in the area of HIRING NEW PROFESSIONAL PERSONNEL?

O None

- A little

- Some

$\circ$ A great deal

5. In your school, how much influence do teachers have over school policy in the area of PLANNING HOW DISCRETIONARY SCHOOL FUNDS SHOULD BE USED?

○ None

- A little

- Some

$\circ$ A great deal

6. In your school, how much influence do teachers have over school policy in the area of DETERMINING BOOKS AND OTHER INSTRUCTIONAL MATERIALS USED IN CLASSROOMS?
○ None
- A little
- Some
$\circ$ A great deal 
7. In your school, how much influence do teachers have over school policy in the area of ESTABLISHING THE CURRICULUM AND INSTRUCTIONAL PROGRAM?

○ None

○ A little

- Some

$\circ$ A great deal

8. In your school, how much influence do teachers have over school policy in the area of DETERMINING THE CONTENT OF IN-SERVICE PROGRAMS?
○ None
- A little
- Some
$\circ$ A great deal

9. In your school, how much influence do teachers have over school policy in the area of SETTING STANDARDS FOR STUDENT BEHAVIOR?

- None

- A little

- Some

$\circ$ A great deal 


\section{Appendix C}

The 5Essentials School Reports Survey has undergone extensive testing for validity and reliability. Individual-level reliabilities, reflecting the ratio of true variance to total variance, are calculated by Rasch analysis for each measure. The goal of Rasch analysis is to have twice as much true variation as error variation, which corresponds to a reliability above 0.8 . School level scores, which measure how reliably schools can be distinguished from each other on each measure, reflect the proportion of variation in the school means due to true variation among schools. These depend on a comparison of the consistency of a measure across respondents within a school to the overall distribution of responses as well as the number of respondents in the schools. The intra-class correlation (ICC) for each measure is estimated using hierarchical linear modeling and represents the proportion of the total variance due to differences between schools. As shown in Table 5, individual-level reliabilities ranged from 0.73 to 0.76 on the teacher survey measure for teacher influence. School-level reliability ranged from 0.72 to 0.80 , and ICC ranged from 0.26 to 0.31 (2014 My Voice, My School Survey Quality Profile Technical Report, p. 46).

Reliability, Intra-class Correlations, and Measure Response Rate by Grade Level

\begin{tabular}{cccccl}
\hline $\begin{array}{l}\text { Measure } \\
\text { Name }\end{array}$ & Grade Level & $\begin{array}{c}\text { Individual } \\
\text { reliability }\end{array}$ & $\begin{array}{l}\text { School-level } \\
\text { reliability }\end{array}$ & ICC & $\begin{array}{l}\text { Measure } \\
\text { response rate }\end{array}$ \\
\hline $\begin{array}{c}\text { Teacher } \\
\text { Influence }\end{array}$ & $\begin{array}{c}\text { Elementary } \\
(\mathrm{K}-8)\end{array}$ & 0.76 & 0.801 & 0.309 & $\begin{array}{l}8,203 / 8,663= \\
94.7 \%\end{array}$ \\
$\begin{array}{c}\text { Teacher } \\
\text { Influence }\end{array}$ & $\begin{array}{c}\text { High School } \\
(9-12)\end{array}$ & 0.73 & 0.719 & 0.256 & $\begin{array}{l}3,952 / 4,245= \\
93.1 \%\end{array}$ \\
\hline
\end{tabular}




\section{Appendix D}

Dear Administrator,

As part of our ongoing efforts to improve the PLC resources provided by DESE to Missouri schools, we are conducting one final survey of Missouri PLC schools.

\section{Click here for MO PLC Teacher Influence Survey}

This is a nine-item survey instrument designed to assess the relationship between the implementation of PLCs in your building and teachers' perceptions of their influence on decision-making. It should take less than two minutes to complete. A summary of the results will be shared with the MO PLC organization as well as you and your leadership team. It will provide valuable information about your ongoing efforts to make your school's PLC as effective as possible.

Please complete the survey yourself, then forward the email below to your leadership team and to all instructional staff who participate on collaborative PLC teams.

Robert L. Gordon, EdD

State Field Director, Missouri Professional Learning Communities, (573) 864-1555

COLLEGE OF EDUCATION

A College on the Move

Dear Educator,

Please follow the link below to complete the Missouri PLC Teacher Influence Survey. The survey is designed to assess the relationship between the implementation of PLCs in your building and teachers' perceptions of their influence on decision-making. It should take less than two minutes to complete. A summary of the results will be shared with the leadership team in your building and will provide valuable information about your ongoing efforts to make your school's PLC as effective as possible. Your answers are completely confidential. A copy of the informed consent document is attached for your information.

\section{Click here for MO PLC Teacher Influence Survey}

Robert L. Gordon, EdD

State Field Director, Missouri Professional Learning Communities, (573) 864-1555 
Appendix E

\section{The Relationship between Professional Learning Community Implementation and Teacher Decision-Making Influence}

What is the study about? You are invited to participate in a research study being conducted as part of the requirements of a doctoral thesis in Educational Leadership and Policy Analysis at the University of Missouri-Columbia. The researcher is interested in your opinions about the degree to which you are involved in decision-making at your school. In an effort to better understand the relationship between PLC implementation and the actual perceptions of teachers at PLC schools on how much they are involved in decision-making, teachers at all schools participating in the Missouri Professional Learning Community organization (MO PLC) are being asked to complete this nine-item survey. Results of the survey will be analyzed and included in the researcher's dissertation, and will also be shared with the administrative staff at MO PLC. They will also be made available to the principal at each participating PLC building.

The first three questions request demographic information (region, name of school, and primary role of the individual completing the survey). The next six questions require multiple choice Likert scale responses. It is estimated that the survey will take less than 2 minutes of your time.

The data collected in this study are anonymous and confidential. The data from the survey are not linked to an email address. Likert scale results will be reported to the MO PLC in aggregate form only. You can choose not to answer any question that you feel uncomfortable answering. Answers will benefit the respondent and the MO PLC by providing information to MO PLC about how participants perceive the degree to which they are involved in decision-making on important issues. There is no compensation for completing the survey. The research is being conducted by the following doctoral candidate, who can be contacted at any time through email and would be happy to answer any questions you have about the study.

\section{Mr. Mark Bowles, mabfz8@mail.missouri.edu}

Your participation in the study by answering the questions in the survey indicates that you understand the information above, that you agree to participate in this study, and that you give consent for your responses to be shared anonymously with the MO PLC. 
Appendix F

Survey Items from the Missouri PLC Implementation Survey 2017-18

\begin{tabular}{ll}
\hline Items & Response choices \\
\hline & The mission focuses on student learning and is \\
Choose the best descriptor & referred to regularly. \\
of your building's & The mission focuses on student learning, but is not \\
collaboratively developed & referred to nor reflected upon regularly. \\
mission. & The mission is in place, but doesn't specifically focus \\
& on student learning. \\
& We do not have a current mission statement. \\
& Our vision was collaboratively developed, is \\
& reviewed regularly, and we have commitments \\
& aligned to our vision. \\
& Our vision was collaboratively developed, is \\
& reviewed regularly, but we have not yet developed \\
Choose the best descriptor & commitments. \\
of your building's vision. & We have begun to collaboratively develop our vision. \\
& We have not yet begun to collaboratively develop our \\
vision. & Collaborative teams share ideas and resources for \\
problem-solving and decision-making within and \\
guilding level SMART
\end{tabular}$\quad \begin{aligned} & \text { across teams. } \\
& \text { Collaborative teams share ideas within teams, and } \\
& \text { members share ideas and resources to problem-solve. } \\
& \text { Choose the best descriptor } \\
& \text { of your building's }\end{aligned}$


Describe the level of trust in your team.

I believe that collaboration through teacher teams is improving the education we provide to all our students.

How is shared decisionmaking encouraged in your building?

Which best describes your collaborative team meetings.

Which best describes how your team uses meeting protocols such as roles, norms, timed agendas, minutes, schedules?
I am comfortable sharing my strengths and weaknesses about teaching and learning with all members of my team.

I am comfortable sharing my strengths and weaknesses about teaching and learning with most members of my team.

I am comfortable sharing my strengths and weaknesses about teaching and learning with some members of my team.

I do not feel comfortable sharing my strengths and weaknesses about teaching and learning with my team.

Yes, and this happens in my team.

Yes, and this happens to a limited extent in my team. Partially, but we have not yet made a noticeable impact on students.

No, teacher collaboration does not impact students. Collaborative teams directly contribute to decisionmaking about critical issues impacting instruction and directly contribute to plans for addressing those issues.

Input and feedback from staff is considered for critical decisions affecting collaboration and instruction.

Input and feedback from staff is regularly requested and used in non-critical issues, but infrequently in critical issues.

Staff has input only on non-critical issues (i.e., treats for teachers, event titles and duty rosters, etc.). Collaborative teams meet weekly during the contract day and are teacher-led, focusing on student learning and data-driven decision-making.

Collaborative teams use an organized structure, meeting at least twice per month during the contract day, with a minimum of guidance from the building leadership team.

Collaborative teams meet regularly outside of the contract day, with the building leadership team making decisions for all/most of the teams. Collaborative teams are not expected to meet on a regular basis.

Our team makes effective use of all meeting protocols.

Our team makes use of most meeting protocols. Our team makes use of some meeting protocols. Our team does not use meeting protocols. 
How do teachers participate in the identification of priority standards?

How does your team utilize identified priority standards?

Choose the best descriptor of your team.

I am a member of a collaborative team that uses student data to drive problem-solving and decisions.

As a team we collaboratively establish SMART goals and implement strategies and action plans based on student data. Choose the best descriptor of your team's use of SMART goals.
All teachers are directly involved in identifying priority standards for the subject areas they teach. Grade level /department representatives identify priority standards in our building/district. Priority standards are identified at the district level with little or no teacher involvement.

Priority standards have not been identified for what I teach.

Our team uses priority standards as the basis for determining our formative assessments on a regular basis.

Our team occasionally uses priority standards in determining formative assessments. (5) Priority standards are displayed and/or used occasionally by individual teachers.

Priority standards are not utilized in developing assessments.

My team collaboratively identifies instructional strategies which are aligned with priority standards and we are committed to implementing them. (7) My team collaboratively identifies instructional strategies, but they are not necessarily aligned to priority standards. (8)

My team discusses instruction, but we do not reach consensus on which strategies are best to implement. (9)

My team does not discuss instructional strategies.

My team routinely reviews student data to inform problem-solving and decisions.

My team tries to link student data to problem-solving and decisions.

My team does not link student data to problemsolving and decisions.

My team does not use student data in our meetings.

Our team has established SMART goals and action plans based on student data.

Our team has established SMART goals and uses action plans in a limited manner.

Our team has established SMART goals but has not developed action plans.

No, we haven't established SMART goals yet. 
What is the level of implementation of schoolwide tiered interventions?
School-wide implementation with review of targeted data points for all students.

Grade or course specific implementation with review of targeted data points for all students.

Limited implementation at the grade or course levels. No immediate steps or actions taken toward

implementation. 


\section{References}

Abbott, A. \& Wren, D. (2016). Using performance task data to improve instruction. The Clearing House, 89(1), 38-45.

Andrews, D. \& Lewis, M. (2007). Transforming practice from within: the power of the professional learning community. In: Professional learning communities:

divergence, depth and dilemmas. Professional Learning. Open University Press, Maidenhead, UK, pp. 132-147. ISBN 033522031

Aston, H. J. and Lambert, N. (2010). Young people's views about their involvement in decision-making. Educational Psychology in Practice, 26(1), 41-51.

Baumeister, R. F., Campbell, J. D., Krueger, J. I., \& Vohs, K. D. (2003). Does high selfesteem cause better performance, interpersonal success, happiness, or healthier lifestyles? Psychological Science in the Public Interest, 4, 1-44.

Benson, N. \& Malone, P. (1987). Teachers' beliefs about shared decision-making and work alienation. Education, 107(3), 244-251.

Berry, B., Johnson, D., \& Montgomery, D. (2005). The power of teacher leadership. Educational Leadership, 62(5), 56.

Berry, B, Wade, C., \& Trantham, P. (2008). Using data, changing teaching. Educational Leadership, 66(4), 80-84.

Bird, J. J., Wang, C., Watson, J. R., \& Murray, L. (2009). Relationships among principal authentic leadership and teacher trust and engagement levels. Journal of School Leadership, 19(2), 153-171.

Bleske-Recheck, A., Morrison, K. M., \& Heidtke, L. D. (2015). Causal inference from descriptions of experimental and non-experimental research: Public understanding 
of correlation-versus-causation. The Journal of General Psychology, 142(1), 4870.

Bolam, R., McMahan, A., Stoll, L., Thomas, S., and Wallace, M. (2005). Creating and sustaining effective professional communities (Research Report No. 637). London: General Teaching Council for England.

Brost. P. (2000). Shared decision-making for better schools. Principal Leadership (High School Ed.), 1(3), 58-63.

Bryk, A.S. (2010). Organizing schools for improvement. Phi Delta Kappan, 91(7), 23-30.

Bryk, A., Camburn, E. \& Louis, K.S. (1999). Professional community in Chicago elementary schools: Facilitating factors and organizational consequences. Educational Administration Quarterly, 35(Supplement), 751-781.

Bryk, A.S., Easton, J.Q., Kerbow, D., Rollow, S.G. \& Sebring, P.A. (1994).The state of Chicago school reform. Phi Delta Kappan, 76(1), 74-78.

Burns, M. K., Gordon, R. L., Naughton, M. R., Preast, J. L., Robb, V., Smith, M., Wang, Z. (2014). Factors of professional learning community implementation and effect on student achievement (Unpublished doctoral dissertation). University of Missouri, Columbia, MO.

Camburn, E., Han, S., \& Sebastian, J. (2017). Assessing the validity of an annual survey for measuring the enacted literacy curriculum. Educational Policy, 31(1), 73-107.

Carpenter, D. (2015). School culture and leadership of professional learning communities. International Journal of Educational Management, 29(5), 682-694. 
Clark, S. N. \& Clark, D. C. (2002). Collaborative decision-making: A promising but underused strategy for middle school improvement. Middle School Journal, 33(4), 52-57.

Conley, S. (1991). Review of research on teacher participation in school decisionmaking. Review of Research in Education, 17, 225-266.

DeNeve, D., Devos, G., and Tuytens, M. (2015). The importance of job resources and self-efficacy for beginning teachers' professional learning in differentiated instruction. Teaching and Teacher Education, 47, 30-41.

Donaldson, St. I. and Grant-Vallone, E. J. (2002). Journal of Business and Psychology, $17(2), 245-260$.

Duffy, E., Mattingly, K., and Randolph, D. (2006). A culture of learning. Independent School, 65(4), 24-28.

DuFour, R. \& Eaker, R. (1998). Professional learning communities at work: Best practices for enhancing student achievement. Bloomington, IN: National Education Service.

DuFour, R., Eaker, R., \& DuFour, R. (2005). On common ground: The power of professional learning communities. Bloomington, IN: National Education Service.

DuFour, R. and Reeves, D. (2015). Professional learning communities still work (if done right). Education Week Teacher. https://www.edweek.org/tm/articles/2015/10/02/professional-learningcommunities-still-work-if-done.html

Field, A. (2013). Discovering statistics using IBM SPSS statistics. Los Angeles, CA: Sage Publications Ltd. 
Gates, S. G. and Watkins, M. (2010). The place of autonomy in school community: Taking a closer look at teacher collaboration. Journal of School Leadership, 20(3), 272-303.

Geraci, B. (1995). Local decision-making: A report from the trenches. Educational Leadership, 53(4), 50-52.

Griffith, R., Massey, D., \& Atkinson, T. S. (2013). Examining the forces that guide teaching decisions. Reading Horizons, 52(4), 305-332.

Grindle, B. W. (1982). Administrative team management: Four essential components. The Clearing House, 56(1), 29-33.

Hallinger and Heck. (1996). Reassessing the principal's role in school effectiveness: A review of empirical research, 1980-1995. Educational Administration Quarterly, $32,5-44$.

Hallinger, P. and Heck, R. H. (2009). Assessing the contribution of distributed leadership to school improvement and growth in math achievement. American Educational Research Journal, 46(3), 659-689.

Hallinger, P. and Heck, R. H. (2010). Leadership for learning: Does collaborative leadership make a difference in school improvement? Educational Management Administration \& Leadership, 38(6), 654-678.

Harris, A. T. (2010). Using professional learning communities to build teacher leadership capacity: Creating sustainable change in education (Unpublished doctoral dissertation). Dominican University of California, San Rafael, CA. 
Heck, R. H. and Hallinger, P. (2005). The study of educational leadership and management. Educational Management Administration \& Leadership, 32(2), 229244.

Hofman, R.H. and Dijkstra, B.J. (2010). Effective teacher professionalization in networks? Teaching and Teacher Education, 26(4), e1031-e1040.

Hollins, E. R., McIntyre, L. R., DeBose, C., Hollins, K. S., \& Towner, A. (2004). Promoting a self-sustaining learning community: Investigating an internal model for teacher development. International Journal of Qualitative Studies in Education, 17(2), 247-264.

Hord. S. M. (1997). Professional learning communities: Communities of continuous inquiry and improvement. Austin, TX: Southwest Educational Development Laboratory. Retrieved from ERIC database. (ED 410659)

Horton, J. (2009). The role of district administration in the establishment of professional learning communities. (Doctoral dissertation, University of Missouri-Columbia). Retrieved from https://mospace.umsystem.edu/xmlui/bitstream/handle/10355/6159/research.pdf?s equence $=3$.

Howey, K. R. (1988). Why teacher leadership? Journal of Teacher Education, 39(1), 2831.

Huffman, J. (2011). Professional learning communities in the USA: Demystifying, creating, and sustaining. International Journal of Learning, 17(12), 321-336. 
Kim, J. (2016). The effects of professional learning communities on middle school math teachers in developing curriculum, instruction, and assessments for common core (Unpublished doctoral dissertation). California State University: Long Beach, CA.

Kruse, S., Louis, K., and Bryk, A. (1994). Building professional community in schools. Madison, WI: Center on Organization and Restructuring Schools.

Lambert, L. (2003). Leadership capacity for lasting school improvement. Alexandria, VA: Association for Supervision and Curriculum Development.

Lange, J. T. (1993). Site-based, shared decision-making: A resource for restructuring. NASSP Bulletin, 76, 549-557.

Lee, V.E., Robinson, S.R., \& Sebastian, J.S. (2012). The quality of instruction in urban high schools: Comparing mathematics and science to English and social studies classes in Chicago. High School Journal, 95(3), 14-48.

Leech, D. W. (1999). Faculty perceptions of shared decision-making and the principal's leadership behaviors in Duval County secondary schools. (Doctoral dissertation, University of North Florida). Retrieved from https://digitalcommons.unf.edu/cgi/viewcontent.cgi?article=1255\&context=etd.

Levenstein, R. (2016). 2014 my voice, my school survey quality profile. Chicago, IL: UChicago Consortium on School Research.

Linder, R. A., Post, G., and Calabrese, K. (2012). Professional learning communities: Practices for successful implementation. The Delta Kappa Gamman Bulletin, 78(3), 13-22.

Lindle, J. C. (1995). Lessons from Kentucky about school-based decision-making. Educational Leadership, 53(4), 20-23. 
Liontos, L. B. (1993). Shared decision-making. OSSC Bulletin, 37(2), 1-50.

Louis, K. S. \& Marks H. M. (1998). Does professional community affect the classroom? Teachers' work and student experiences in restructuring schools. American Journal of Education, 106(4), 532-575.

Louis, K.S., Marks, H. M., \& Kruse, S. (1996). Teachers’ professional community in restructuring schools. American Education Research Journal, 33(4), 757-798.

Maag, J. W. (2009). Resistance to change: Overcoming institutional and individual limitations for improving student behavior through PLCs. Journal of the American Academy of Special Education Professionals, Spring-Summer, 41-57.

Marks, H. M., \& Printy, S. M. (2003). Principal leadership and school performance: An integration of transformational and instructional leadership. Educational Administration Quarterly, 39(3), 370-397.

Mokoena, S. (2011). Participative decision-making: Perceptions of school stakeholders in South Africa. Journal of Social Science, 29(2), 119-131.

Moller, G. (2006). Teacher leadership emerges within professional learning communities. Journal of School Leadership, 16(5), 520-533.

Murphy, J. (1994). Transformational change and the evolving role of the principal: Early empirical evidence. In J. Murphy \& K. S. Louis (Eds), Reshaping the principalship: Insights from transformational reform efforts (pp. 20-53). Thousand Oaks, CA: Corwin Press.

Nelson, T. H., Slavit, D., and Deuel, A. (2012). Two dimensions of an inquiry stance toward student-learning data. Teachers College Record, 114(8), 1-42. 
Odden, E. R. and Wohlstetter, P. (1995). Making school-based management work. Educational Leadership, 52(5), 32-37.

Phillips, J. (2003). Powerful learning: Creating learning communities in urban school reform. Journal of Curriculum and Supervision, 18(3), 240-258.

Poekert, P. E. (2012). Examining the impact of collaborative professional development on teacher practice. Teacher Education Quarterly, 39(4), 97-118.

Price, P. C., Jhangiani, R. S., and Chiang, I. A. Research methods in psychology. $2^{\text {nd }}$ Ed. Adapted by The Saylor Foundation under a Creative Commons Attribution-Non Commercial-ShareAlike 3.0 License without attribution as requested by the work's original creator or licensee.

Priest, D. I. (2015). Collaboration in professional learning communities and development of teacher efficacy and trust in Alabama schools (Unpublished doctoral dissertation). University of Alabama: Tuscaloosa, AL.

Provini, C. (2013). Why don’t professional learning communities work? Education World. https://www.educationworld.com/a_admin/professional-learningcommunity-pitfalls-best-practices.shtml.

Rosenholtz, S. (1989). Teacher's workplace: The social organization of schools. New York: Longman.

Rosenman, R., Tennekoon, V., and Hill, L. (2011). Measuring bias in self-reported data. International Journal of Behavioral Healthcare Research, 2(4), 320-332.

Roy, P. and Hord, S. M. (2006). It's everywhere, but what is it? Professional learning communities. Journal of School Leadership, 16(5), 491-501. 
Sackney, L. \& Walter, K. (2006). Canadian perspectives on beginning principals: Their role in building capacity for learning communities. Journal of Educational Administration, 44(4), 341-358.

Sarafidou, J.-O. and Chatziioannidis, G. (2013). Teacher participation in decision-making and its impact on school and teachers. International Journal of Educational Management, 27(2), 170-183.

Schechter, C. (2008). Organizational learning mechanisms: The meaning, measure and implications for school improvement. Educational Administration Quarterly, 44(2), 155-186.

Servage, L. (2009). Critical and transformative practices in professional learning communities. Teacher Education Quarterly, 35(1), 63-77.

Shetzer, S. D. (2011). A study of the relationship between teacher efficacy and professional learning communities in an urban high school. (Doctoral dissertation, University of Houston). Retrieved from https://uhir.tdl.org/handle/10657/580

Short, P. M. \& Greer, J. T. (1989). Increasing teacher autonomy through shared governance: Effects on policy making and student outcomes. Retrieved from ERIC database. (ED319096)

Sigurðardóttir, A. K. (2010). Professional learning community in relation to school effectiveness. Scandinavian Journal of Educational Research, 54(5), 395-412.

Skalski, A. K. and Romero, M. (2011). Data-based decision-making. Principal Leadership, 11(5), 12-16. 
Smylie, M. A. and Denny, J. W. (1990). Teacher leadership: Tensions and ambiguities in organizational perspective. Educational Administration Quarterly, 26(3), 235259.

Smylie, M. A., Lazarus, V., \& Brownlee-Conyers, J. (1996). Instructional outcomes of school-based participative decision-making. Educational evaluation and policy analysis, 18(3), 181-198.

Somech, A. (2010). Participative decision-making in schools: A mediating-moderating analytical framework for understanding school and teacher outcomes.

Educational Administration Quarterly, 46(2), 174-209.

Spillane, J. P., Halverson, R., and Diamond, J. B. (2004). Towards a theory of leadership practice: A distributed perspective. Journal of Curriculum Studies, 36(1), 3-34.

Stewart, K. A. (2014). Effects of professional learning communities in Alabama black belt schools: Case study (Doctoral dissertation, Grand Canyon University). Retrieved from https://pqdtopen-proquest-

com.proxy.mul.missouri.edu/doc/1537385034.html?FMT=AI\&pubnum=3619414

Stoll, L., Bolam, R., McMahon, A., Wallace, M., \& Thomas, S. (2006). Professional learning communities: A review of the literature. Journal of Educational Change, 7(4), 221-258.

Strahan, D. (2003). Promoting a collaborative professional culture in three elementary schools that have beaten the odds. The Elementary School Journal, 104(2), 127146. 
Streck. M. T. (2009). Distributed leadership and shared decision-making leadership practices that promote collaboration (Unpublished doctoral dissertation). The Sage Colleges: Albany, NY.

Supovitz, J. A. (2002). Developing communities of instructional practice. Teachers College Record, 104(8), 1591-1626.

Supovitz, J. A. \& Christman, J. B. (2003). Developing communities of instructional practice: Lessons for Cincinnati and Philadelphia. Retrieved from ERIC database. (ED498331)

Taylor, F. (1911). The principles of scientific management. New York, NY: Harper \& Brothers

Thompson, S. C., Gregg, L., \& Niska, J. M. (2004). Professional learning communities, leadership, and student learning. Research in Middle Level Education Online, 28(1). Retrieved from https://www.tandfonline.com/doi/abs/10.1080/19404476.2004.11658173.

Toole, J.C. \& Louis, K.S. (2002). The role of professional learning communities in international education. In K. Leithwood \& P. Hallinger (eds), Second international handbook of educational leadership and administration. Dordrecht: Kluwer.

Turner, M. (2012). Teacher efficacy beliefs in collaborative learning communities: A statewide study in large high schools (Unpublished doctoral dissertation). Ohio University: Athens, $\mathrm{OH}$. 
Visser, P. S., Krosnick, J. A., Marquette, J., and Curtin, M. (2000). Mail surveys for election forecasting? An evaluation of the Columbis Dispatch Poll. Public Opinion Quarterly, 60(2), 181-227.

Watson, C. (2014). Effective professional learning communities? The possibilities for teachers as agents of change in schools. British Educational Research Journal, $40(1), 18-29$.

White, P. A. (1992). Empowerment under "ideal" school-site autonomy. Educational Evaluation and Policy Analysis, 14(1), 69-82.

Wohlstetter, P. (1995). Getting school-based management right: What works and what doesn’t. Phi Delta Kappan, 77(1), 22-26.

Wohlstetter, P., Smyer, R., \& Mohrman, S. A. (1994, April). New boundaries for schoolbased management: The high involvement model. Paper presented at the annual meeting of the American Educational Research Association, New Orleans, LA.

York-Barr, J. \& Duke, K. (2004). What do we know about teacher leadership? Findings from two decades of scholarship. Review of Educational Research, 74(3), 255316. 


\section{Section 6-Scholarly Practitioner Reflection}

In this section, I am asked to reflect on two questions: (1) How has the dissertation influenced your practice as an educational leader, and (2) How has the dissertation process influenced you as a scholar? Although I will address these two questions separately below, my first reflection is that the two questions are, in many respects, the same question: To be an educational leader is to be a scholar. One can never stop reading, researching, and relating the information gained to one's practice as an educational leader. They are, in essence, two sides of the same coin. The ELPA program has challenged me on both fronts, and with this dissertation, I reach the culmination of a six-year journey that has profoundly impacted me both as a scholar and as a leader.

\section{How has the dissertation influenced your practice as an educational leader?}

As part of the research for this dissertation, I examined professional learning community (PLC) frameworks and their relationship to teacher decision-making. An essential element of PLC is supportive and shared leadership capable of distributing decision-making to instructional staff (Roy \& Hord, 2006). Additionally, it is clear, from the work of DuFour and Eaker (1998) and the PLC implementation process championed by the MO PLC organization reflected in the six strands that form the framework of their implementation assessment (see http://www.moplc.org/uploads/1/3/4/8/13486647/mo_plc_imp_rubric_yearly_targets_ma rked_fy18.pdf)) that teams form the backbone of PLC. As a result of this dissertation process, I am convinced that these two skills - the ability to distribute leadership and the ability to lead effective teams - are the two most crucial leadership skills for any 
administrative leaders working in a district involved in implementing PLC as a means to establish a culture of collaboration that embeds the ability to change in response to students' needs and new research into the daily processes that govern the school. Because my goal, upon completion of the Ed.D. degree, is to return to the public education setting with a particular expertise in PLC, I am especially interested in whether or not this dissertation process has positively influenced my leadership abilities in these two areas. It has.

I came to the Ed.D. program already equipped with the desire to distribute leadership. That desire was a driving force behind my decision to design a dissertation to find a relationship between PLC implementation and teacher influence. I was well aware of anecdotal evidence from districts involved in PLC implementation that teacher empowerment was not happening. Therefore, I was not surprised when my data analysis did not reveal any significant relationship between PLC implementation and teacher influence. My observation was that districts were aggressive at implementing most of the elements of PLC with the exception of any kind of substantive efforts to increase teachers' influence in decision-making. The most obvious explanation based on the history of reform in public education in the United States was that administrators and Boards of Education are reluctant to take the uncertain and unpredictable step of empowering teachers with significant decision-making powers. That was an issue we were having courageous conversations about at Cape Girardeau at the Administrative Council level during the planning stages of PLC implementation while I was superintendent. My openness to and encouragement of teacher empowerment as superintendent in that district was, I believe, a refreshing and motivating quality for our 
administrative staff, and it is one of my chief regrets that I was not able to stay with the district to see those efforts to fruition. One of the driving forces of my desire to return to public school administration is to continue that effort.

The sentiments I have just described have their basis in participatory management theory, and the same reasons that make it a suitable theoretical framework for my dissertation make it an effective lens through which to reflect on the impact this dissertation process has had on me as a leader. Participatory management is a process that engages all members of an organization or organizational division in jointly identifying its vision, goals, and strategies, and involves them in key areas of decisionmaking (Spillane et al., 2005). At its core is the empowerment of individuals which serves to enhance morale and motivation, increase job satisfaction, and promote a sense of responsibility and commitment to the organization (Sarafidou \& Chatziioannidis, 2013). Participatory management emphasizes the importance of collaborative decisionmaking as the focus of new organizational management practices that serve to cultivate synergistic creativity and facilitate the incorporation of high-performance practices into the workplace (MacBeath, 2005; Harris, 2010) and results in a commitment to decisions, a perception that higher quality decisions were made, increased staff cohesion, and increased trust among staff members and principals (Lange, 1993). If I ever had any doubts as to the importance of collaborative leadership along the tenets of participatory management theory, working on this dissertation has removed them.

Similarly, as a result of the dissertation process, I am much more aware of the leadership behaviors that research identifies as important for developing a learning community and increasing the participation of teachers in the decision-making process: 
A commitment to distributed leadership and the real transfer of power from principals to teachers (Brost, 2000; Odden \& Wohlstetter, 1995; Wohlstetter, 1995; Wohlstetter et al., 1994; Wilson, 2016); open, collaborative, facilitative, and supportive relationships (Smylie \& Denny, 1990); authenticity (Bird et al., 2009); trustworthiness and respectful of teachers (Carpenter, 2015). In my current position, I work with a number of different teams. Having the ability to articulate specific strategies for transforming a group of individuals into a high functioning team has made me much more intentional and much more effective at creating and leading them. I now am purposeful at continuously monitoring the social health of the teams I work with. In order to create a supportive environment with open communication and collaboration, and to empower teams that I supervise with responsibility for independently and creatively achieving goals and finding solutions to problems, I provide them with clear instructions and well-defined tasks, adequate resources, reliable information, and technical and group process assistance. I make it my responsibility to maintain an open and collaborative climate, manage disruptive behaviors, manage differences, summarize important decisions, evaluate group processes, and intervene when necessary to help team members practice positive, open communication skills.

Conducting research for this dissertation has increased my knowledge of PLCs considerably, and that may have some concrete implications on my job search. PLCs will continue to play a significant role in educational reform: Schools which have implemented PLCs will be looking for administrators to fill open positions who have expertise in this area, and schools who are contemplating PLC implementation will be similarly inclined. Having the depth of knowledge that I have about the background of 
PLCs, PLC frameworks, PLC implementation processes, research concerning the impact of PLCs on student achievement, research concerning principal leadership behaviors most highly correlated with successful PLC implementation, and the benefits of teacher collaboration and involvement in decision-making enhances my value as an administrative applicant, giving me a much greater likelihood of successfully competing for the opportunity to return to a position as an educational leader in public education.

\section{How has the dissertation process influenced you as a scholar?}

I will use adult learning theory to address the influence that the dissertation process has had on me as a scholar. Merriam \& Bierema (2014) discuss three assumptions about adult learners that strike me as especially descriptive of my learning needs: The importance of engaging with personal experiences, the need for application of learning, and having clear reasons for learning. All of us in the doctoral cohort are old enough to have amassed a wealth of personal experiences that inform who we are and how we interact with others in our positions of leadership. Engaging in learning activities that draw from those experiences provides depth to learning. Even more importantly, in my opinion, engaging personal experiences spotlights those experiences in a way that gives one the opportunity to reflect and self-assess, causing those experiences to undergo an intellectual metamorphosis which leads to new and powerful insights that can be applied immediately to one's professional practice. Problem-based learning (like the Wicked Problem from our first summer) is the epitome of this approach. Finally, although it actually comes first in the process, I absolutely need to be clear about the reason I am studying something. In public school and college, it was enough simply to enjoy the process of learning something new. I rarely questioned why: 
It was enough that it was a means to the end of achieving a grade or a degree. The older I get, the more motivated I am by seeing the application of learning at the outset. I think that is mostly due to having so many more demands on my time, which requires that I ration and prioritize the activities I commit to.

All three of these assumptions were met during the dissertation process. The choice of a problem of practice in my current setting created an immediate connection to nearly 20 years of personal experience in public education. My background in middle level education and one of its cornerstones, interdisciplinary teams, was the beginning of my understanding of the power of collaboration. Exposure to DuFour and Eaker's seminal work on PLC in the late 90's stoked those flames, and having the opportunity now to devote my doctoral research to the process of PLC implementation and teacher empowerment has been an extraordinary scholarly experience. I do not consider myself a researcher: I always kept up with required readings and engaged in scholarly discussions, but have never gone past required expectations of reading and studying during my years of graduate coursework. Having the motivation of being able to immediately apply information to my work as an administrator and educational leader inspired me to enthusiastically search for more research in a quest to become an expert on PLC implementation. Finally, I had absolute clarity on the reasons I was studying these topics: To gain knowledge, complete my doctorate, and obtain a leadership position from which I could exert an influence on increasing teachers' involvement in decision-making processes. I fully expect to continue studying these issues after the dissertation process has concluded. 
As an educational leader, I find myself in a position to influence the scholarship of those I supervise. Gill (2010) discusses the importance of reflective inquiry (including a list of questions to facilitate reflection on, in, and for action), establishing a shared vision, and a focus on dialogue. While my current position does not offer me the opportunity to share what I have learned about PLC implementation and teacher influence specifically, it has certainly opened doors to share my newfound enthusiasm for research. The mission of our program is to maximize the learning opportunities for students who are first generation, low income, or have documented disabilities. We meet every Monday morning to review upcoming plans. I have dedicated a portion of that weekly meeting to professional development and have led discussions on a variety of topics, including issues related to social justice, appreciative advising, and research about the unique needs of the students we serve. Preskill \& Brookfield (2009) derscribed the need for open dialogue: "If leaders are able to encourage climates or structures that allow expression of new ideas and unfamiliar perspectives, opportunities for learning abound" (p. 25), and it has been no less enlightening for me than others I work with to engage in those opportunities on a regular basis. I have no doubt that engaging in research for this dissertation has played the biggest role in my pursuit of these opportunities.

To go along with the above reflections, there are some additional, very practical impacts that the dissertation process has had on me as a scholar. I am now comfortable with conducting research in general and quantitative research in particular, including interpreting and manipulating descriptive data and conducting regression analysis. Using search engines and library search filters to locate references whenever I need them has become second nature. Having read literally hundreds of research papers over the past 
six years, I find that I can navigate them with ease and extract information I need in a fraction of the time that it took me at the outset of the Ed.D. program. That has caused me to be a much more critical consumer of research. I am much more aware of the misinterpretation of research and have found myself multiple times on the Ellis Library search page to quickly dig up some studies to clarify information I have heard in conversation or through the media. I also find that I am much more interested in doing research. When I started the program, I anticipated that it was extremely likely that I would complete the dissertation and be happily done with research projects. To the contrary, as I look past my dissertation defense, I find myself imagining all sorts of follow up studies to dig deeper into the meaning behind some of the findings in my study. More remarkably, most of them would be qualitative research designs, something I never imagined that I would be interested in. 


\section{Appendices}

\section{Appendix A}

Survey Items from the UChicago Consortium on School Research 5Essentials School Reports Survey

Items

How much influence do teachers have over school policy in each of the areas below?

Hiring new professional personnel

Planning how discretionary school funds should be used

Determining books and other instructional materials used in classrooms

Establishing the curriculum and instructional programs

Determining the content of in-service programs

Setting standards for student behavior 
Appendix B

\section{MO PLC Teacher Influence Survey}

10. Please choose your region.

- Southeast (Cape Girardeau)

- Heart of Missouri (Columbia)

- Kansas City

- Northeast (Kirksville)

- Northwest (Maryville)

- South Central (Rolla)

○ Southwest Agency for Teaching, Leading and Learning (Springfield)

$\circ$ EdPlus (St. Louis)

$\circ$ Central (Warrensburg)

11. Choose your [name of region] area school. [Pull-down menu of all schools in the region]

12. What is your primary role?

$\circ$ Building administrator

- General education teacher

- Special education teacher

○ Other role

13. In your school, how much influence do teachers have over school policy in the area of HIRING NEW PROFESSIONAL PERSONNEL?

O None

- A little

- Some

$\circ$ A great deal

14. In your school, how much influence do teachers have over school policy in the area of PLANNING HOW DISCRETIONARY SCHOOL FUNDS SHOULD BE USED?

○ None

- A little

- Some

$\circ$ A great deal

15. In your school, how much influence do teachers have over school policy in the area of DETERMINING BOOKS AND OTHER INSTRUCTIONAL MATERIALS USED IN CLASSROOMS?

○ None

- A little

- Some

- A great deal 
16. In your school, how much influence do teachers have over school policy in the area of ESTABLISHING THE CURRICULUM AND INSTRUCTIONAL PROGRAM?

○ None

○ A little

- Some

$\circ$ A great deal

17. In your school, how much influence do teachers have over school policy in the area of DETERMINING THE CONTENT OF IN-SERVICE PROGRAMS?
○ None
- A little
- Some
- A great deal

18. In your school, how much influence do teachers have over school policy in the area of SETTING STANDARDS FOR STUDENT BEHAVIOR?

- None

- A little

- Some

$\circ \quad$ A great deal 


\section{Appendix C}

The 5Essentials School Reports Survey has undergone extensive testing for validity and reliability. Individual-level reliabilities, reflecting the ratio of true variance to total variance, are calculated by Rasch analysis for each measure. The goal of Rasch analysis is to have twice as much true variation as error variation, which corresponds to a reliability above 0.8 . School level scores, which measure how reliably schools can be distinguished from each other on each measure, reflect the proportion of variation in the school means due to true variation among schools. These depend on a comparison of the consistency of a measure across respondents within a school to the overall distribution of responses as well as the number of respondents in the schools. The intra-class correlation (ICC) for each measure is estimated using hierarchical linear modeling and represents the proportion of the total variance due to differences between schools. As shown in Table 5, individual-level reliabilities ranged from 0.73 to 0.76 on the teacher survey measure for teacher influence. School-level reliability ranged from 0.72 to 0.80 , and ICC ranged from 0.26 to 0.31 (2014 My Voice, My School Survey Quality Profile Technical Report, p. 46).

Reliability, Intra-class Correlations, and Measure Response Rate by Grade Level

\begin{tabular}{cccccc}
\hline Measure Name & Grade Level & $\begin{array}{c}\text { Individual } \\
\text { reliability }\end{array}$ & $\begin{array}{l}\text { School-level } \\
\text { reliability }\end{array}$ & ICC & $\begin{array}{l}\text { Measure } \\
\text { response rate }\end{array}$ \\
\hline $\begin{array}{c}\text { Teacher } \\
\text { Influence }\end{array}$ & $\begin{array}{c}\text { Elementary } \\
(\mathrm{K}-8)\end{array}$ & 0.76 & 0.801 & 0.309 & $\begin{array}{l}8,203 / 8,663= \\
94.7 \%\end{array}$ \\
$\begin{array}{c}\text { Teacher } \\
\text { Influence }\end{array}$ & $\begin{array}{c}\text { High School } \\
(9-12)\end{array}$ & 0.73 & 0.719 & 0.256 & $\begin{array}{l}3,952 / 4,245= \\
93.1 \%\end{array}$ \\
\hline
\end{tabular}




\section{Appendix D}

Dear Administrator,

As part of our ongoing efforts to improve the PLC resources provided by DESE to Missouri schools, we are conducting one final survey of Missouri PLC schools.

\section{Click here for MO PLC Teacher Influence Survey}

This is a nine-item survey instrument designed to assess the relationship between the implementation of PLCs in your building and teachers' perceptions of their influence on decision-making. It should take less than two minutes to complete. A summary of the results will be shared with the MO PLC organization as well as you and your leadership team. It will provide valuable information about your ongoing efforts to make your school's PLC as effective as possible.

Please complete the survey yourself, then forward the email below to your leadership team and to all instructional staff who participate on collaborative PLC teams.

Robert L. Gordon, EdD

State Field Director, Missouri Professional Learning Communities, (573) 864-1555

COLLEGE OF EDUCATION

A College on the Move

Dear Educator,

Please follow the link below to complete the Missouri PLC Teacher Influence Survey. The survey is designed to assess the relationship between the implementation of PLCs in your building and teachers' perceptions of their influence on decision-making. It should take less than two minutes to complete. A summary of the results will be shared with the leadership team in your building and will provide valuable information about your ongoing efforts to make your school's PLC as effective as possible. Your answers are completely confidential. A copy of the informed consent document is attached for your information.

\section{Click here for MO PLC Teacher Influence Survey}

Robert L. Gordon, EdD

State Field Director, Missouri Professional Learning Communities, (573) 864-1555

COLLEGE OF EDUCATION 
Appendix E

\section{The Relationship between Professional Learning Community Implementation and Teacher Decision-Making Influence}

What is the study about? You are invited to participate in a research study being conducted as part of the requirements of a doctoral thesis in Educational Leadership and Policy Analysis at the University of Missouri-Columbia. The researcher is interested in your opinions about the degree to which you are involved in decision-making at your school. In an effort to better understand the relationship between PLC implementation and the actual perceptions of teachers at PLC schools on how much they are involved in decision-making, teachers at all schools participating in the Missouri Professional Learning Community organization (MO PLC) are being asked to complete this nine-item survey. Results of the survey will be analyzed and included in the researcher's dissertation, and will also be shared with the administrative staff at MO PLC. They will also be made available to the principal at each participating PLC building.

The first three questions request demographic information (region, name of school, and primary role of the individual completing the survey). The next six questions require multiple choice Likert scale responses. It is estimated that the survey will take less than 2 minutes of your time.

The data collected in this study are anonymous and confidential. The data from the survey are not linked to an email address. Likert scale results will be reported to the MO PLC in aggregate form only. You can choose not to answer any question that you feel uncomfortable answering. Answers will benefit the respondent and the MO PLC by providing information to MO PLC about how participants perceive the degree to which they are involved in decisionmaking on important issues. There is no compensation for completing the survey. The research is being conducted by the following doctoral candidate, who can be contacted at any time through email and would be happy to answer any questions you have about the study.

\section{Mr. Mark Bowles, mabfz8@mail.missouri.edu}

Your participation in the study by answering the questions in the survey indicates that you understand the information above, that you agree to participate in this study, and that you give consent for your responses to be shared anonymously with the MO PLC. 
Appendix F

Survey Items from the Missouri PLC BAT Survey 2017-18

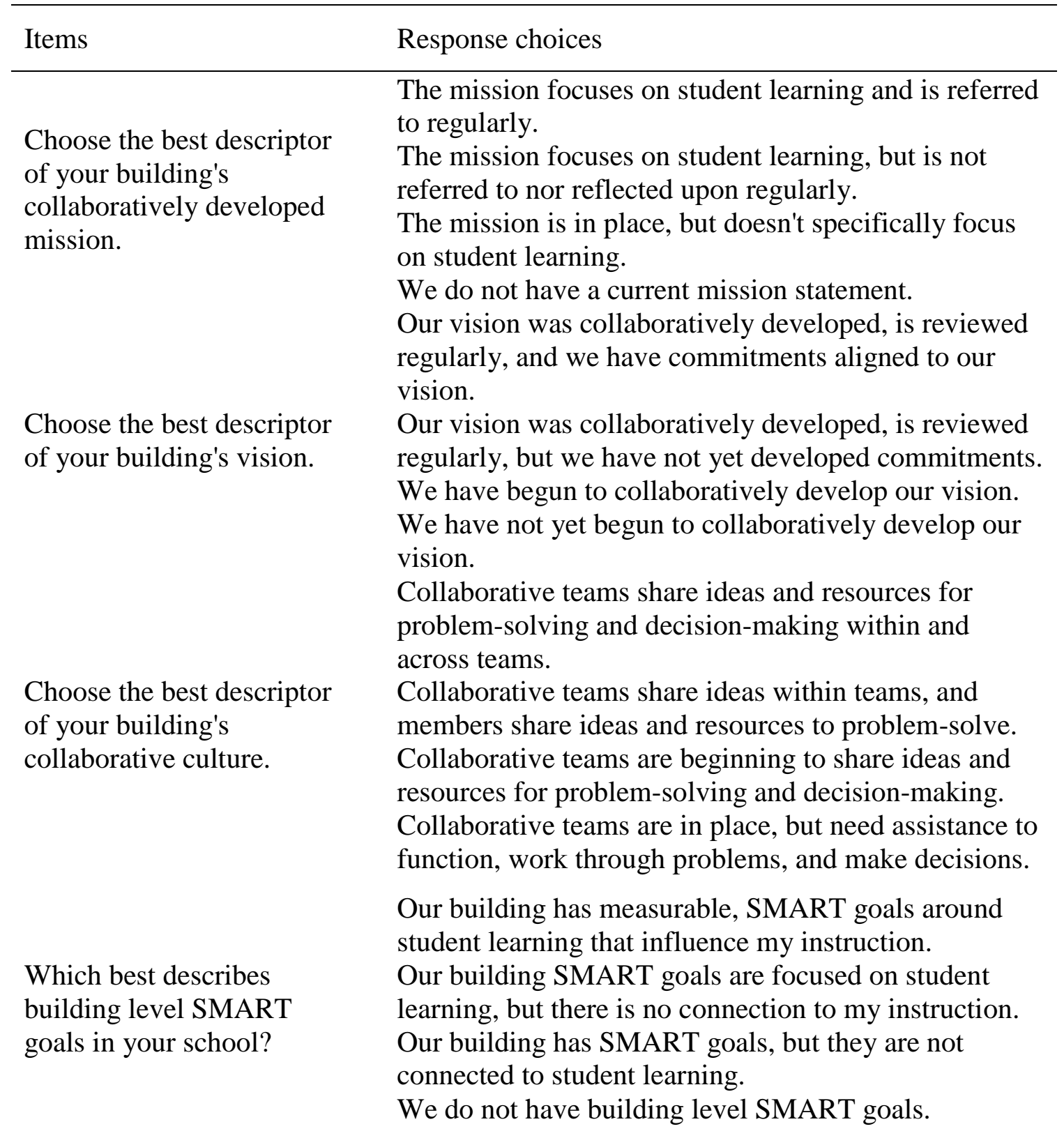


Describe the level of trust in your team.

I believe that collaboration through teacher teams is improving the education we provide to all our students.

How is shared decisionmaking encouraged in your building?

Which best describes your collaborative team meetings.

Which best describes how your team uses meeting protocols such as roles, norms, timed agendas, minutes, schedules?
I am comfortable sharing my strengths and weaknesses about teaching and learning with all members of my team.

I am comfortable sharing my strengths and weaknesses about teaching and learning with most members of my team.

I am comfortable sharing my strengths and weaknesses about teaching and learning with some members of my team.

I do not feel comfortable sharing my strengths and weaknesses about teaching and learning with my team. Yes, and this happens in my team.

Yes, and this happens to a limited extent in my team. Partially, but we have not yet made a noticeable impact on students.

No, teacher collaboration does not impact students. Collaborative teams directly contribute to decisionmaking about critical issues impacting instruction and directly contribute to plans for addressing those issues. Input and feedback from staff is considered for critical decisions affecting collaboration and instruction. Input and feedback from staff is regularly requested and used in non-critical issues, but infrequently in critical issues.

Staff has input only on non-critical issues (i.e., treats for teachers, event titles and duty rosters, etc.). Collaborative teams meet weekly during the contract day and are teacher-led, focusing on student learning and data-driven decision-making.

Collaborative teams use an organized structure, meeting at least twice per month during the contract day, with a minimum of guidance from the building leadership team.

Collaborative teams meet regularly outside of the contract day, with the building leadership team making decisions for all/most of the teams.

Collaborative teams are not expected to meet on a regular basis.

Our team makes effective use of all meeting protocols. Our team makes use of most meeting protocols. Our team makes use of some meeting protocols. Our team does not use meeting protocols. 
How do teachers participate in the identification of priority standards?

How does your team utilize identified priority standards?

Choose the best descriptor of your team.

I am a member of a collaborative team that uses student data to drive problem-solving and decisions.

As a team we collaboratively establish SMART goals and implement strategies and action plans based on student data. Choose the best descriptor of your team's use of SMART goals.
All teachers are directly involved in identifying priority standards for the subject areas they teach.

Grade level/department representatives identify priority standards in our building/district. Priority standards are identified at the district level with little or no teacher involvement.

Priority standards have not been identified for what I teach.

Our team uses priority standards as the basis for determining our formative assessments on a regular basis.

Our team occasionally uses priority standards in determining formative assessments. (5) Priority standards are displayed and/or used occasionally by individual teachers.

Priority standards are not utilized in developing assessments.

My team collaboratively identifies instructional strategies which are aligned with priority standards and we are committed to implementing them. (7) My team collaboratively identifies instructional strategies, but they are not necessarily aligned to priority standards. (8)

My team discusses instruction, but we do not reach consensus on which strategies are best to implement. (9)

My team does not discuss instructional strategies.

My team routinely reviews student data to inform problem-solving and decisions.

My team tries to link student data to problem-solving and decisions.

My team does not link student data to problem-solving and decisions.

My team does not use student data in our meetings.

Our team has established SMART goals and action plans based on student data.

Our team has established SMART goals and uses action plans in a limited manner.

Our team has established SMART goals but has not developed action plans.

No, we haven't established SMART goals yet. 
What is the level of implementation of schoolwide tiered interventions?
School-wide implementation with review of targeted data points for all students.

Grade or course specific implementation with review of targeted data points for all students.

Limited implementation at the grade or course levels. No immediate steps or actions taken toward

implementation. 


\section{Appendix G}

Regression Analysis for PLC Implementation on New Personnel Hiring

\begin{tabular}{|c|c|c|c|c|c|c|}
\hline \multirow{3}{*}{ Model } & \multicolumn{3}{|c|}{ Simple Regression Model } & \multicolumn{3}{|c|}{ Multiple Regression Model } \\
\hline & \multicolumn{2}{|c|}{$\begin{array}{c}\text { Unstandardized } \\
\text { Coefficients }\end{array}$} & \multirow{2}{*}{ Sig. } & \multicolumn{2}{|c|}{$\begin{array}{l}\text { Unstandardized } \\
\text { Coefficients }\end{array}$} & \multirow{2}{*}{ Sig. } \\
\hline & $\mathrm{B}$ & Std. Error & & $\mathrm{B}$ & Std. Error & \\
\hline (Constant) & 2.242 & 0.574 & 0.000 & 9.496 & 3.099 & 0.265 \\
\hline BIS & 0.000 & 0.007 & 0.941 & 0.000 & 0.008 & 0.954 \\
\hline Size & & & & 0.000 & 0.001 & 0.893 \\
\hline \%Minority & & & & 0.009 & 0.006 & 0.110 \\
\hline Attendance & & & & -0.004 & 0.029 & 0.878 \\
\hline$\% \mathrm{~F} / \mathrm{R}$ & & & & -0.018 & 0.005 & 0.001 \\
\hline Engl/LA & & & & 0.004 & 0.006 & 0.539 \\
\hline Math & & & & -0.002 & 0.005 & 0.715 \\
\hline Exp/ADA & & & & $-3.129 \mathrm{E}-5$ & 0.000 & 0.639 \\
\hline Y2 & & & & 0.328 & 0.275 & 0.238 \\
\hline Y3 & & & & 0.301 & 0.244 & 0.222 \\
\hline Y4 & & & & -0.012 & 0.278 & 0.964 \\
\hline Middle & & & & -0.017 & 0.266 & 0.949 \\
\hline HS & & & & -0.387 & 0.271 & 0.160 \\
\hline Rural/Urban & & & & -0.266 & 0.296 & 0.374 \\
\hline
\end{tabular}




\begin{tabular}{|c|c|c|c|c|c|c|}
\hline \multicolumn{7}{|c|}{ Appendix G (cont.) } \\
\hline ssion & alysis $f$ & PLC Imp & ntat & i Spendir & Discretio & Funds \\
\hline \multirow{3}{*}{ Model } & \multicolumn{3}{|c|}{ Simple Regression Model } & \multicolumn{3}{|c|}{ Multiple Regression Model } \\
\hline & \multicolumn{2}{|c|}{$\begin{array}{l}\text { Unstandardized } \\
\text { Coefficients }\end{array}$} & \multirow{2}{*}{ Sig. } & \multicolumn{2}{|c|}{$\begin{array}{l}\text { Unstandardized } \\
\text { Coefficients }\end{array}$} & \multirow{2}{*}{ Sig. } \\
\hline & $\mathrm{B}$ & Std. Error & & $\mathrm{B}$ & Std. Error & \\
\hline (Constant) & 1.741 & 0.430 & 0.000 & 0.875 & 2.341 & 0.710 \\
\hline BIS & 0.002 & 0.005 & 0.653 & 0.002 & 0.006 & 0.724 \\
\hline Size & & & & 0.000 & 0.001 & 0.855 \\
\hline \%Minority & & & & 0.001 & 0.004 & 0.762 \\
\hline Attendance & & & & 0.000 & 0.022 & 0.994 \\
\hline$\% \mathrm{~F} / \mathrm{R}$ & & & & -0.008 & 0.004 & 0.036 \\
\hline Engl/LA & & & & 0.004 & 0.004 & 0.369 \\
\hline Math & & & & -0.002 & 0.004 & 0.553 \\
\hline Exp/ADA & & & & $2.10 \mathrm{E}-05$ & 0.000 & 0.676 \\
\hline Y2 & & & & 0.193 & 0.208 & 0.356 \\
\hline Y3 & & & & 0.264 & 0.184 & 0.157 \\
\hline Y4 & & & & 0.031 & 0.210 & 0.882 \\
\hline Middle & & & & -0.211 & 0.201 & 0.298 \\
\hline HS & & & & -0.200 & 0.205 & 0.332 \\
\hline Rural/Urban & & & & 0.219 & 0.224 & 0.334 \\
\hline
\end{tabular}




\begin{tabular}{|c|c|c|c|c|c|c|}
\hline \multirow{3}{*}{ Model } & \multicolumn{3}{|c|}{ Simple Regression Model } & \multicolumn{3}{|c|}{ Multiple Regression Model } \\
\hline & \multicolumn{2}{|c|}{$\begin{array}{l}\text { Unstandardized } \\
\text { Coefficients }\end{array}$} & \multirow[t]{2}{*}{ Sig. } & \multicolumn{2}{|c|}{$\begin{array}{l}\text { Unstandardized } \\
\text { Coefficients }\end{array}$} & \multirow[t]{2}{*}{ Sig. } \\
\hline & $\mathrm{B}$ & Std. Error & & $\mathrm{B}$ & Std. Error & \\
\hline (Constant) & 3.466 & 0.395 & 0.000 & 0.976 & 2.125 & 0.648 \\
\hline BIS & -0.003 & 0.005 & 0.554 & -0.003 & 0.005 & 0.570 \\
\hline Size & & & & 0.000 & 0.001 & 0.634 \\
\hline \%Minority & & & & -0.007 & 0.004 & 0.098 \\
\hline Attendance & & & & 0.026 & 0.020 & 0.192 \\
\hline$\% \mathrm{~F} / \mathrm{R}$ & & & & -0.003 & 0.003 & 0.365 \\
\hline Engl/LA & & & & -0.003 & 0.004 & 0.483 \\
\hline Math & & & & 0.004 & 0.003 & 0.216 \\
\hline Exp/ADA & & & & $-4.31 \mathrm{E}-06$ & 0.000 & 0.925 \\
\hline $\mathrm{Y} 2$ & & & & 0.106 & 0.188 & 0.577 \\
\hline Y3 & & & & 0.296 & 0.167 & 0.083 \\
\hline Y4 & & & & 0.026 & 0.191 & 0.890 \\
\hline Middle & & & & 0.390 & 0.182 & 0.038 \\
\hline HS & & & & 0.284 & 0.186 & 0.133 \\
\hline Rural/Urban & & & & -0.017 & 0.203 & 0.935 \\
\hline
\end{tabular}


Appendix G (cont.)

Regression Analysis for PLC Implementation on Choice of Curriculum

\begin{tabular}{|c|c|c|c|c|c|c|}
\hline \multirow{3}{*}{ Model } & \multicolumn{3}{|c|}{ Simple Regression Model } & \multicolumn{3}{|c|}{ Multiple Regression Model } \\
\hline & \multicolumn{2}{|c|}{$\begin{array}{l}\text { Unstandardized } \\
\text { Coefficients }\end{array}$} & \multirow[t]{2}{*}{ Sig. } & \multicolumn{2}{|c|}{$\begin{array}{l}\text { Unstandardized } \\
\text { Coefficients }\end{array}$} & \multirow[t]{2}{*}{ Sig. } \\
\hline & $\mathrm{B}$ & Std. Error & & $\mathrm{B}$ & Std. Error & \\
\hline (Constant) & 3.516 & 0.415 & 0.000 & -0.234 & 2.131 & 0.913 \\
\hline BIS & -0.002 & 0.005 & 0.721 & -0.004 & 0.005 & 0.407 \\
\hline Size & & & & 0.001 & 0.001 & 0.353 \\
\hline$\%$ Minority & & & & -0.011 & 0.004 & 0.008 \\
\hline Attendance & & & & 0.033 & 0.020 & 0.098 \\
\hline$\% \mathrm{~F} / \mathrm{R}$ & & & & 0.000 & 0.003 & 0.888 \\
\hline Engl/LA & & & & -0.003 & 0.004 & 0.417 \\
\hline Math & & & & 0.005 & 0.003 & 0.155 \\
\hline Exp/ADA & & & & $1.40 \mathrm{E}-05$ & 0.000 & 0.760 \\
\hline Y2 & & & & 0.212 & 0.189 & 0.267 \\
\hline Y3 & & & & 0.418 & 0.168 & 0.016 \\
\hline Y4 & & & & 0.164 & 0.191 & 0.394 \\
\hline Middle & & & & 0.341 & 0.183 & 0.068 \\
\hline HS & & & & 0.340 & 0.186 & 0.075 \\
\hline Rural/Urban & & & & 0.078 & 0.204 & 0.703 \\
\hline
\end{tabular}




\begin{tabular}{|c|c|c|c|c|c|c|}
\hline \multicolumn{7}{|c|}{ Appendix G (cont.) } \\
\hline Regression $A$ & alysis fo & LC Imple & entatic & Selection of & In-Service & \\
\hline \multirow{3}{*}{ Model } & \multicolumn{3}{|c|}{ Simple Regression Model } & \multicolumn{3}{|c|}{ Multiple Regression Model } \\
\hline & \multicolumn{2}{|c|}{$\begin{array}{l}\text { Unstandardized } \\
\text { Coefficients }\end{array}$} & \multirow[t]{2}{*}{ Sig. } & \multicolumn{2}{|c|}{$\begin{array}{l}\text { Unstandardized } \\
\text { Coefficients }\end{array}$} & \multirow[t]{2}{*}{ Sig. } \\
\hline & $\mathrm{B}$ & Std. Error & & $\mathrm{B}$ & Std. Error & \\
\hline (Constant) & 2.761 & 0.433 & 0.000 & 1.837 & 2.428 & 0.453 \\
\hline BIS & -0.002 & 0.005 & 0.711 & 0.002 & 0.006 & 0.763 \\
\hline Size & & & & 0.000 & 0.001 & 0.823 \\
\hline \%Minority & & & & -0.002 & 0.004 & 0.655 \\
\hline Attendance & & & & 0.020 & 0.022 & 0.368 \\
\hline$\% \mathrm{~F} / \mathrm{R}$ & & & & -0.007 & 0.004 & 0.064 \\
\hline Engl/LA & & & & -0.004 & 0.005 & 0.381 \\
\hline Math & & & & 0.001 & 0.004 & 0.892 \\
\hline Exp/ADA & & & & $1.34 \mathrm{E}-05$ & 0.000 & 0.798 \\
\hline $\mathrm{Y} 2$ & & & & 0.223 & 0.215 & 0.306 \\
\hline Y3 & & & & 0.391 & 0.191 & 0.046 \\
\hline Y4 & & & & 0.098 & 0.218 & 0.654 \\
\hline Middle & & & & 0.292 & 0.208 & 0.167 \\
\hline HS & & & & 0.325 & 0.212 & 0.132 \\
\hline Rural/Urban & & & & -0.021 & 0.232 & 0.929 \\
\hline
\end{tabular}


Appendix G (cont.)

Regression of PLC Implementation on Setting Standards for Student Behavior

\begin{tabular}{|c|c|c|c|c|c|c|}
\hline \multirow{3}{*}{ Model } & \multicolumn{3}{|c|}{ Simple Regression Model } & \multicolumn{3}{|c|}{ Multiple Regression Model } \\
\hline & \multicolumn{2}{|c|}{$\begin{array}{l}\text { Unstandardized } \\
\text { Coefficients }\end{array}$} & \multirow{2}{*}{ Sig. } & \multicolumn{2}{|c|}{$\begin{array}{l}\text { Unstandardized } \\
\text { Coefficients }\end{array}$} & \multirow{2}{*}{ Sig. } \\
\hline & $\mathrm{B}$ & Std. Error & & $\mathrm{B}$ & Std. Error & \\
\hline (Constant) & 2.880 & 3.900 & 0.000 & -0.669 & 2.218 & 0.764 \\
\hline BIS & 0.002 & 0.004 & 0.701 & 0.006 & 0.005 & 0.296 \\
\hline Size & & & & -0.001 & 0.001 & 0.340 \\
\hline$\%$ Minority & & & & -0.002 & 0.004 & 0.607 \\
\hline Attendance & & & & 0.029 & 0.020 & 0.163 \\
\hline$\% \mathrm{~F} / \mathrm{R}$ & & & & -0.004 & 0.003 & 0.311 \\
\hline Engl/LA & & & & 0.001 & 0.004 & 0.750 \\
\hline Math & & & & -0.001 & 0.003 & 0.830 \\
\hline Exp/ADA & & & & $4.64 \mathrm{E}-05$ & 0.000 & 0.333 \\
\hline Y2 & & & & 0.218 & 0.197 & 0.272 \\
\hline Y3 & & & & 0.058 & 0.174 & 0.741 \\
\hline Y4 & & & & -0.089 & 0.199 & 0.658 \\
\hline Middle & & & & 0.102 & 0.190 & 0.594 \\
\hline HS & & & & 0.041 & 0.194 & 0.834 \\
\hline Rural/Urban & & & & 0.147 & 0.212 & 0.491 \\
\hline
\end{tabular}




\section{References}

Abbott, A. \& Wren, D. (2016). Using performance task data to improve instruction. The Clearing House, 89(1), 38-45.

Alutto, J. \& Belasco, J. (1972). A typology for participation in organizational decisionmaking. Patterns of teacher participation in school system decision-making. Administrative Science Quarterly, 17(1), 117-125.

Andrews, D. \& Lewis, M. (2007). Transforming practice from within: the power of the professional learning community. In: Professional learning communities: divergence, depth and dilemmas. Professional Learning. Open University Press, Maidenhead, UK, pp. 132-147. ISBN 033522031

Aston, H. J. and Lambert, N. (2010). Young people's views about their involvement in decision-making. Educational Psychology in Practice, 26(1), 41-51.

Baumeister, R. F., Campbell, J. D., Krueger, J. I., \& Vohs, K. D. (2003). Does high selfesteem cause better performance, interpersonal success, happiness, or healthier lifestyles? Psychological Science in the Public Interest, 4(), 1-44.

Ben-Peretz, M. (2001). The impossible role of teacher educators in a changing world. Journal of Teacher Education, 52(1), 48-56.

Benson, N. \& Malone, P. (1987). Teachers' beliefs about shared decision-making and work alienation. Education, 107(3), 244-251.

Berry, B., Johnson, D., \& Montgomery, D. (2005). The power of teacher leadership. Educational Leadership, 62(5), 56.

Berry, B, Wade, C., \& Trantham, P. (2008). Using data, changing teaching. Educational Leadership, 66(4), 80-84. 
Bird, J. J., Wang, C., Watson, J. R., \& Murray, L. (2009). Relationships among principal authentic leadership and teacher trust and engagement levels. Journal of School Leadership, 19(2), 153-171.

Blasé, J. (1989). The micropolitics of the school: The everyday political orientation of teachers toward open school principals. Educational Administration Quarterly, 25(4), 377-407.

Bleske-Rechek, A., Morrison, K. M., and Heidtke, L. D. (2015). Causal inference from descriptions of experimental and non-experimental research: Public understanding of correlation-versus-causation. The Journal of General Psychology, 142(1), 4870.

Bolam, R., McMahan, A., Stoll, L., Thomas, S., and Wallace, M. (2005). Creating and sustaining effective professional communities (Research Report No. 637). London: General Teaching Council for England.

Bolman, L. G. and Deal, T. E. (2008). Reframing organizations: Artistry, choice, and leadership. San Francisco: Jossey-Bass.

Bridges, E. (1967). A model for shared decision-making in the school principalship. Central Midwestern Regional Educational Laboratory, Occasional Paper Series, Number 2. ED 013480.

Bridgman, A. (1985). States launching barrage of initiatives, survey finds. Education Week, February 6, 1985, 1, 31.

Brost. P. (2000). Shared decision-making for better schools. Principal Leadership (High School Ed.), 1(3), 58-63.

Bryk, A.S. (2010). Organizing schools for improvement. Phi Delta Kappan, 91(7), 23-30. 
Bryk, A., Camburn, E. \& Louis, K.S. (1997). Professional community in Chicago elementary schools: Facilitating factors and organizational consequences. Educational Administration Quarterly, 35(Supplement), 751-781.

Bryk, A.S., Easton, J.Q., Kerbow, D., Rollow, S.G. \& Sebring, P.A. (1994). The state of Chicago school reform. Phi Delta Kappan, 76(1), 74-78.

Burns, M. K., Gordon, R. L., Naughton, M. R., Preast, J. L., Robb, V., Smith, M., Wang, Z. (2014). Factors of professional learning community implementation and effect on student achievement (Unpublished doctoral dissertation). University of Missouri, Columbia, MO.

Butcher, J. \& Kritsonis. W. (2007). Human resource management: Managerial efficacy in recruiting and retaining teachers-national implications. Retrieved from ERIC database. ED 497357

Camburn, E., Han, S., \& Sebastian, J. (2017). Assessing the validity of an annual survey for measuring the enacted literacy curriculum. Educational Policy, 31(1), 73-107. Carnegie Forum on Education and the Economy Task Force on Teaching as a Profession. (1986). A Nation Prepared: Teachers for the $21^{\text {st }}$ century. Retrieved from ERIC database. ED 268120

Carpenter, D. (2015). School culture and leadership of professional learning communities. International Journal of Educational Management, 29(5), 682-694.

Clark, S. N. \& Clark, D. C. (2002). Collaborative decision-making: A promising but underused strategy for middle school improvement. Middle School Journal, 33(4), 52-57. 
Conley, S. (1991). Review of research on teacher participation in school decisionmaking. Review of Research in Education, 17, 225-266.

Conley, S. C., Schmidle, T., and Shedd, J. B. (1988). Teacher participation in the management of school systems. Teachers College Record, 90(2), 259-280.

Cooper, J. E., Ponder, G., Merritt, S., and Matthews, C. (2005). High-performing high schools: Patterns of success. NASSP Bulletin, 89(645), 2-23.

Costa A. M. (2012). A mixed methods program evaluation on the effectiveness of a school redesign model on teacher empowerment and student achievement (Doctoral dissertation). Retrieved from https://scholarworks.waldenu.edu/dissertations/1026/.

Darling-Hammond, L., Bullmaster, M. L., \& Cobb, V. L. (1995). Rethinking teacher leadership through professional development schools. The Elementary School Journal, 96(1), 87-106.

DeNeve, D., Devos, G., and Tuytens, M. (2015). The importance of job resources and self-efficacy for beginning teachers' professional learning in differentiated instruction. Teaching and Teacher Education, 47, 30-41.

Donaldson, St. I. and Grant-Vallone, E. J. (2002). Journal of Business and Psychology, $17(2), 245-260$.

Duffy, E., Mattingly, K., and Randolph, D. (2006). A culture of learning. Independent School, 65(4), 24-28.

DuFour, R. \& Eaker, R. (1998). Professional learning communities at work: Best practices for enhancing student achievement. Bloomington, IN: National Education Service. 
DuFour, R., Eaker, R., \& DuFour, R. (2005). On common ground: The power of professional learning communities. Bloomington, IN: National Education Service.

DuFour, R. and Reeves, D. (2015). Professional learning communities still work (if done right). Education Week Teacher. https://www.edweek.org/tm/articles/2015/10/02/professional-learningcommunities-still-work-if-done.html

Duke, D. L. (1980). Teachers and shared decision-making: The costs and benefits of involvement. Educational Administration Quarterly, 16, 93-106.

Eaker, R., DuFour, R., \& Burnette, R. (2002). Getting started: Reculturing schools to become professional learning communities. Bloomington, IN: National Education Service.

Field, A. (2013). Discovering statistics using IBM SPSS statistics. Los Angeles, CA: Sage Publications Ltd.

Firestone, W. A. (1977). Participation and influence in the planning of educational change. Journal of Applied Behavioral Science, 13(2), 184-191.

Fitzgerald, T. \& Gunter, H. (2006). Leading learning: Middle leadership in schools in England and New Zealand. Management in Education, 20(3), 6-8.

Fullan, M. (2001). The new meaning of educational change ( $3^{\text {rd }}$ ed.). New York and London: Teachers College Press and Routledge Falmer.

Gates, S. G. and Watkins, M. (2010). The place of autonomy in school community: Taking a closer look at teacher collaboration. Journal of School Leadership, 20(3), 272-303. 
Geraci, B. (1995). Local decision-making: A report from the trenches. Educational Leadership, 53(4), 50-52.

Gill, S. J. (2009). Developing a learning culture in nonprofit organizations. Thousand Oaks, CA: Sage.

Griffin, G. A. (1985). The school as a workplace and the master teacher concept. The Elementary School Journal, 86(1), ii+1-16.

Griffith, R., Massey, D., \& Atkinson, T. S. (2013). Examining the forces that guide teaching decisions. Reading Horizons, 52(4), 305-332.

Grindle, B. W. (1982). Administrative team management: Four essential components. The Clearing House, 56(1), 29-33.

Hallinger and Heck. (1996). Reassessing the principal's role in school effectiveness: A review of empirical research, 1980-1995. Educational Administration Quarterly, $32,5-44$.

Hallinger, P. and Heck, R. H. (2009). Assessing the contribution of distributed leadership to school improvement and growth in math achievement. American Educational Research Journal, 46(3), 659-689.

Hallinger, P. and Heck, R. H. (2010). Leadership for learning: Does collaborative leadership make a difference in school improvement? Educational Management Administration \& Leadership, 38(6), 654-678.

Harris, A. T. (2010). Using professional learning communities to build teacher leadership capacity: Creating sustainable change in education (Unpublished doctoral dissertation). Dominican University of California, San Rafael, CA. 
Hofman, R.H. and Dijkstra, B.J. (2010). Effective teacher professionalization in networks? Teaching and Teacher Education, 26(4), e1031-e1040.

Hollins, E. R., McIntyre, L. R., DeBose, C., Hollins, K. S., \& Towner, A. (2004). Promoting a self-sustaining learning community: Investigating an internal model for teacher development. International Journal of Qualitative Studies in Education, 17(2), 247-264.

Hord. S. M. (1997). Professional learning communities: Communities of continuous inquiry and improvement. Austin, TX: Southwest Educational Development Laboratory. Retrieved from ERIC database. (ED 410659)

Horton, J. (2009). The role of district administration in the establishment of professional learning communities. (Doctoral dissertation, University of Missouri-Columbia). Retrieved from https://mospace.umsystem.edu/xmlui/bitstream/handle/10355/6159/research.pdf?s equence $=3$.

Howey, K. R. (1988). Why teacher leadership? Journal of Teacher Education, 39(1), 2831.

Huffman, J. (2011). Professional learning communities in the USA: Demystifying, creating, and sustaining. International Journal of Learning, 17(12), 321-336.

InPraxis Group Inc. (2006). Professional learning communities: An exploration. School Improvement Branch, Basic Learning, Alberta Education.

Kim, J. (2016). The effects of professional learning communities on middle school math teachers in developing curriculum, instruction, and assessments for common core (Unpublished doctoral dissertation). California State University: Long Beach, CA. 
Kingston, P. W. (1986). Theory at risk: Accounting for the excellence movement. Sociological Forum, 1(4), 632-656.

Kruse, S., Louis, K., and Bryk, A. (1994). Building professional community in schools. Madison, WI: Center on Organization and Restructuring Schools.

Lambert, L. (2003). Leadership capacity for lasting school improvement. Alexandria, VA: Association for Supervision and Curriculum Development.

Lee, V.E., Robinson, S.R., \& Sebastian, J.S. (2012). The quality of instruction in urban high schools: Comparing mathematics and science to English and social studies classes in Chicago. High School Journal, 95(3), 14-48.

Lee, V. E., Smith, J. B., \& Croninger, R.G. (1995). Another look at high school restructuring. Issues in restructuring schools. Madison, WI: Center on Organization and Restructuring of Schools, School of Education, University of Wisconsin-Madison.

Leech, D. W. (1999). Faculty perceptions of shared decision-making and the principal's leadership behaviors in Duval County secondary schools. (Doctoral dissertation, University of North Florida). Retrieved from https://digitalcommons.unf.edu/cgi/viewcontent.cgi?article=1255\&context=etd.

Levenstein, R. (2016). 2014 my voice, my school survey quality profile. Chicago, IL: UChicago Consortium on School Research.

Lieberman, A. (1995). Practices that support teacher development: Transforming conceptions of professional learning. Phi Delta Kappan, 76(8), 591596.Lieberman. 1988. 
Linder, R. A., Post, G., and Calabrese, K. (2012). Professional learning communities: Practices for successful implementation. The Delta Kappa Gamman Bulletin, 78(3), 13-22.

Lindle, J. C. (1995). Lessons from Kentucky about school-based decision-making. Educational Leadership, 53(4), 20-23.

Liontos, L. B. (1993). Shared decision-making. OSSC Bulletin, 37(2), 1-50.

Little, J.W. (1982). Norms of collegiality and experimentation: Workplace conditions ofschool success. American Educational Research Journal, 19(3), 325-340.Louis and Marks. 1998.

Louis, K. S., Kruse, S., \& Raywid, M. A. (1996). Putting teachers at the center of reform: Learning schools and professional communities. NASSP Bulletin, 80(580), 9-12.

Louis, K. S. \& Marks H. M. (1998). Does professional community affect the classroom? Teachers' work and student experiences in restructuring schools. American Journal of Education, 106(4), 532-575.

Louis, K.S., Marks, H. M., \& Kruse, S. (1996). Teachers’ professional community in restructuring schools. American Education Research Journal, 33(4), 757-798.

Maag, J. W. (2009). Resistance to change: Overcoming institutional and individual limitations for improving student behavior through PLCs. Journal of the American Academy of Special Education Professionals, Spring-Summer, 41-57.

Malanowski, R. M., Kachris, P., \& Kennedy, V. (1986). Professional analysis teams in schools: A case study. Paper presented at the annual meeting of the American Educational Research Association, San Francisco. 
Malen, B. and Ogawa, R. T. (1988). Profesional-patron influence on site-based governance councils: A confounding case study. Educational Evaluation and Poilcy Analysis, 10(4), 251-270.

Malen, B. and Hart, A. W. (1987). Career ladder reform: A multi-level analysis of initial efforts. Educational Evaluation and Policy Analysis, 9(1), 9-23.

Marks, H. M., \& Printy, S. M. (2003). Principal leadership and school performance: An integration of transformational and instructional leadership. Educational Administration Quarterly, 39(3), 370-397.

Merriam, S. B., \& Bierema, L. L. (2014). Adult learning: Linking theory and practice. San Francisco, CA: Jossey-Bass.

Mertons, S. and Yarger, S. J. (1988). Teaching as a profession: Leadership, empowerment, and involvement. Journal of Teacher Education, 39(1), 32-37.

Mintzberg, H. (2011). The five basic parts of the organization. In J. Shafritz, J. Ott, \& Y. Jang (Eds.), Classics of organizational theory (7th ed., pp. 222-233). Boston, MA: Wadsworth.

Missouri Department of Elementary and Secondary Education. (2012). Glossary of 2012 Accountability Reporting Terms. Retrieved from https://dese.mo.gov/sites/default/files/msip5-glossary-of-terms.pdf

Mohrman, A. M. (1978). Participation in decision-making: A multidimensional perspective. Educational Administration Quarterly, 14(1), 13-29.

Mokoena, S. (2011). Participative decision-making: Perceptions of school stakeholders in South Africa. Journal of Social Science, 29(2), 119-131. 
Moller, G. (2006). Teacher leadership emerges within professional learning communities. Journal of School Leadership, 16(5), 520-533.

Mulford, B. \& Silins, H. (2003). Leadership for organizational learning and improved student outcomes: What do we know? Cambridge Journal of Education, 33(2), $175-195$.

Murphy, J. (1994). Redefining the principalship in restructuring schools. NASSP Bulletin, 78(560), 94-99.

The National Commission on Excellence. (1983). A Nation at Risk. Retrieved from https://www2.ed.gov/pubs/NatAtRisk/risk.html

Nelson, T. H., Slavit, D., and Deuel, A. (2012). Two dimensions of an inquiry stance toward student-learning data. Teachers College Record, 114(8), 1-42.

Newmann, F. M. and Wehlage, G. G. (1995). Successful school restructuring: A report to the public and educators. Madison, WI: Center on Organization and Restructuring of Schools.

Public Law 107-110, 107 ${ }^{\text {th }}$ Cong., 115 STAT. 1425 (2001) (enacted).

Murphy, J. (1994). Transformational change and the evolving role of the principal: Early empirical evidence. In J. Murphy \& K. S. Louis (Eds), Reshaping the principalship: Insights from transformational reform efforts (pp. 20-53). Thousand Oaks, CA: Corwin Press.

Murphy, J., Evertson, C. M., and Radnofsky, M. (1991). Restructuring schools: Fourteen elementary and secondary teachers' perspectives on reform. The Elementary School Journal, 92(2), 135-148. 
Odden, E. R. and Wohlstetter, P. (1995). Making school-based management work. Educational Leadership, 52(5), 32-37.

Peterson, K. D., Marks, H. M., and Warren, V. D. (1996). SBDM in restructured schools: Organizational conditions, pedagogy and student learning. Madison, WI: Center on Organization and Restructuring of Schools.

Phillips, J. (2003). Powerful learning: Creating learning communities in urban school reform. Journal of Curriculum and Supervision, 18(3), 240-258.

Poekert, P. E. (2012). Examining the impact of collaborative professional development on teacher practice. Teacher Education Quarterly, 39(4), 97-118.

Preskill, S., \& Brookfield, S. D. (2009). Learning as a way of leading: Lessons from the struggle for social justice. San Francisco, CA: Jossey-Bass.

The President's Commission on Industrial Competitiveness. (1985). Report of the President's commission on industrial competitiveness. Retrieved from https://babel.hathitrust.org/cgi/pt?id=pur1.32754066835715\&view=1up\&seq=5.

Price, P. C., Jhangiani, R. S., and Chiang, I. A. Research methods in psychology. $2^{\text {nd }}$ Ed. Adapted by The Saylor Foundation under a Creative Commons Attribution-Non Commercial-ShareAlike 3.0 License without attribution as requested by the work's original creator or licensee.

Priest, D. I. (2015). Collaboration in professional learning communities and development of teacher efficacy and trust in Alabama schools (Unpublished doctoral dissertation). University of Alabama: Tuscaloosa, AL. 
Provini, C. (2013). Why don’t professional learning communities work? Education World. Retrieved from https://www.educationworld.com/a_admin/professionallearning-community-pitfalls-best-practices.shtml.

Rosenholtz, S. (1989). Teacher's workplace: The social organization of schools. New York: Longman.

Rosenman, R., Tennekoon, V., and Hill, L. (2011). Measuring bias in self-reported data. International Journal of Behavioral Healthcare Research, 2(4), 320-332.

Roy, P. \& Hord, S. M. (2006). It's everywhere, but what is it? Professional learning communities. Journal of School Leadership, 16(5), 491-501.

Sackney, L. \& Walter, K. (2006). Canadian perspectives on beginning principals: Their role in building capacity for learning communities. Journal of Educational Administration, 44(4), 341-358.

Sarafidou, J.-O. and Chatziioannidis, G. (2013). Teacher participation in decision-making and its impact on school and teachers. International Journal of Educational Management, 27(2), 170-183.

Schechter, C. (2008). Organizational learning mechanisms: The meaning, measure and implications for school improvement. Educational Administration Quarterly, 44(2), 155-186.

Sebastian, J. \& Allensworth, E. (2012). The influence of principal leadership on classroom instruction and student learning: A study of mediated pathways to learning. Educational Administration Quarterly, 48(4), 626-663. 
Sebastian, Allensworth, \& Huang. (2016). The role of teacher leadership in how principals influence classroom instruction and student learning. American Journal of Education, 123(1), 69-108.

Sebastian, Allensworth, \& Stevens. (2014). The influence of school leadership on classroom participation: Examining configurations of organizational supports. Teachers College Record, 116, 1-36.

Senge, P. M. (1990). The fifth discipline: The art and practice of the learning organization. New York: Doubleday/Currency, 1990.

Servage. L. (2006). Making space for critical reflection in professional learning communities. Education Canada, 47(1), 14-17.

Servage, L. 2008. Critical and transformative practices in professional learning communities. Teacher Education Quarterly, 35(1), 63-77.

Servage, L. (2009). Critical and transformative practices in professional learning communities. Teacher Education Quarterly, 35(1), 63-77.

Shedd, J. B. (1988). Collective bargaining, school reform, and the management of school systems. Educational Administration Quarterly, 24(4), 405-415.

Shetzer, S. D. (2011). A study of the relationship between teacher efficacy and professional learning communities in an urban high school. (Doctoral dissertation, University of Houston). Retrieved from https://uhir.tdl.org/handle/10657/580

Short, P. M. \& Greer, J. T. (1989). Increasing teacher autonomy through shared governance: Effects on policy making and student outcomes. Retrieved from ERIC database. (ED319096) 
Sigurðardóttir, A. K. (2010). Professional learning community in relation to school effectiveness. Scandinavian Journal of Educational Research, 54(5), 395-412.

Skalski, A. K. and Romero, M. (2011). Data-based decision-making. Principal Leadership, 11(5), 12-16.

Smith, J. B., Lee, V. E., \& Newmann, F. M. (2001). Instruction and achievement in Chicago elementary schools. Improving Chicago's schools. Consortium on Chicago School Research, IL. ED 470298

Smylie, M. A. and Denny, J. W. (1990). Teacher leadership: Tensions and ambiguities in organizational perspective. Educational Administration Quarterly, 26(3), 235259.

Smylie, M. A., Lazarus, V., \& Brownlee-Conyers, J. (1996). Instructional outcomes of school-based participative decision-making. Educational evaluation and policy analysis, 18(3), 181-198.

Somech, A. (2010). Participative decision-making in schools: A mediating-moderating analytical framework for understanding school and teacher outcomes.

Educational Administration Quarterly, 46(2), 174-209.

Spillane, J. P., Halverson, R., and Diamond, J. B. (2004). Towards a theory of leadership practice: A distributed perspective. Journal of Curriculum Studies, 36(1), 3-34.

Stewart, K. A. 2(014). Effects of professional learning communities in Alabama black belt schools: Case study (Doctoral dissertation, Grand Canyon University). Retrieved from https://pqdtopen-proquestcom.proxy.mul.missouri.edu/doc/1537385034.html?FMT=AI\&pubnum=3619414 
Stoll, L., Bolam, R., McMahon, A., Wallace, M., \& Thomas, S. (2006). Professional learning communities: A review of the literature. Journal of Educational Change, 7(4), 221-258.

Strahan, D. 2(003). Promoting a collaborative professional culture in three elementary schools that have beaten the odds. The Elementary School Journal, 104(2), 127146.

Supovitz, J. A. (2002). Developing communities of instructional practice. Teachers College Record, 104(8), 1591-1626.

Supovitz, J. A. \& Christman, J. B. (2003). Developing communities of instructional practice: Lessons for Cincinnati and Philadelphia. Retrieved from ERIC database. (ED498331)

Task Force on Education for Economic Growth. (1983). Action for Excellence. Denver, CO: The Education Commission of the States.

Taylor, F. (1911). The principles of scientific management. New York, NY: Harper \& Brothers

Taylor, D. L. \& Bogotch, I. E. 1(994). School-level effects of teachers' participation in decision-making. Educational Evaluation and Policy Analysis, 16(3), 302-319.

Thompson, S. C., Gregg, L., \& Niska, J. M. (2004). Professional learning communities, leadership, and student learning. Research in Middle Level Education Online, 28(1). Retrieved from https://www.tandfonline.com/doi/abs/10.1080/19404476.2004.11658173.

Toole, J.C. \& Louis, K.S. (2002). The role of professional learning communities in international education. In K. Leithwood \& P. Hallinger (eds), Second 
International Handbook of Educational Leadership and Administration. Dordrecht: Kluwer.

Turner, M. (2012). Teacher efficacy beliefs in collaborative learning communities: A statewide study in large high schools (Unpublished doctoral dissertation). Ohio University: Athens, $\mathrm{OH}$.

UChicago Consortium on School Research. (2013). 5Essentials School Reports. Retrieved from https://consortium.uchicago.edu/surveys\#topResources

Visser, P. S., Krosnick, J. A., Marquette, J., and Curtin, M. (2000). Mail surveys for election forecasting? An evaluation of the Columbis Dispatch Poll. Public Opinion Quarterly, 60(2), 181-227.

Watson, C. (2014). Effective professional learning communities? The possibilities for teachers as agents of change in schools. British Educational Research Journal, 40(1), 18-29.

Wenger, E. C. and Snyder, W. M. (2000). Communities of practice: The organizational frontier. Harvard Business Review, 78(1), 139-145.

Westheimer, J. (1999). Communities and consequences: An inquiry into ideology and practice in teachers' professional work. Educational Administration Quarterly, 35(1), 71-105.

White, P. A. (1992). Empowerment under "ideal" school-site autonomy. Educational Evaluation and Policy Analysis, 14(1), 69-82.

Wilson, A. (2016). From professional practice to practical leader: Teacher leadership in professional learning communities. International Journal of Teacher Leadership, $7(2), 45-62$. 
Wohlstetter, P. (1995). Getting school-based management right: What works and what doesn’t. Phi Delta Kappan, 77(1), 22-26.

Wohlstetter, P., Smyer, R., \& Mohrman, S. A. (1994). New boundaries for school-based management: The high involvement model. Paper presented at the annual meeting of the American Educational Research Association, New Orleans, LA.

York-Barr, J. \& Duke, K. (2004). What do we know about teacher leadership? Findings from two decades of scholarship. Review of Educational Research, 74(3), 255316.

Zmuda, A., Kuklis, R., and Kline, E. (2004). Transforming schools: Creating a culture of continuous improvement. Alexandria, VA: Association for Supervision \& Curriculum Development. 


\section{Vita}

Dr. Mark Bowles is currently serving as Director of the TRiO Student Support Services program at the Day Campus (Columbia, MO) of Columbia College. He is a lifelong learner and educator who began his teaching career at Jefferson Junior High School in the Columbia Public School District (Columbia, MO) in $7^{\text {th }}$ and $9^{\text {th }}$ grade science in 1986. After five years of teaching, Dr. Bowles moved to southeast Missouri as a middle school building-level administrator (Perryville, MO) and then to the Cape Girardeau School District as a central office administrator. Upon leaving Cape Public Schools, Dr. Bowles spent seven years in church administration as Director of Education and Youth Ministries at New McKendree UMC (Jackson, MO), and then moved to Columbia, MO in 2012 to work on his doctorate in Educational Leadership and Policy Analysis at the University of Missouri-Columbia. He was hired as an assistant director in the Admissions Office at Columbia College in 2013 and served in that capacity until accepting the director position with TRiO SSS in 2017. 